Supporting Information for:

\title{
Tuning the Porosity, Solubility, and Gas Storage Properties of Cuboctahedral Coordination Cages via Amide or Ester Functionalization
}

Garrett A. Taggart, ${ }^{\dagger, \S}$ Alexandra M. Antonio, ${ }^{\dagger, \S}$ Gregory R. Lorzing, ${ }^{\dagger}{ }^{\ddagger}$ Glenn P. A. Yap, ${ }^{\dagger}$ and Eric D. Bloch*,†

'Department of Chemistry and Biochemistry, University of Delaware, Newark, Delaware 19716, United States ¿Center for Neutron Science, Department of Chemical and Biomolecular Engineering, University of Delaware, Newark, Delaware 19716, USA

*E-mail: edb@udel.edu 


\section{List of Contents}

\begin{tabular}{|l|c|}
\hline Ligand Synthesis and NMRs of Ligands & S-3 \\
\hline Solvothermal Cage Synthesis & S-9 \\
\hline Post-Synthetic Modification of Cages & S-13 \\
\hline NMR Spectra of Cages & S-15 \\
\hline Crystal Structures & S-26 \\
\hline Powder X-Ray Diffraction & S-34 \\
\hline FT-IR Spectra & S-35 \\
\hline BET Surface Area Isotherms & S-38 \\
\hline Table of Surface Areas & S-42 \\
\hline
\end{tabular}


Synthesis of $\mathrm{Cr}_{2}(\mathrm{OAc})_{4}{ }^{1}{ }^{\text {The }}$ material was synthesized via a modified literature procedure. In a dry, $250 \mathrm{~mL}$ round-bottom flask, add Cr powder $(2.9699 \mathrm{~g}, 57.11 \mathrm{mmol})$ and $\mathrm{HBr}(2 \mathrm{~mL})$ to a solution of acetic acid $(80 \mathrm{~mL})$ and acetic anhydride $(20 \mathrm{~mL})$. The solution was refluxed under nitrogen for 48 hours. Upon cooling, a brick red powder precipitates. The powder was quickly filtered using a swivel frit and washed with diethyl ether under $\mathrm{N}_{2}$. The solid was quickly transferred into an $\mathrm{N}_{2}$-atmosphere glovebox.

\section{Ligand Syntheses:}

Synthesis of 5-benzoyl-NH(CO)-bdc: Benzoyl chloride $(4.3101 \mathrm{~g}, 30.79 \mathrm{mmol})$ and 5-amino1,3-benzenedicarboxylic acid $(4.5588 \mathrm{~g}, 25.17 \mathrm{mmol}$ ) were heated in $300 \mathrm{~mL}$ of THF overnight at $80{ }^{\circ} \mathrm{C}$ in a round bottom flask. The flask was subjected to rotary evaporation to remove solvent and the resulting precipitate was washed with chloroform and filtered with a Buchner funnel. Three subsequent chloroform washes were done to remove any excess acyl chloride resulting in 6.5173 g (90.79 \% yield) of 5-benzamido-1,3-benzenedicarboxylic acid. ${ }^{1} \mathrm{H}$ NMR (400 MHz, DMSO-d 6 ): $\delta=10.62(\mathrm{~s}, 1 \mathrm{H}, \mathrm{NH}), 8.69(\mathrm{~s}, 2 \mathrm{H}, \mathrm{CH}$ arom $), 8.23(\mathrm{~s}, 1 \mathrm{H}, \mathrm{CH}$ arom $), 8.01(\mathrm{~m}, 2 \mathrm{H}$, arom $), 7.58$ (m, $3 \mathrm{H}$, arom).

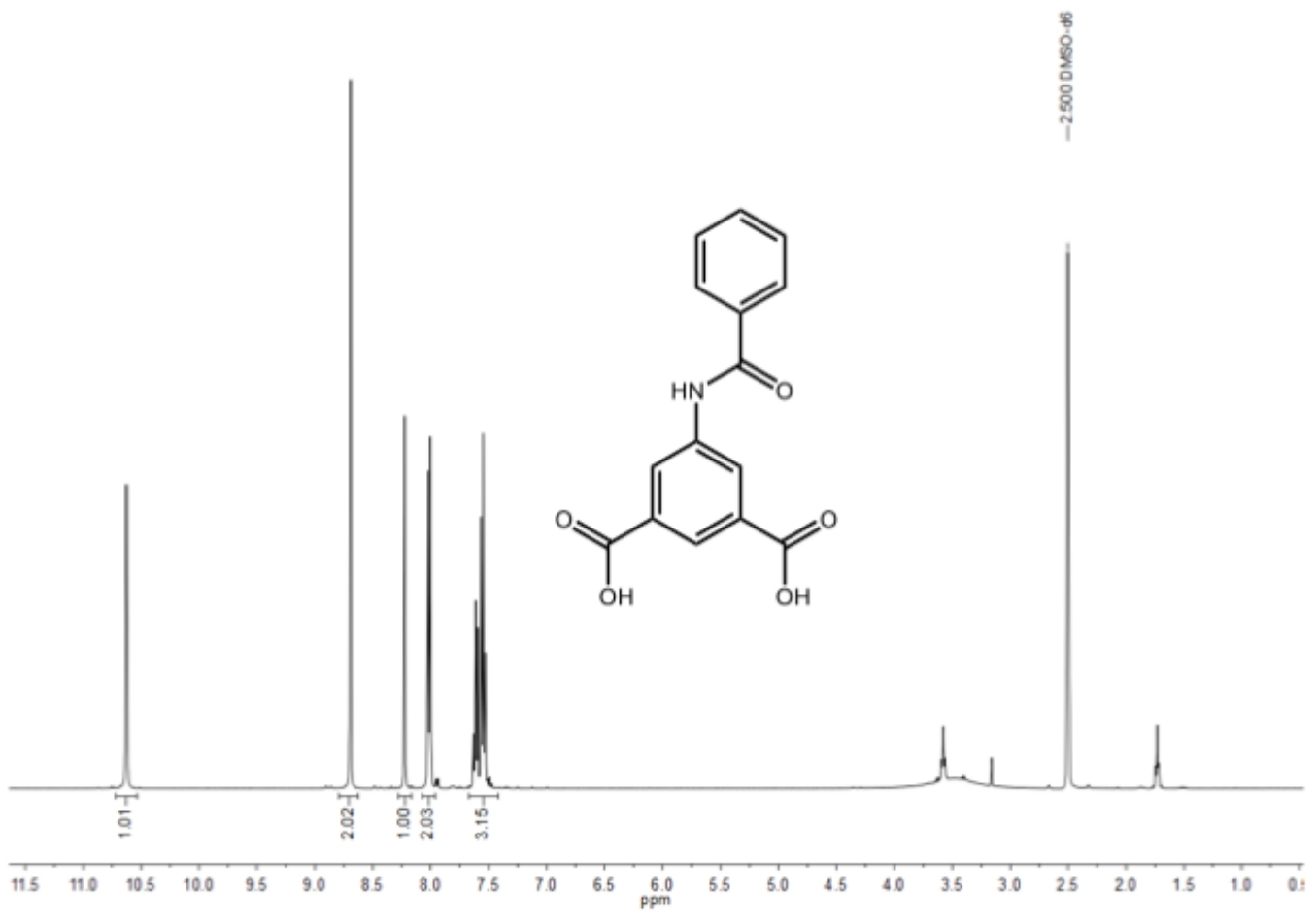

Figure S1. ${ }^{1} \mathrm{H}-\mathrm{NMR}$ spectrum of 5-benzoyl-NH(CO)-bdc in DMSO-d6. 
Synthesis of 5-(4-methoxybenzoyl)-NH(CO)-bdc: 4-methoxybenzoyl chloride (5.2579 g, 30.82 $\mathrm{mmol}$ ) and 5-amino-1,3-benzenedicarboxylic acid $(5.1485 \mathrm{~g}, 28.43 \mathrm{mmol})$ were heated in $300 \mathrm{~mL}$ of THF overnight at $80{ }^{\circ} \mathrm{C}$ in a round bottom flask. The flask was subjected to rotary evaporation to remove solvent and the resulting precipitate was washed with chloroform and filtered with a Buchner funnel. Three subsequent chloroform washes were done to remove any excess acyl chloride resulting in $8.4228 \mathrm{~g}(94.06 \%$ yield) of 5-(4-methoxybenzamido)-1,3benzenedicarboxylic acid. ${ }^{1} \mathrm{H}$ NMR (400 MHz, DMSO): $\delta=10.45$ (s, 1H, NH), $8.67(\mathrm{~s}, 2 \mathrm{H}, \mathrm{CH}$ arom), 8.20 (s, $1 \mathrm{H}, \mathrm{CH}$ arom), 8.01 (m, $2 \mathrm{H}, \mathrm{CH}$ arom), $7.08\left(\mathrm{~m}, 3 \mathrm{H}\right.$, arom) 3.84 (s, $\left.3 \mathrm{H}, \mathrm{OCH}_{3}\right)$.

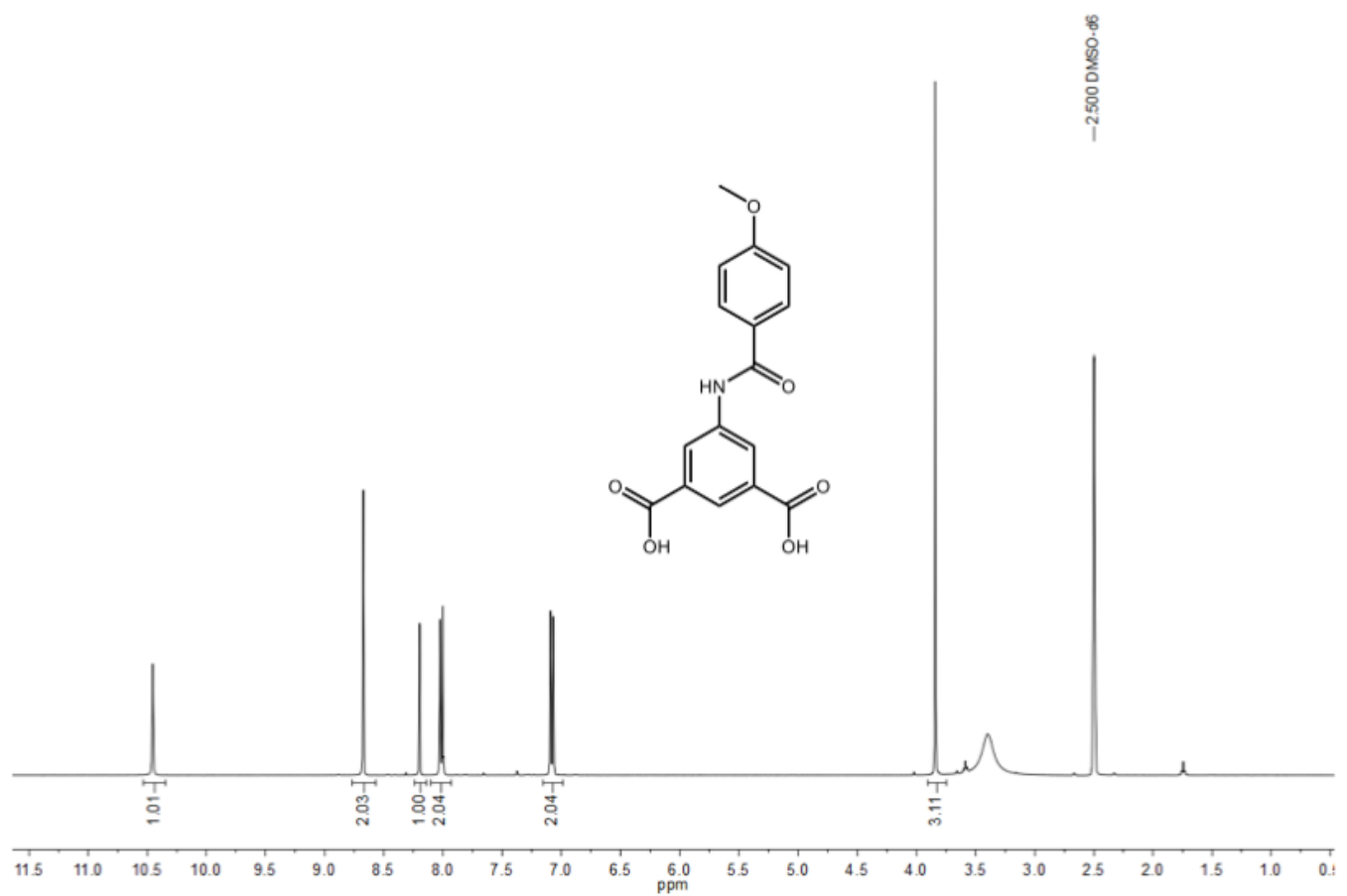

Figure S2. ${ }^{1} \mathrm{H}-\mathrm{NMR}$ spectrum of 5-(4-methoxybenzoyl)-NH(CO)-bdc in DMSO-d 6 . 
Synthesis of 5-(3,5,5-trimethylhexanoyl)-NH(CO)-bdc: 3,5,5-trimethylhexanoyl chloride (3 $\mathrm{mL}, 15.79 \mathrm{mmol})$ and 5-amino-1,3-benzenedicarboxylic acid (2.1194 g, $11.71 \mathrm{mmol})$ were heated in $300 \mathrm{~mL}$ of THF overnight at $80{ }^{\circ} \mathrm{C}$ in a round bottom flask. The flask was subjected to rotary evaporation to remove solvent and the resulting precipitate was washed with chloroform and filtered with a Buchner funnel. Three subsequent chloroform washes were done to remove any excess acyl chloride resulting in $2.8834 \mathrm{~g}$ (80.12\% yield) of 5-(3,5,5-trimethylhexanoylamido)1,3-benzenedicarboxylic acid. ${ }^{1} \mathrm{H}-\mathrm{NMR}(400 \mathrm{MHz}, \mathrm{DMSO}): \delta=10.24$ (s, 1H, NH), 8.24 (s, 2H, $\mathrm{CH}$ arom), 8.14 (s, $1 \mathrm{H}, \mathrm{CH}$ arom), $1.2\left(\mathrm{~m}, 17 \mathrm{H}, \mathrm{CH}, \mathrm{CH}_{2}, \mathrm{CH}_{3}\right)$.

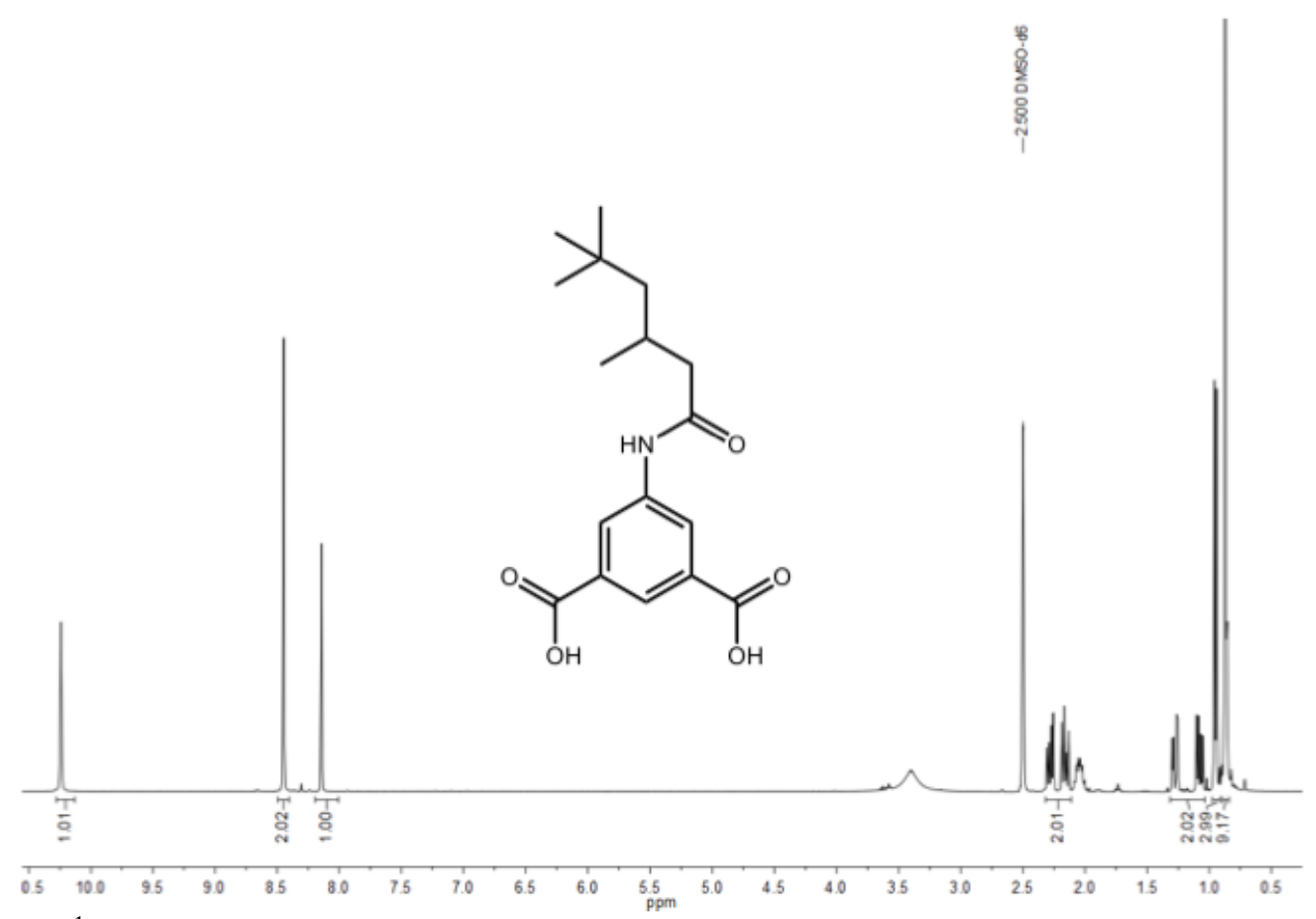

Figure S3. ${ }^{1} \mathrm{H}-\mathrm{NMR}$ spectrum of 5-(3,5,5-trimethylhexanoyl)-NH(CO)-bdc in DMSO-d 6 . 
Synthesis of 5-phenylacetyl-NH(CO)-bdc: Phenylacetyl chloride (5.4597 g, $35.32 \mathrm{mmol}$ ) and 5amino-1,3-benzenedicarboxylic acid $(4.8103 \mathrm{~g}, 26.56 \mathrm{mmol})$ were heated in $200 \mathrm{~mL}$ of THF overnight at $80^{\circ} \mathrm{C}$ in a $250 \mathrm{~mL}$ round bottom flask. The flask was subjected to rotary evaporation to remove solvent and the resulting precipitate was filtered and washed three times with chloroform to remove any excess acyl chloride yielding $8.1642 \mathrm{~g}$ (90.88 \% yield) of 5phenylacetylamido-1,3-benzenedicarboxylic acid. ${ }^{1} \mathrm{H}-\mathrm{NMR}$ (400 MHz, DMSO): $\delta=10.60(\mathrm{~s}, 1 \mathrm{H}$, $\mathrm{NH}), 8.46$ (s, 2H, CH arom), 8.16 (s, $1 \mathrm{H}, \mathrm{CH}$ arom), 7.31 (m, 5H, $\mathrm{CH}$ arom), $3.68\left(\mathrm{~s}, 2 \mathrm{H}, \mathrm{CH}_{2}\right)$.

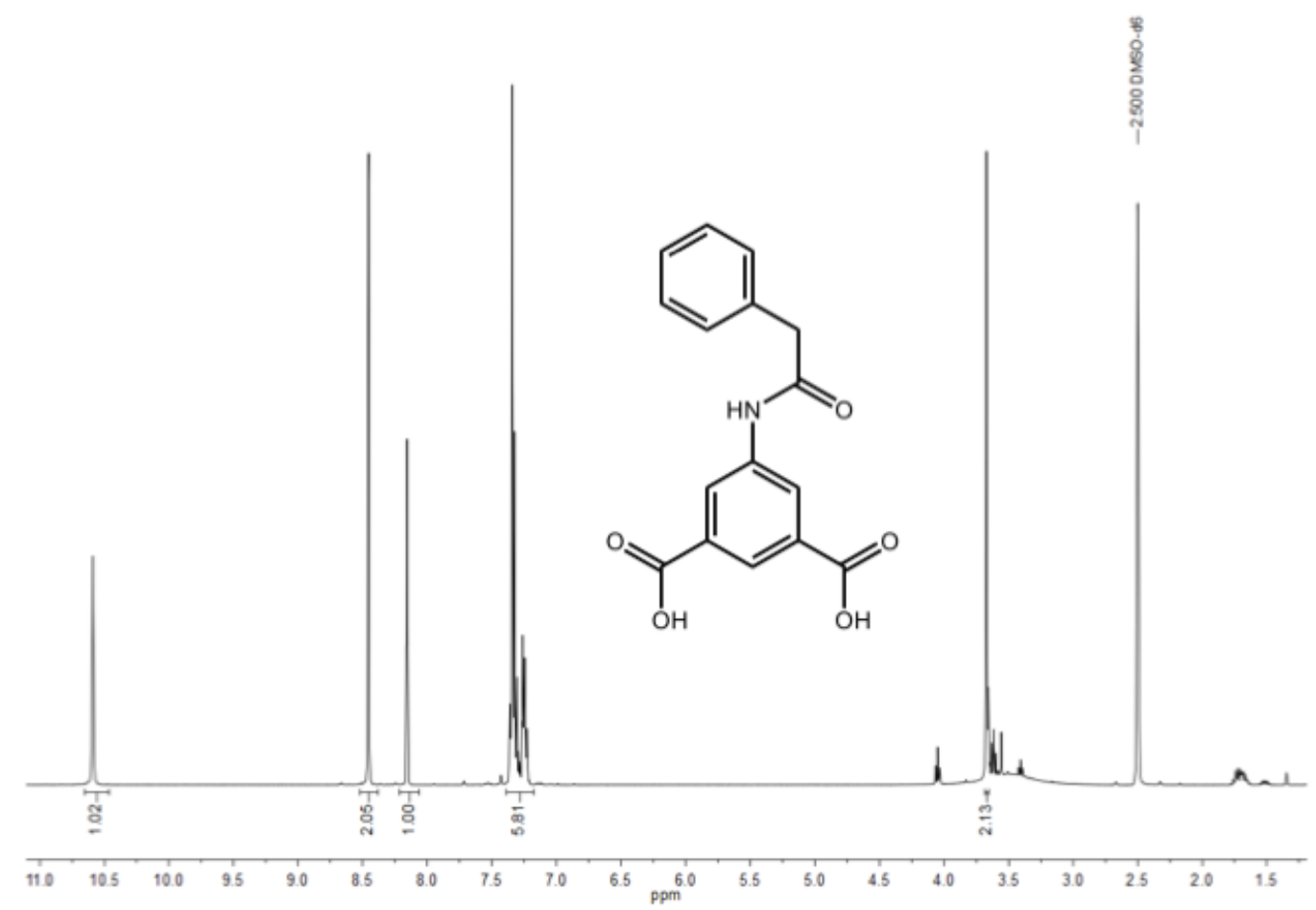

Figure S4. ${ }^{1} \mathrm{H}-\mathrm{NMR}$ spectrum of 5-phenylacetyl-NH(CO)-bdc in DMSO-d 6 . 
Synthesis of 5-diphenylacetyl-NH(CO)-bdc: Diphenylacetyl chloride (4.3694 g, $18.94 \mathrm{mmol})$ and 5-amino-1,3-benzenedicarboxylic acid $(3.3155 \mathrm{~g}, 18.31 \mathrm{mmol})$ were heated in $200 \mathrm{~mL}$ of THF overnight at $80^{\circ} \mathrm{C}$ in a $250 \mathrm{~mL}$ round bottom flask. The flask was subjected to rotary evaporation to remove solvent and the resulting precipitate was filtered and washed three times with chloroform to remove any excess acyl chloride yielding $5.6277 \mathrm{~g}(81.89 \%$ yield $)$ of 5 diphenylacetylamido-1,3-benzenedicarboxylic acid ${ }^{1} \mathrm{H}-\mathrm{NMR}$ (400 MHz, DMSO): $\delta=10.88$ (s, $1 \mathrm{H}, \mathrm{NH}), 8.48$ (s, 2H, CH arom), $8.15(\mathrm{~s}, 1 \mathrm{H}, \mathrm{CH}$ arom), 7.32 (m, 10H, $\mathrm{CH}$ arom), $5.19(\mathrm{~s}, 1 \mathrm{H}$, $\left.\mathrm{CH}_{2}\right)$.

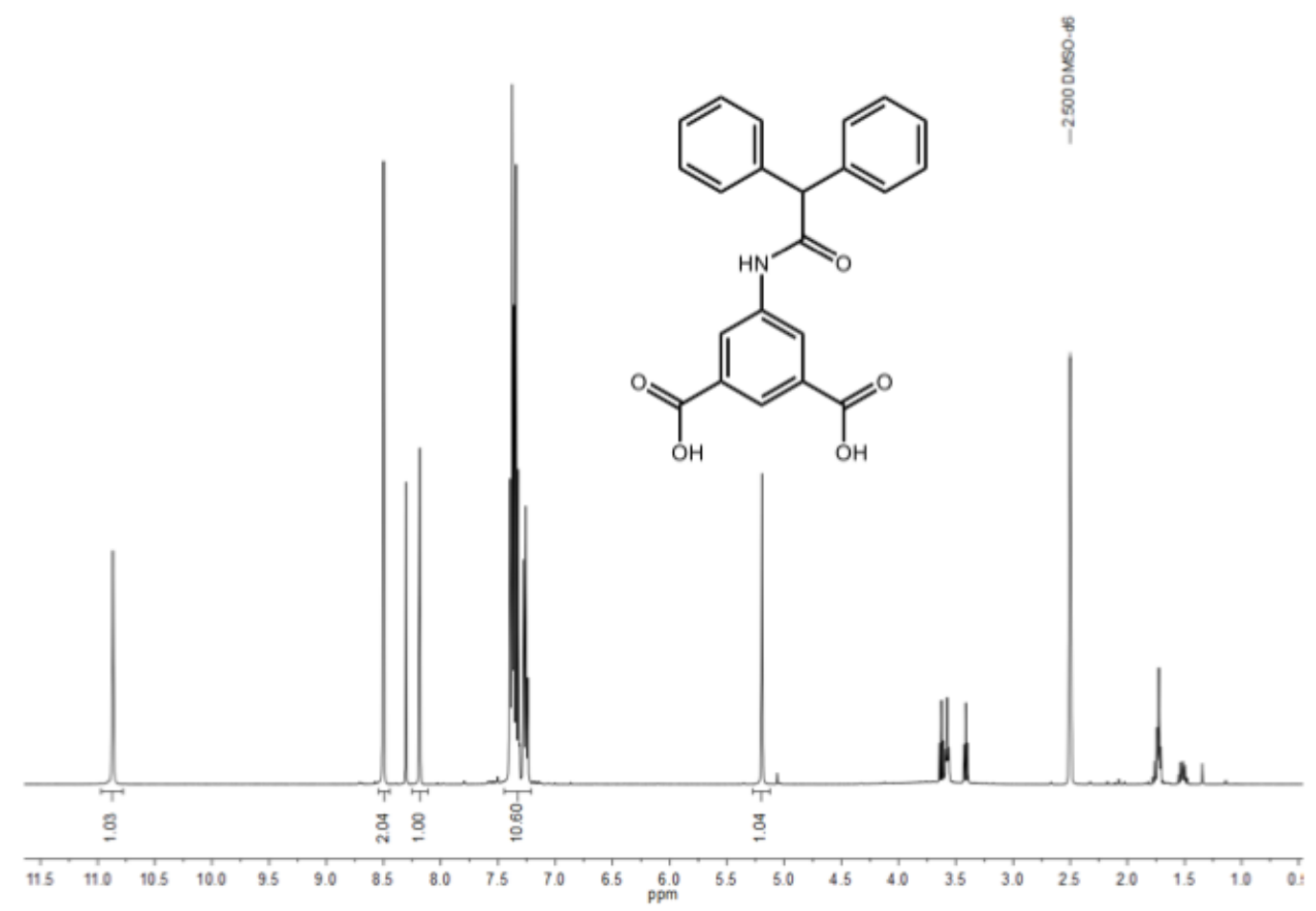

Figure S5. ${ }^{1} \mathrm{H}-\mathrm{NMR}$ spectrum of 5-diphenylacetyl-NH(CO)-bde in DMSO-d 6 . 
Synthesis of 5-lauroyl-NH(CO)-bdc: Lauroyl chloride (4 mL, $17.30 \mathrm{mmol})$ and 5-amino-1,3benzenedicarboxylic acid $(2.0315 \mathrm{~g}, 11.22 \mathrm{mmol})$ were heated in $200 \mathrm{~mL}$ of THF overnight at 80 ${ }^{\circ} \mathrm{C}$ in a $250 \mathrm{~mL}$ round bottom flask. The flask was subjected to rotary evaporation to remove solvent and the resulting precipitate was filtered and washed three times with chloroform to remove any excess acyl chloride yielding $3.7386 \mathrm{~g}$ (69.0 \%) of 5-lauroylamido-1,3benzenedicarboxylic acid ${ }^{1} \mathrm{H}-\mathrm{NMR}$ (400 MHz, DMSO): $\delta=10.24$ (s, 1H, NH), 8.45 (s, 2H, CH arom), 8.14 (s, $1 \mathrm{H}, \mathrm{CH}$ arom), 2.28 (dd, $\left.1 \mathrm{H}, \mathrm{CH}_{2}\right), 2.16$ (dd, $\left.1 \mathrm{H}, \mathrm{CH}_{2}\right), 2.04\left(\mathrm{~m}, 1 \mathrm{H}, \mathrm{CH}_{2}\right), 1.28$ (dd, $1 \mathrm{H}, \mathrm{CH}_{2}$ ), 1.07 (dd, $\left.1 \mathrm{H}, \mathrm{CH}_{2}\right), 0.95$ (d, 3H, $\left.\mathrm{CH}_{3}\right), 0.87$ (m, 9H, $\mathrm{CH}_{2}$ ).

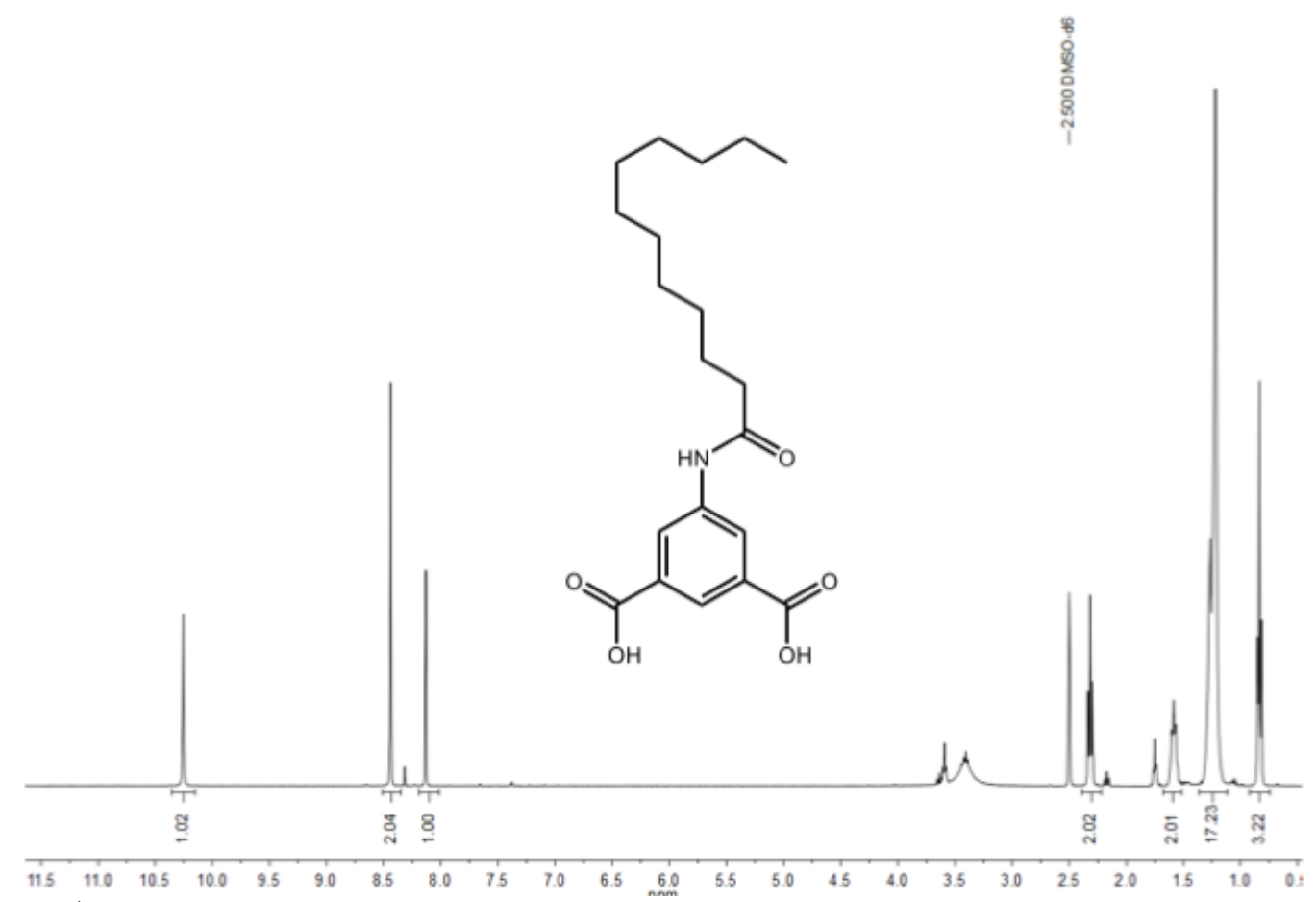

Figure S6. ${ }^{1} \mathrm{H}-\mathrm{NMR}$ spectrum of 5-lauroyl-NH(CO)-bdc in DMSO-d $\mathrm{d}_{6}$. 


\section{Cage Synthesis:}

Synthesis of $\mathbf{C u}_{24}$ (5-benzoyl-NH(CO)-bdc) ${ }_{24}$. Copper (II) acetate monohydrate $(0.1961 \mathrm{~g}, 0.9822$ $\mathrm{mmol})$ and 5-benzamido-1,3-benzenedicarboxylic acid $(0.2401 \mathrm{~g}, 0.842 \mathrm{mmol})$ were added to 20 $\mathrm{mL}$ of DMF in a $20 \mathrm{~mL}$ scintillation vial at room temperature. The vials were left uncapped and undisturbed in a fume hood for 2 weeks to evaporate, yielding crystalline product. Residual DMF solution was decanted, and the precipitate was washed with methanol. The methanol was decanted and fresh methanol was added and decanted 3 additional times over the course of 2 days to fully exchange and remove any DMF. The samples were then evacuated under vacuum to remove solvent and activated for gas adsorption measurements.

Synthesis of $\mathrm{Cu}_{24}$ (5-(4-methoxybenzoyl)-NH(CO)-bdc) 24. Copper (II) acetate monohydrate (0.2051 g, $1.027 \mathrm{mmol})$ and 5-(4-methoxybenzamido)-1,3-benzenedicarboxylic acid (0.2306 g, $0.731 \mathrm{mmol}$ ) were added to $20 \mathrm{~mL}$ of DMF in a $20 \mathrm{~mL}$ scintillation vial at room temperature. The vials were left uncapped and undisturbed in a fume hood for 2 weeks to evaporate, yielding crystalline product. Residual DMF solution was decanted, and the precipitate was washed with methanol. The methanol was decanted and fresh methanol was added and decanted 3 additional times over the course of 2 days to fully exchange and remove any DMF. The samples were then evacuated under vacuum to remove solvent and activated for gas adsorption measurements.

Synthesis of $\mathrm{Cu}_{24}(\mathbf{5}-(3,5,5-$ trimethylhexanoyl)-NH(CO)-bdc)24. Copper (II) acetate monohydrate (0.1984 g, $0.9937 \mathrm{mmol})$ and 5-(3,5,5-trimethylhexanoylamido)-1,3benzenedicarboxylic acid $(0.2321 \mathrm{~g}, 0.755 \mathrm{mmol})$ were added to $20 \mathrm{~mL}$ of DMF in a $20 \mathrm{~mL}$ scintillation vial at room temperature. The vials were left uncapped and undisturbed in a fume hood for 2 weeks to evaporate, yielding crystalline product. Residual DMF solution was decanted, and the precipitate was washed with methanol. The methanol was decanted and fresh methanol was added and decanted 3 additional times over the course of 2 days to fully exchange and remove any DMF. The samples were then evacuated under vacuum to remove solvent and activated for gas adsorption measurements.

Synthesis of $\mathbf{C u}_{24}(5-p h e n y l a c e t y l-N H(C O)-b d c)_{24}$. Copper (II) acetate monohydrate (0.2008 g, $1.006 \mathrm{mmol})$ and 5-phenylacetylamido-1,3-benzenedicarboxylic acid (0.2422 g, $0.809 \mathrm{mmol})$ were added to $20 \mathrm{~mL}$ of DMF in a $20 \mathrm{~mL}$ scintillation vial at room temperature. The vials were left uncapped and undisturbed in a fume hood for 2 weeks to evaporate, yielding crystalline product. Residual DMF solution was decanted, and the precipitate was washed with methanol. The methanol was decanted and fresh methanol was added and decanted 3 additional times over the course of 2 days to fully exchange and remove any DMF. The samples were then evacuated under vacuum to remove solvent and activated for gas adsorption measurements.

Synthesis of $\mathbf{C u}_{24}$ (5-diphenylacetyl-NH(CO)-bdc)24. Copper (II) acetate monohydrate (0.2027 g, $1.015 \mathrm{mmol})$ and 5-diphenylacetylamido-1,3-benzenedicarboxylic acid (0.2818 g, $0.751 \mathrm{mmol})$ were added to $20 \mathrm{~mL}$ of DMF in a $20 \mathrm{~mL}$ scintillation vial at room temperature. The vials were left uncapped and undisturbed in a fume hood for 2 weeks to evaporate, yielding crystalline product. Residual DMF solution was decanted, and the precipitate was washed with methanol. The methanol was decanted and fresh methanol was added and decanted 3 additional times over the course of 2 days to fully exchange and remove any DMF. The samples were then evacuated under vacuum to remove solvent and activated for gas adsorption measurements. 


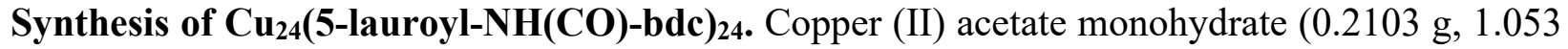
$\mathrm{mmol})$ and 5-lauroylamido-1,3-benzenedicarboxylic acid $(0.2444 \mathrm{~g}, 0.672 \mathrm{mmol})$ were added to $20 \mathrm{~mL}$ of DMF in a $20 \mathrm{~mL}$ scintillation vial at room temperature. The vials were left uncapped and undisturbed in a fume hood for 2 weeks to evaporate, yielding crystalline product. Residual DMF solution was decanted, and the precipitate was washed with methanol. The methanol was decanted and fresh methanol was added and decanted 3 additional times over the course of 2 days to fully exchange and remove any DMF. The samples were then evacuated under vacuum to remove solvent and activated for gas adsorption measurements.

Synthesis of $\mathrm{Cu}_{24}(\mathrm{OH}-b d c)_{24}{ }^{2}$ The material was synthesized via a modified literature procedure. $\mathrm{Cu}\left(\mathrm{NO}_{3}\right)_{2}$ (0.605 g, $\left.2.60 \mathrm{mmol}\right)$, 5-hydroxy-1,3-benzenedicarboxylic acid $(0.450 \mathrm{~g}, 2.47 \mathrm{mmol})$ and 10 drops of 2,6-lutidine were added to a $100 \mathrm{~mL}$ VWR jar and dissolved in $75 \mathrm{~mL}$ methanol and $15 \mathrm{~mL} \mathrm{N,N-Dimethylacetamide} \mathrm{(DMA).} \mathrm{After} 5$ days at room temperature, blue crystals formed. The crystals were washed at room temperature three times with THF and dried under vacuum to form a blue/green powder.

Synthesis of $\mathbf{C r}_{24}$ (5-benzoyl-NH(CO)-bdc $)_{24}$. Chromium (II) acetate $\left(\mathrm{Cr}(\mathrm{OAc})_{2}\right)(0.3095 \mathrm{~g}$, $1.351 \mathrm{mmol})$ and 5-benzoylamido-1,3-benzenedicarboxylic acid $(0.2178 \mathrm{~g}, 0.764 \mathrm{mmol})$ were added to a $20 \mathrm{~mL}$ scintillation vial and dissolved in $15 \mathrm{~mL}$ of anhydrous $\mathrm{N}, \mathrm{N}$-dimethylformamide (DMF) and $5 \mathrm{~mL}$ anhydrous methanol. The dark purple solution was heated to $75{ }^{\circ} \mathrm{C}$ in an aluminum block dry bath overnight. Additional anhydrous methanol was layered on to the DMF solution to yield purple crystals. Precipitate was washed with methanol and decanted at least four times and dried under vacuum for gas adsorption measurements.

Synthesis of $\mathbf{C r}_{24}$ (5-(4-methoxybenzoyl)-NH(CO)-bdc) ${ }_{24}$. Chromium (II) acetate $\left(\mathrm{Cr}(\mathrm{OAc})_{2}\right)$ $(0.3032 \mathrm{~g}, 1.323 \mathrm{mmol})$ and 5-(4-methoxybenzamido)-1,3-benzenedicarboxylic acid (0.2027 $\mathrm{g}$, $0.643 \mathrm{mmol}$ ) were added to a $20 \mathrm{~mL}$ scintillation vial and dissolved in $15 \mathrm{~mL}$ of DMF and $5 \mathrm{~mL}$ of methanol. The dark purple solution was heated to $75{ }^{\circ} \mathrm{C}$ in an aluminum block dry bath overnight. Additional anhydrous methanol was layered on to the DMF solution to yield a pale pink powder. Precipitate was washed with methanol and decanted at least four times and dried under vacuum for gas adsorption measurements.

Synthesis of $\mathrm{Cr}_{24}(\mathbf{5 - ( 3 , 5 , 5 - t r i m e t h y l h e x a n o y l ) - N H ( C O ) - b d c})_{24}$. Chromium (II) acetate $\left(\mathrm{Cr}(\mathrm{OAc})_{2}\right) \quad(0.2994 \quad \mathrm{~g}, \quad 1.307 \mathrm{mmol}) \quad$ and 5-(3,5,5-trimethylhexanoylamido)-1,3benzenedicarboxylic acid $(0.2188 \mathrm{~g}, 0.712 \mathrm{mmol})$ were added to a $20 \mathrm{~mL}$ scintillation vial and dissolved in $15 \mathrm{~mL}$ of DMF and $5 \mathrm{~mL}$ of methanol. The dark purple solution was heated to $75^{\circ} \mathrm{C}$ in an aluminum block dry bath overnight. Additional anhydrous methanol was layered on to the DMF solution to yield a pale pink powder. Precipitate was washed with methanol and decanted at least four times and dried under vacuum for gas adsorption measurements.

Synthesis of $\mathbf{C r}_{24}$ (5-phenylacetyl-NH(CO)-bdc) ${ }_{24}$. Chromium (II) acetate $\left(\mathrm{Cr}(\mathrm{OAc})_{2}\right)(0.3033 \mathrm{~g}$, $1.324 \mathrm{mmol})$ and 5-phenylacetylamido-1,3-benzenedicarboxylic acid $(0.2293 \mathrm{~g}, 0.766 \mathrm{mmol})$ were added to a $20 \mathrm{~mL}$ scintillation vial and dissolved in $15 \mathrm{~mL}$ of DMF and $5 \mathrm{~mL}$ of methanol. The dark purple solution was heated to $75^{\circ} \mathrm{C}$ in an aluminum block dry bath overnight. Additional anhydrous methanol was layered on to the DMF solution to yield a pale pink powder. Precipitate was washed with methanol and decanted at least four times and dried under vacuum for gas 
adsorption measurements.

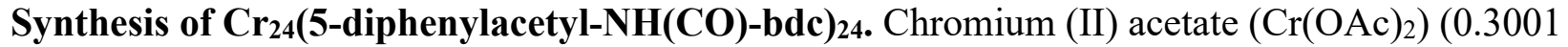
g, $1.310 \mathrm{mmol})$ and 5-diphenylacetylamido-1,3-benzenedicarboxylic acid (0.2439 g, $0.650 \mathrm{mmol})$ were added to a $20 \mathrm{~mL}$ scintillation vial and dissolved in $15 \mathrm{~mL}$ of DMF and $5 \mathrm{~mL}$ of methanol. The dark purple solution was heated to $75^{\circ} \mathrm{C}$ in an aluminum block dry bath overnight. Additional anhydrous methanol was layered on to the DMF solution to yield a pale pink powder. Precipitate was washed with methanol and decanted at least four times and dried under vacuum at $50{ }^{\circ} \mathrm{C}$ for gas adsorption measurements.

Synthesis of $\mathbf{C r}_{24}$ (5-lauroyl-NH(CO)-bdc) ${ }_{24}$. Chromium (II) acetate (Cr(OAc) 2$)(0.2964$ g, 1.294 $\mathrm{mmol})$ and 5-lauroylamido-1,3-benzenedicarboxylic acid $(0.2309 \mathrm{~g}, 0.635 \mathrm{mmol})$ were added to a $20 \mathrm{~mL}$ scintillation vial and dissolved in $15 \mathrm{~mL}$ of DMF and $5 \mathrm{~mL}$ of methanol. The dark purple solution was heated to $75{ }^{\circ} \mathrm{C}$ in an aluminum block dry bath overnight. Additional anhydrous methanol was layered on to the DMF solution to yield a pale pink powder. Precipitate was washed with methanol and decanted at least four times and dried under vacuum for gas adsorption measurements.

Synthesis of $\mathrm{Cr}_{24}(\mathrm{OH}-\mathrm{bdc})_{24} \cdot^{3} \mathrm{Cr}_{2}(\mathrm{OAc})_{4} \quad(0.100 \mathrm{~g}, 0.266 \mathrm{mmol})$ and 5-hydroxy-1,3benzenedicarboxylic acid $(0.096 \mathrm{~g}, 0.527 \mathrm{mmol})$ were added to a $20 \mathrm{~mL}$ scintillation vial and dissolved in $8 \mathrm{~mL}$ of anhydrous DMF and $2 \mathrm{~mL}$ of anhydrous methanol. The solution was heated at $70{ }^{\circ} \mathrm{C}$ for 2 days. The purple crystals were washed at room temperature three times with anhydrous THF, exchanging the solvent every 8 hours, and dried under vacuum to yield a purple powder.

Synthesis of $\mathbf{C r}_{24}\left(\mathbf{N H}_{2} \text {-bdc }\right)_{24} \cdot \mathrm{Cr}_{2}(\mathrm{OAc})_{4} \quad(0.100 \mathrm{~g}, 0.266 \mathrm{mmol})$ and 5-hydroxy-1,3benzenedicarboxylic acid $(0.096 \mathrm{~g}, 0.527 \mathrm{mmol})$ were added to a $20 \mathrm{~mL}$ scintillation vial and dissolved in $6 \mathrm{~mL}$ of anhydrous N,N-Diethylformamide (DEF) and $4 \mathrm{~mL}$ of anhydrous methanol. The solution was heated at $70{ }^{\circ} \mathrm{C}$ for 2 days. The purple crystalline powder was washed at room temperature three times with anhydrous THF, exchanging the solvent every 8 hours, and dried under vacuum to yield a purple powder.

Synthesis of $\mathrm{Mo}_{24}(\mathbf{5}-\mathrm{diphenylacetyl-NH(CO)-bdc)})_{24}$. $\mathrm{Mo}_{2}(\mathrm{OAc})_{4}(0.100 \mathrm{~g}, 0.234 \mathrm{mmol})$ and 5diphenylacetylamido-1,3-benzenedicarboxylic acid $(0.0878 \mathrm{~g}, 0.234 \mathrm{mmol})$ were added to a 20 $\mathrm{mL}$ scintillation vial and dissolved in $5 \mathrm{~mL}$ of DMF upon heating at $100{ }^{\circ} \mathrm{C}$ in a dry bath in an $\mathrm{N}_{2}$ glovebox. About $15 \mathrm{~mL}$ of anhydrous methanol was used to precipitate out orange powder. This powder was washed with anhydrous methanol, exchanging the solvent every 8 hours, and dried under vacuum to yield an orange powder. To synthesize crystals, $\mathrm{Mo}_{2}(\mathrm{OAc})_{4}(0.0416 \mathrm{~g}$, $0.097 \mathrm{mmol})$ and 5-diphenylacetylamido-1,3-benzenedicarboxylic acid (0.0365 g, $0.097 \mathrm{mmol})$ were added to a $20 \mathrm{~mL}$ scintillation vial and dissolved in $4 \mathrm{~mL}$ of $\mathrm{DMF}$ and $16 \mathrm{~mL}$ of $\mathrm{MeOH}$. Upon heating at $75^{\circ} \mathrm{C}$ for 3 days, orange crystals formed.

Synthesis of $\mathrm{Mo}_{24}(\mathbf{5}-\mathrm{lauroyl}-\mathrm{NH}(\mathrm{CO})-\mathbf{b d c})_{24} \cdot \mathrm{Mo}_{2}(\mathrm{OAc})_{4}(0.100 \mathrm{~g}, 0.234 \mathrm{mmol})$ and 5lauroylamido-1,3-benzenedicarboxylic acid $(0.0850 \mathrm{~g}, 0.234 \mathrm{mmol})$ were added to a $20 \mathrm{~mL}$ scintillation vial and dissolved in $5 \mathrm{~mL}$ of DMF upon heating at $100{ }^{\circ} \mathrm{C}$ in a dry bath in an $\mathrm{N}_{2}$ glovebox. About $15 \mathrm{~mL}$ of anhydrous methanol was used to precipitate out orange powder. This 
powder was washed with anhydrous methanol, exchanging the solvent every 8 hours, and dried under vacuum to yield an orange powder.

Synthesis of $\mathrm{Mo}_{24}(\mathrm{OH}-\mathrm{bdc})_{24 \cdot}{ }^{4} \mathrm{Mo}_{2}(\mathrm{OAc})_{4}(0.100 \mathrm{~g}, 0.234 \mathrm{mmol})$ and 5-hydroxy-1,3benzenedicarboxylic acid $(0.0426 \mathrm{~g}, 0.234 \mathrm{mmol})$ were added to a $20 \mathrm{~mL}$ scintillation vial and dissolved in $10 \mathrm{~mL}$ of anhydrous N,N'-Dimethylpropyleneurea (DMPU). The solution was heated at $120{ }^{\circ} \mathrm{C}$ for 2 days. The bright red crystals were washed at room temperature three times with anhydrous THF, exchanging the solvent every 8 hours, and dried under vacuum to yield a bright orange powder.

Synthesis of $\mathrm{Mo}_{24}\left(\mathbf{N H}_{2} \text {-bdc }\right)_{24} \cdot \mathrm{Mo}_{2}(\mathrm{OAc})_{4}(0.100 \mathrm{~g}, \quad 0.234 \mathrm{mmol})$ and 5-amino-1,3benzenedicarboxylic acid $(0.0423 \mathrm{~g}, 0.234 \mathrm{mmol})$ were added to a $20 \mathrm{~mL}$ scintillation vial and dissolved in $10 \mathrm{~mL}$ of anhydrous DEF. The solution was heated at $120{ }^{\circ} \mathrm{C}$ for 2 days. The orange crystalline powder was washed at room temperature three times with anhydrous THF, exchanging the solvent every 8 hours, and dried under vacuum to yield a dark orange powder. 


\section{Synthesis of Post-Synthetically Modified Cages:}

Synthesis of $\mathbf{M o}_{24}$ (5-diphenylacetyl-O(CO)-bdc) $24 \cdot \mathrm{Mo}_{24}(\mathrm{OH}-\mathrm{bdc})_{24}(0.139 \mathrm{~g}, 0.5 \mathrm{mmol})$, diphenylacetyl chloride $(0.230 \mathrm{~g}, 1 \mathrm{mmol})$ were added to a $20 \mathrm{~mL}$ scintillation vial and dissolved in $10 \mathrm{~mL}$ THF. In a separate vial, 2,2,6,6-tetramethylpiperidine $(0.141 \mathrm{~g}, 1 \mathrm{mmol})$ was dissolved in $10 \mathrm{~mL}$ of THF. This solution was added to the former and the resulting solution was stirred in a $40{ }^{\circ} \mathrm{C}$ dry bath for 12 hours. The solution was evaporated under vacuum until $\sim 2 \mathrm{~mL}$ of solution remained. To this remaining solution, $\sim 18 \mathrm{~mL}$ of methanol was used to crash out the postsynthetically modified cage. The powder was then washed at room temperature three times with $\mathrm{MeOH}$ and dried under vacuum to produce an orange powder.

Synthesis of Mo24(5-diphenylacetyl-NH(CO)-bdc) ${ }_{24} \cdot \mathrm{Mo}_{24}\left(\mathrm{NH}_{2} \text {-bdc }\right)_{24}(0.139 \mathrm{~g}, 0.5 \mathrm{mmol})$, diphenylacetyl chloride $(0.230 \mathrm{~g}, 1 \mathrm{mmol})$ were added to a $20 \mathrm{~mL}$ scintillation vial and dissolved in $10 \mathrm{~mL}$ THF. In a separate vial, 2,2,6,6-tetramethylpiperidine $(0.141 \mathrm{~g}, 1 \mathrm{mmol})$ was dissolved in $10 \mathrm{~mL}$ of THF. This solution was added to the former and the resulting solution was stirred in a $40{ }^{\circ} \mathrm{C}$ dry bath for 12 hours. The solution was evaporated under vacuum until $\sim 2 \mathrm{~mL}$ of solution remained. To this remaining solution, $\sim 18 \mathrm{~mL}$ of methanol was used to crash out the postsynthetically modified cage. The powder was then washed at room temperature three times with $\mathrm{MeOH}$ and dried under vacuum to produce an orange powder.

Synthesis of Mo24(5-lauroyl-O(CO)-bdc) 24 . $\mathrm{Mo}_{24}(\mathrm{OH}-\mathrm{bdc})_{24}(0.139 \mathrm{~g}, 0.5 \mathrm{mmol})$, lauroyl chloride $(0.220 \mathrm{~g}, 1 \mathrm{mmol})$ were added to a $20 \mathrm{~mL}$ scintillation vial and dissolved in $10 \mathrm{~mL}$ THF. In a separate vial, 2,2,6,6-tetramethylpiperidine $(0.141 \mathrm{~g}, 1 \mathrm{mmol})$ was dissolved in $10 \mathrm{~mL}$ of THF. This solution was added to the former and the resulting solution was stirred in a $40^{\circ} \mathrm{C}$ dry bath for 12 hours. The solution was evaporated under vacuum until $\sim 2 \mathrm{~mL}$ of solution remained. To this remaining solution, $\sim 18 \mathrm{~mL}$ of methanol was used to crash out the post-synthetically modified cage. The powder was then washed at room temperature three times with $\mathrm{MeOH}$ and dried under vacuum to produce an orange powder.

Synthesis of Mo24(5-lauroyl-NH(CO)-bdc $)_{24} \cdot \mathrm{Mo}_{24}\left(\mathrm{NH}_{2}-\mathrm{bdc}\right)_{24}(0.139 \mathrm{~g}, 0.5 \mathrm{mmol})$, lauroyl chloride $(0.220 \mathrm{~g}, 1 \mathrm{mmol})$ were added to a $20 \mathrm{~mL}$ scintillation vial and dissolved in $10 \mathrm{~mL}$ THF. In a separate vial, 2,2,6,6-tetramethylpiperidine $(0.141 \mathrm{~g}, 1 \mathrm{mmol})$ was dissolved in $10 \mathrm{~mL}$ of THF. This solution was added to the former and the resulting solution was stirred in a $40{ }^{\circ} \mathrm{C}$ dry bath for 12 hours. The solution was evaporated under vacuum until $\sim 2 \mathrm{~mL}$ of solution remained. To this remaining solution, $\sim 18 \mathrm{~mL}$ of methanol was used to crash out the post-synthetically modified cage. The powder was then washed at room temperature three times with $\mathrm{MeOH}$ and dried under vacuum to produce an orange powder.

Synthesis of $\mathbf{C r}_{24}$ (5-diphenylacetyl-O(CO)-bdc) ${ }_{24} \cdot \mathrm{Cr}_{24}(\mathrm{OH}-\mathrm{bdc})_{24}(0.116 \mathrm{~g}, 0.5 \mathrm{mmol})$, diphenylacetyl chloride $(0.230 \mathrm{~g}, 1 \mathrm{mmol})$ were added to a $20 \mathrm{~mL}$ scintillation vial and dissolved in $10 \mathrm{~mL}$ THF. In a separate vial, 2,2,6,6-tetramethylpiperidine $(0.141 \mathrm{~g}, 1 \mathrm{mmol})$ was dissolved in $10 \mathrm{~mL}$ of THF. This solution was added to the former and the resulting solution was stirred in a $40{ }^{\circ} \mathrm{C}$ dry bath for 12 hours. The solution was evaporated under vacuum until $\sim 2 \mathrm{~mL}$ of solution remained. To this remaining solution, $\sim 18 \mathrm{~mL}$ of methanol was used to crash out the postsynthetically modified cage. The powder was then washed at room temperature three times with $\mathrm{MeOH}$ and dried under vacuum to produce a purple powder. 
Synthesis of $\mathbf{C r}_{24}$ (5-diphenylacetyl-NH(CO)-bdc) ${ }_{24} \cdot \mathrm{Cr}_{24}\left(\mathrm{NH}_{2} \text {-bdc) }\right)_{24}(0.116 \mathrm{~g}, 0.5 \mathrm{mmol})$, diphenylacetyl chloride $(0.230 \mathrm{~g}, 1 \mathrm{mmol})$ were added to a $20 \mathrm{~mL}$ scintillation vial and dissolved in $10 \mathrm{~mL}$ THF. In a separate vial, 2,2,6,6-tetramethylpiperidine $(0.141 \mathrm{~g}, 1 \mathrm{mmol})$ was dissolved in $10 \mathrm{~mL}$ of THF. This solution was added to the former and the resulting solution was stirred in a $40{ }^{\circ} \mathrm{C}$ dry bath for 12 hours. The solution was evaporated under vacuum until $\sim 2 \mathrm{~mL}$ of solution remained. To this remaining solution, $\sim 18 \mathrm{~mL}$ of methanol was used to crash out the postsynthetically modified cage. The powder was then washed at room temperature three times with $\mathrm{MeOH}$ and dried under vacuum to produce a purple powder.

Synthesis of $\mathrm{Cr}_{24}$ (5-lauroyl-O(CO)-bdc) ${ }_{24} \cdot \mathrm{Cr}_{24}(\mathrm{OH}-\mathrm{bdc})_{24}(0.116 \mathrm{~g}, 0.5 \mathrm{mmol})$, lauroyl chloride $(0.220 \mathrm{~g}, 1 \mathrm{mmol})$ were added to a $20 \mathrm{~mL}$ scintillation vial and dissolved in $10 \mathrm{~mL}$ THF. In a separate vial, 2,2,6,6-tetramethylpiperidine $(0.141 \mathrm{~g}, 1 \mathrm{mmol})$ was dissolved in $10 \mathrm{~mL}$ of THF. This solution was added to the former and the resulting solution was stirred in a $40^{\circ} \mathrm{C}$ dry bath for 12 hours. The solution was evaporated under vacuum until $\sim 2 \mathrm{~mL}$ of solution remained. To this remaining solution, $\sim 18 \mathrm{~mL}$ of methanol was used to crash out the post-synthetically modified cage. The powder was then washed at room temperature three times with $\mathrm{MeOH}$ and dried under vacuum to produce a purple powder.

Synthesis of $\mathbf{C r}_{24}$ (5-lauroyl-NH(CO)-bdc $)_{24} \mathrm{Cr}_{24}\left(\mathrm{NH}_{2}-\mathrm{bdc}\right)_{24}(0.116 \mathrm{~g}, 0.5 \mathrm{mmol})$, lauroyl chloride $(0.220 \mathrm{~g}, 1 \mathrm{mmol})$ were added to a $20 \mathrm{~mL}$ scintillation vial and dissolved in $10 \mathrm{~mL}$ THF. In a separate vial, 2,2,6,6-tetramethylpiperidine $(0.141 \mathrm{~g}, 1 \mathrm{mmol})$ was dissolved in $10 \mathrm{~mL}$ of THF. This solution was added to the former and the resulting solution was stirred in a $40{ }^{\circ} \mathrm{C}$ dry bath for 12 hours. The solution was evaporated under vacuum until $\sim 2 \mathrm{~mL}$ of solution remained. To this remaining solution, $\sim 18 \mathrm{~mL}$ of methanol was used to crash out the post-synthetically modified cage. The powder was then washed at room temperature three times with $\mathrm{MeOH}$ and dried under vacuum to produce a purple powder.

Synthesis of $\mathbf{C u}_{24}(\mathbf{5}-\mathrm{diphenylacetyl-O(CO)-bdc})_{24} \cdot \mathrm{Cu}_{24}(\mathrm{OH}-\mathrm{bdc})_{24}(0.122 \mathrm{~g}, 0.5 \mathrm{mmol})$, diphenylacetyl chloride $(0.115 \mathrm{~g}, 0.5 \mathrm{mmol})$ were added to a $20 \mathrm{~mL}$ scintillation vial and dissolved in $10 \mathrm{~mL}$ THF. In a separate vial, 2,2,6,6-tetramethylpiperidine $(0.70 \mathrm{~g}, 0.5 \mathrm{mmol})$ was dissolved in $10 \mathrm{~mL}$ of THF. This solution was added to the former and the resulting solution was stirred in a $40{ }^{\circ} \mathrm{C}$ dry bath for 12 hours. The solution was evaporated under vacuum until $\sim 2 \mathrm{~mL}$ of solution remained. To this remaining solution, $\sim 18 \mathrm{~mL}$ of methanol was used to crash out the postsynthetically modified cage. The powder was then washed at room temperature three times with $\mathrm{MeOH}$ and dried under vacuum to produce a blue/green powder.

Synthesis of $\mathbf{C u}_{24}$ (5-lauroyl-O(CO)-bdc) ${ }_{24} \cdot \mathrm{Cu}_{24}(\mathrm{OH}-\mathrm{bdc})_{24}(0.122 \mathrm{~g}, 0.5 \mathrm{mmol})$, lauroyl chloride $(0.110 \mathrm{~g}, 0.5 \mathrm{mmol})$ were added to a $20 \mathrm{~mL}$ scintillation vial and dissolved in $10 \mathrm{~mL}$ THF. In a separate vial, 2,2,6,6-tetramethylpiperidine $(0.70 \mathrm{~g}, 0.5 \mathrm{mmol})$ was dissolved in $10 \mathrm{~mL}$ of THF. This solution was added to the former and the resulting solution was stirred in a $40^{\circ} \mathrm{C}$ dry bath for 12 hours. The solution was evaporated under vacuum until $\sim 2 \mathrm{~mL}$ of solution remained. To this remaining solution, $\sim 18 \mathrm{~mL}$ of methanol was used to crash out the post-synthetically modified cage. The powder was then washed at room temperature three times with $\mathrm{MeOH}$ and dried under vacuum to produce a blue powder. 


\section{Chromium(II) Cage NMR Spectra:}

The Cr(II)-based cages are generally soluble in DMF and diamagnetic which allows NMR experiments to be performed on the cages without acid digestions of the materials. However, due to the chemical shift of DMF- $\mathrm{d}_{7}$, some of the aromatic peaks corresponding to the isophthalic acid portion of the ligand are not visible.

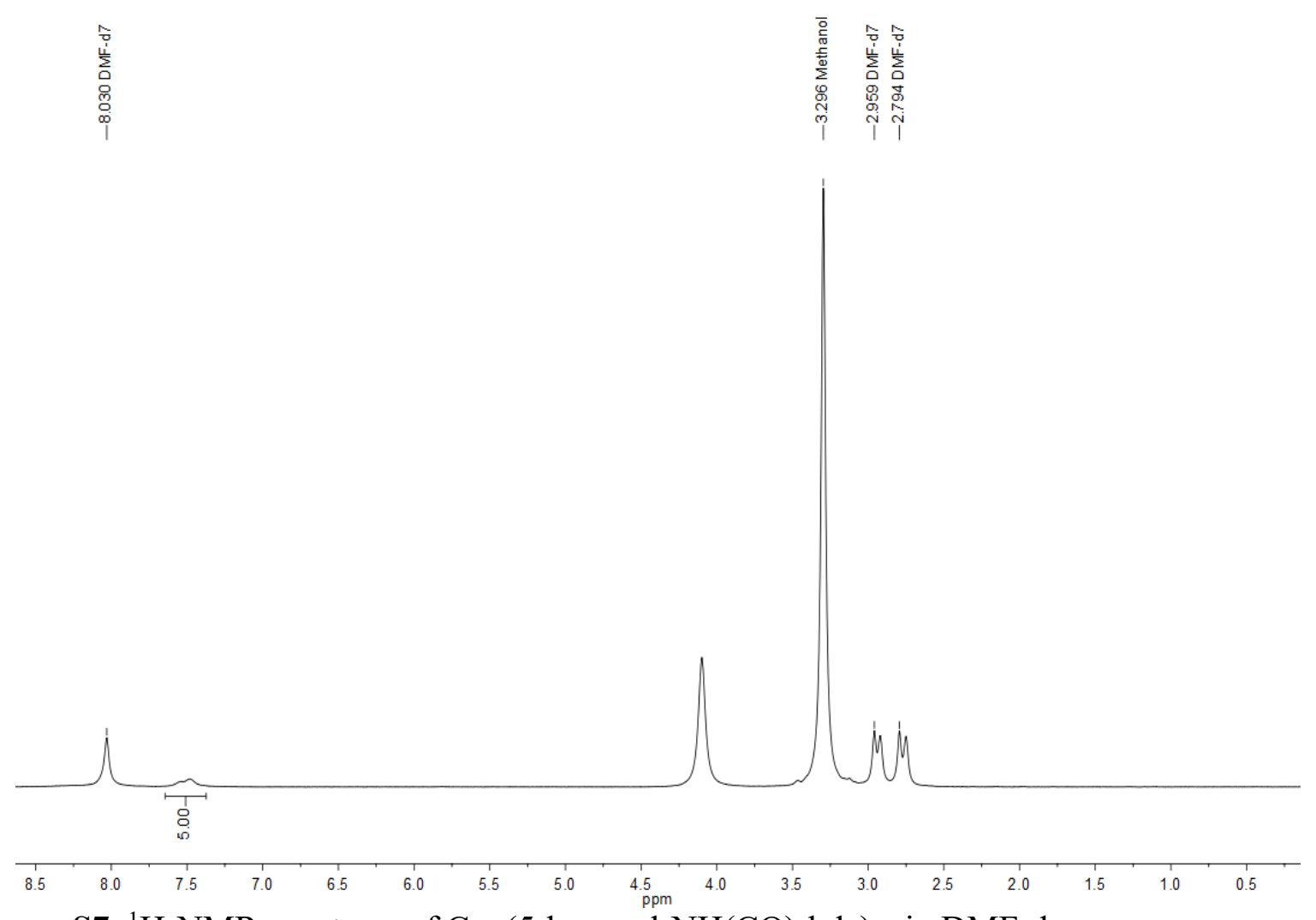

Figure S7. ${ }^{1} \mathrm{H}-\mathrm{NMR}$ spectrum of $\mathrm{Cr}_{24}(5 \text {-benzoyl-NH(CO)-bdc })_{24}$ in $\mathrm{DMF}-\mathrm{d}_{7}$. 


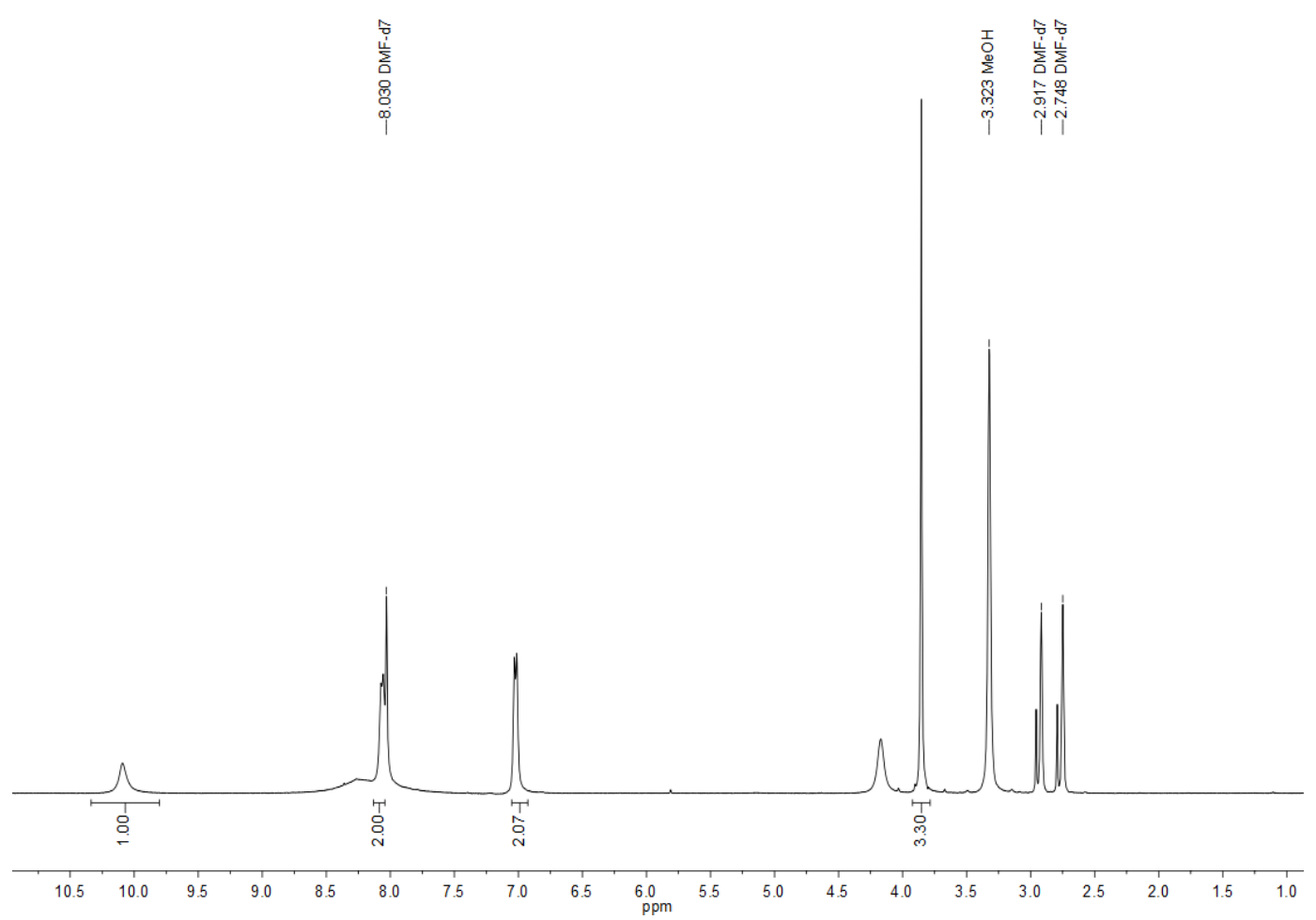

Figure S8. ${ }^{1} \mathrm{H}-\mathrm{NMR}$ spectrum of $\mathrm{Cr}_{24}$ (5-(4-methoxybenzoyl)-NH(CO)-bdc) 24 in DMF-d 7 .

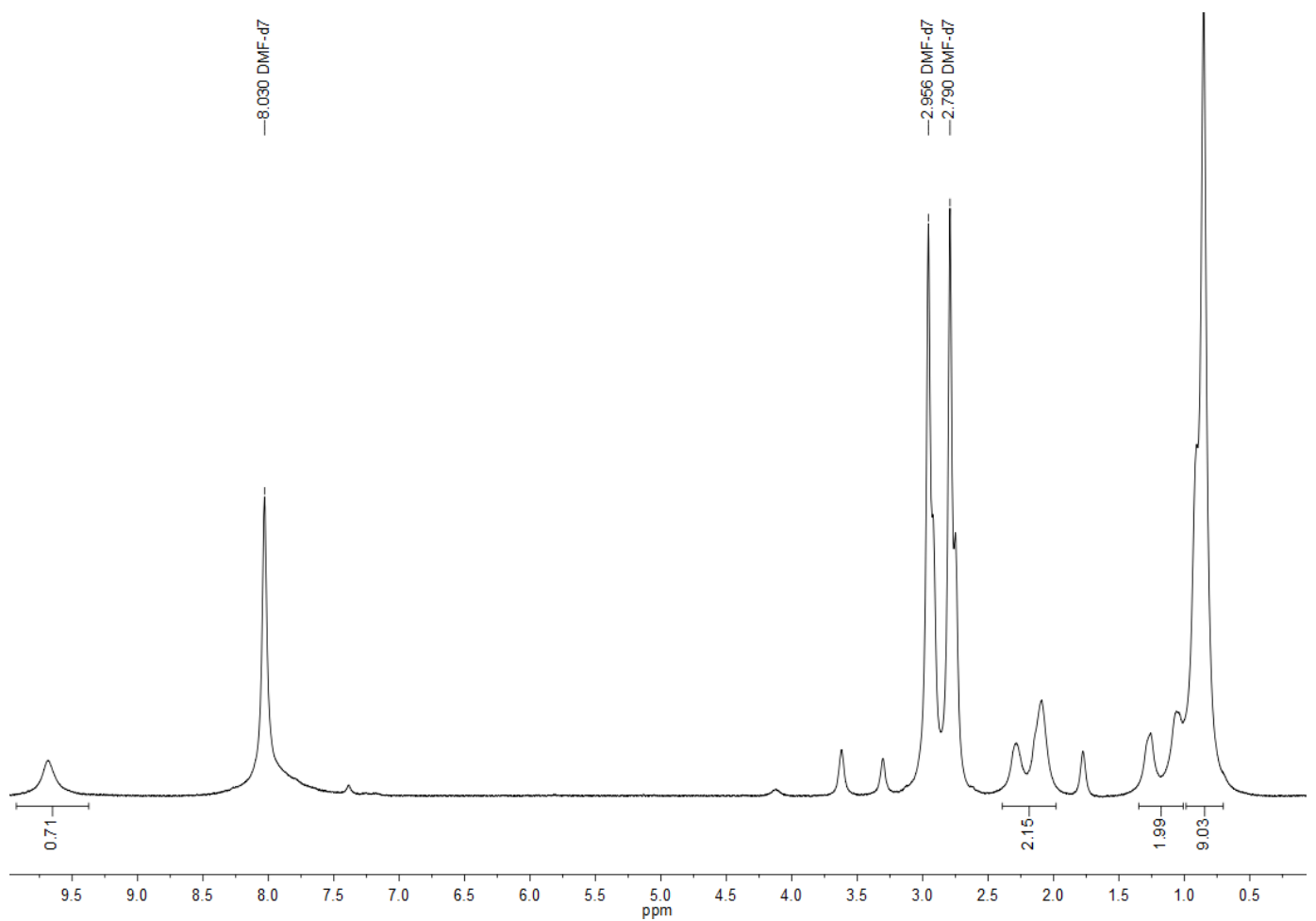

Figure S9. ${ }^{1} \mathrm{H}-\mathrm{NMR}$ spectrum of $\mathrm{Cr}_{24}\left(5-\left(3,5,5\right.\right.$-trimethylhexanoyl)-NH(CO)-bdc) ${ }_{24}$ in DMF-d . 

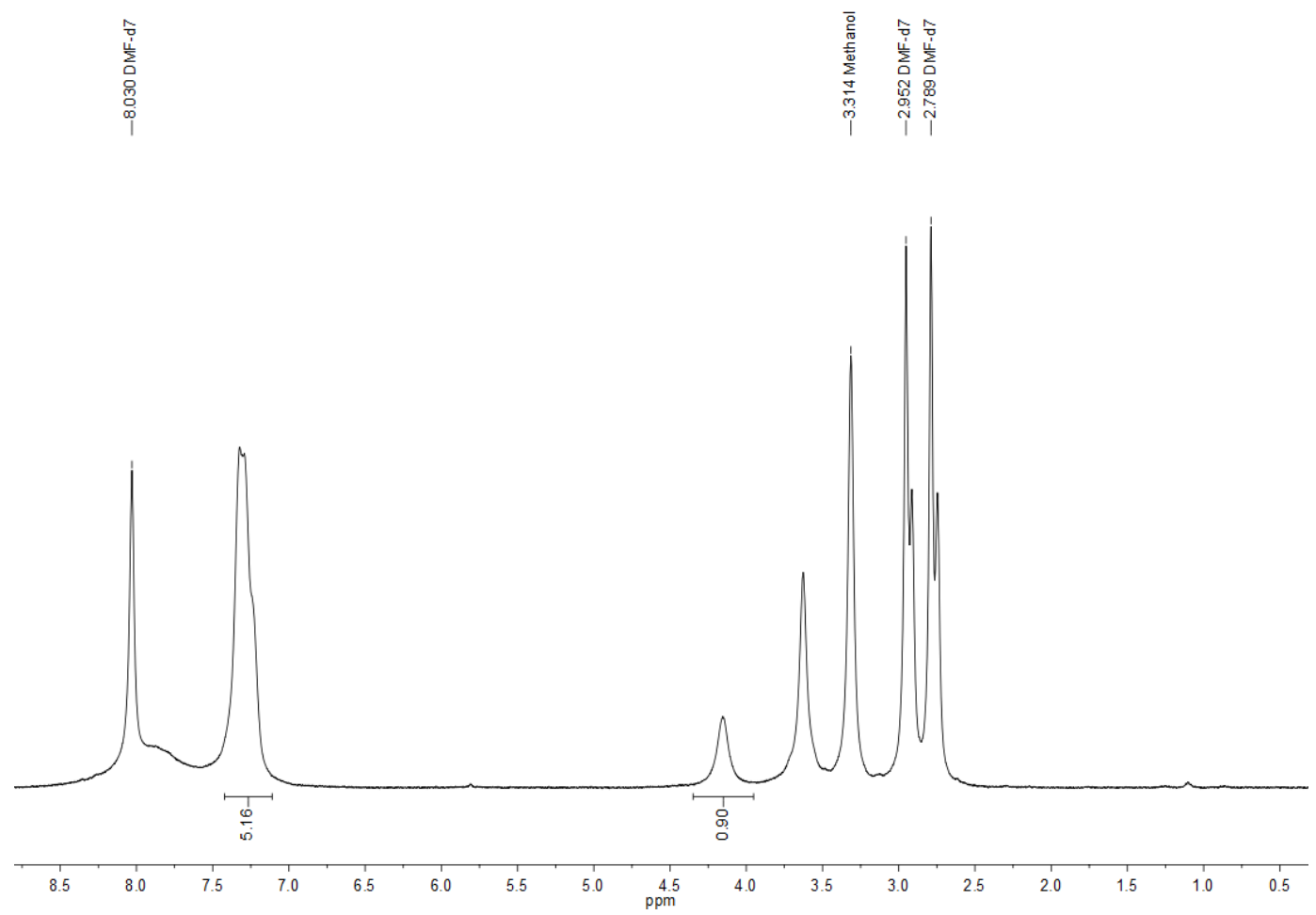

Figure S10. ${ }^{1} \mathrm{H}-\mathrm{NMR}$ spectrum of $\mathrm{Cr}_{24}(5 \text {-phenylacetyl-NH(CO)-bdc })_{24}$ in DMF-d 7 .

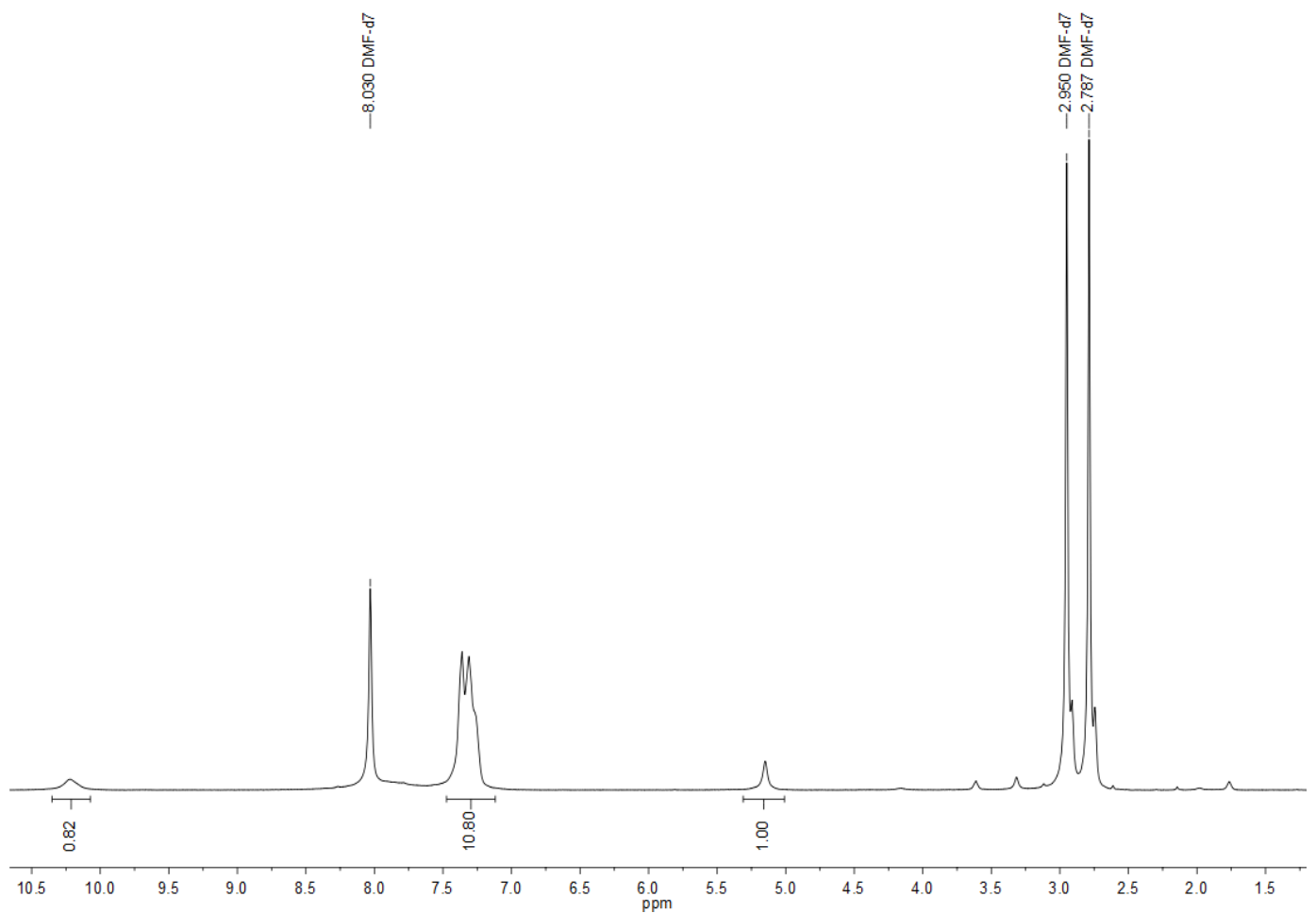

Figure S11. ${ }^{1} \mathrm{H}-\mathrm{NMR}$ spectrum of $\mathrm{Cr}_{24}\left(5\right.$-diphenylacetyl-NH(CO)-bdc) ${ }_{24}$ in DMF-d . 

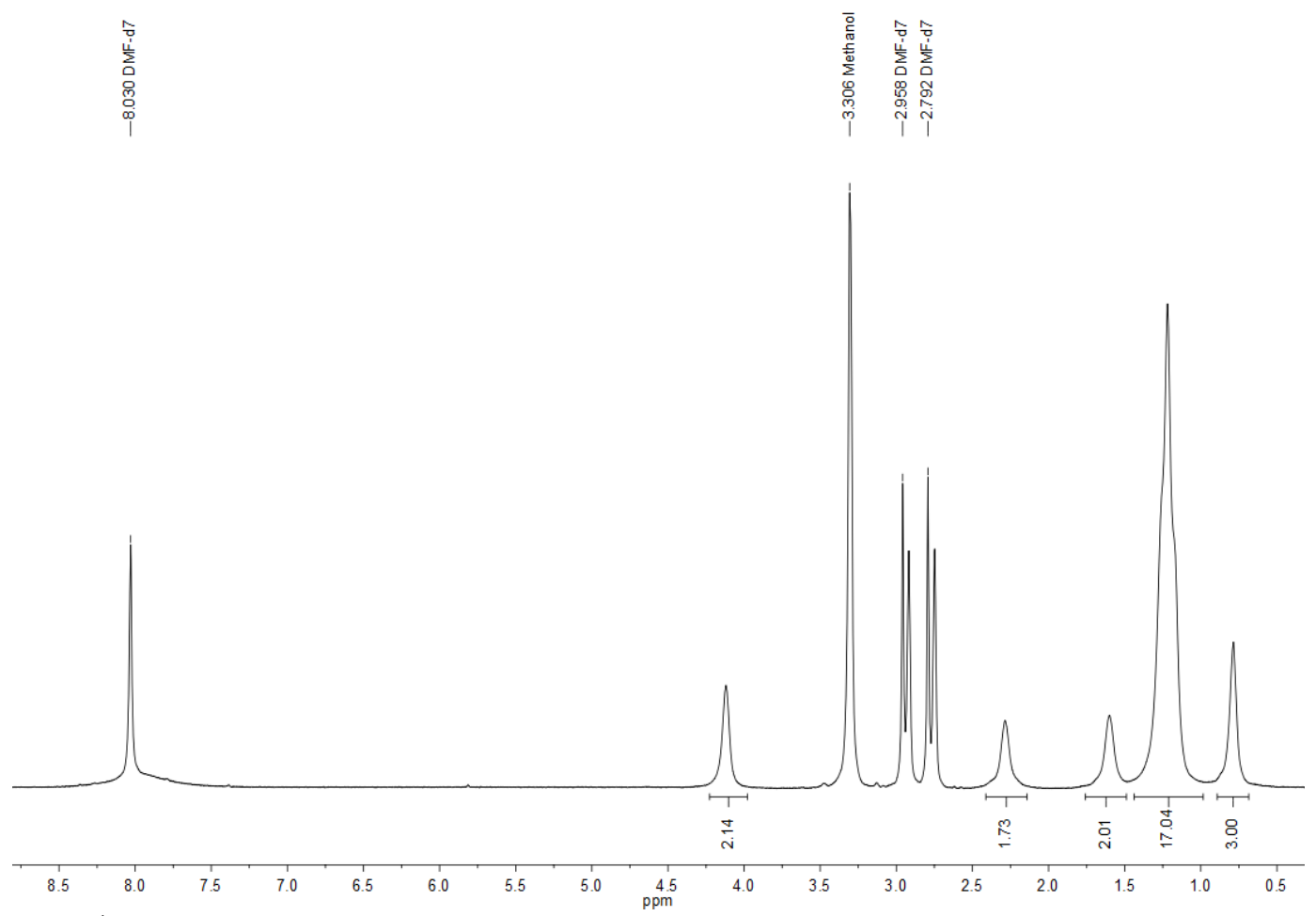

Figure S12. ${ }^{1} \mathrm{H}-\mathrm{NMR}$ spectrum of $\mathrm{Cr}_{24}(5-\text { lauroyl-NH(CO)-bdc })_{24}$ in DMF-d 7 . 
Molybdenum(II) Cage NMR Spectra:

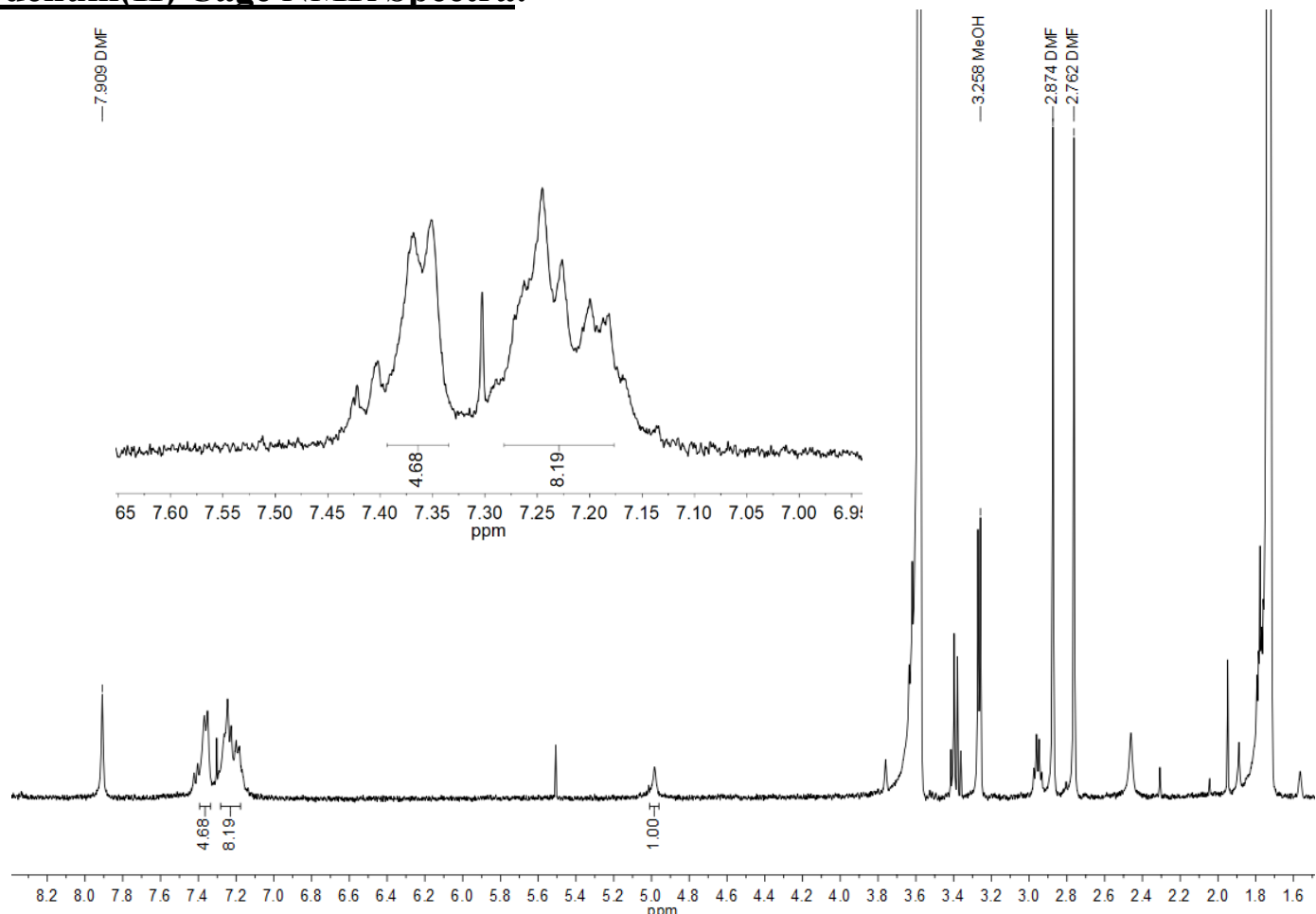

Figure S13. ${ }^{1} \mathrm{H}-\mathrm{NMR}$ spectrum of $\mathrm{Mo}_{24}\left(5\right.$-diphenylacetyl-NH(CO)-bdc) ${ }_{24}$ in THF-d 8 .

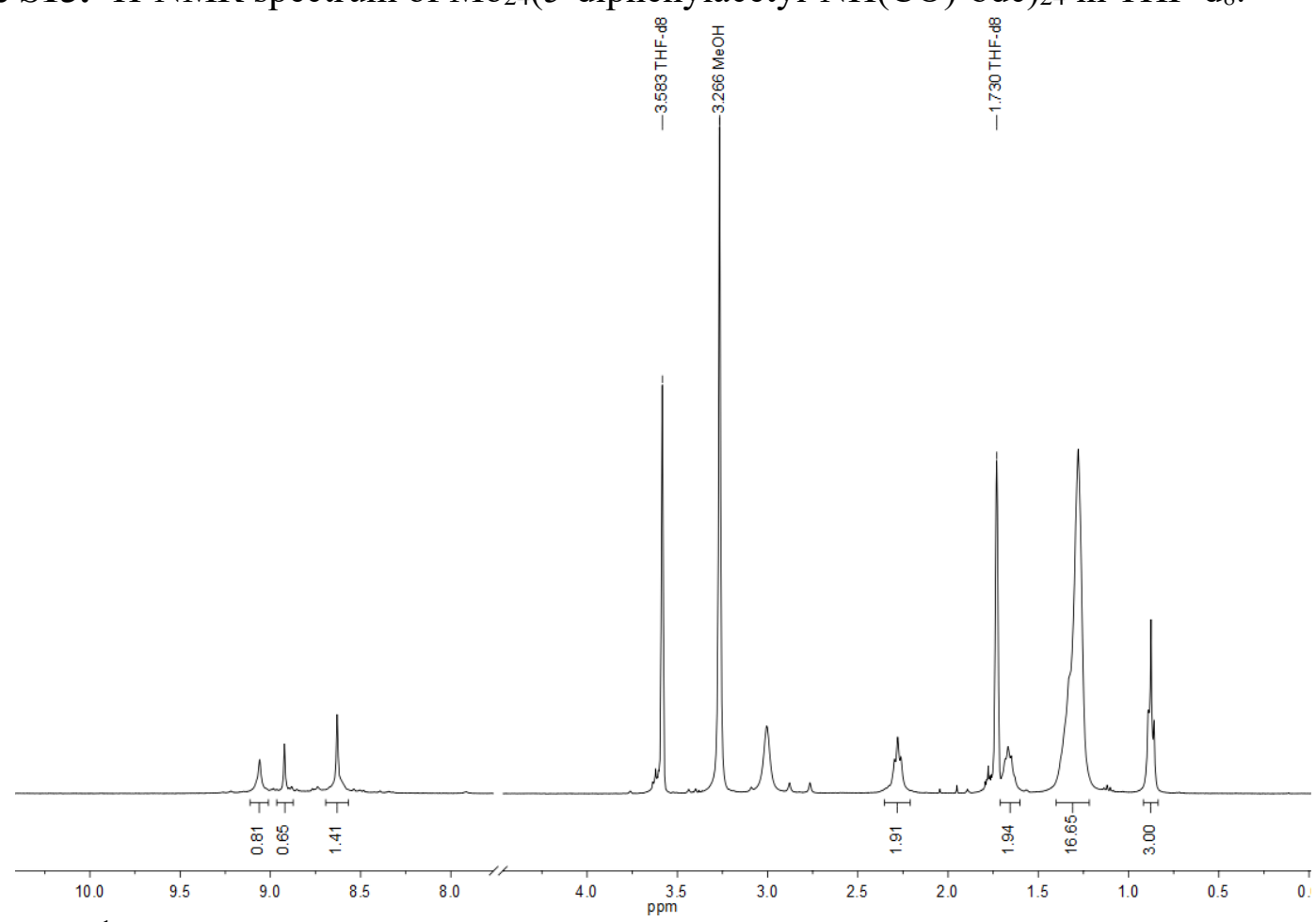

Figure S14. ${ }^{1} \mathrm{H}-\mathrm{NMR}$ spectrum of $\mathrm{Mo}_{24}\left(5-\right.$ lauroyl-NH(CO)-bdc) $_{24}$ in THF-d8.

NMR Spectra of Molybdenum(II) PSM Cages: 


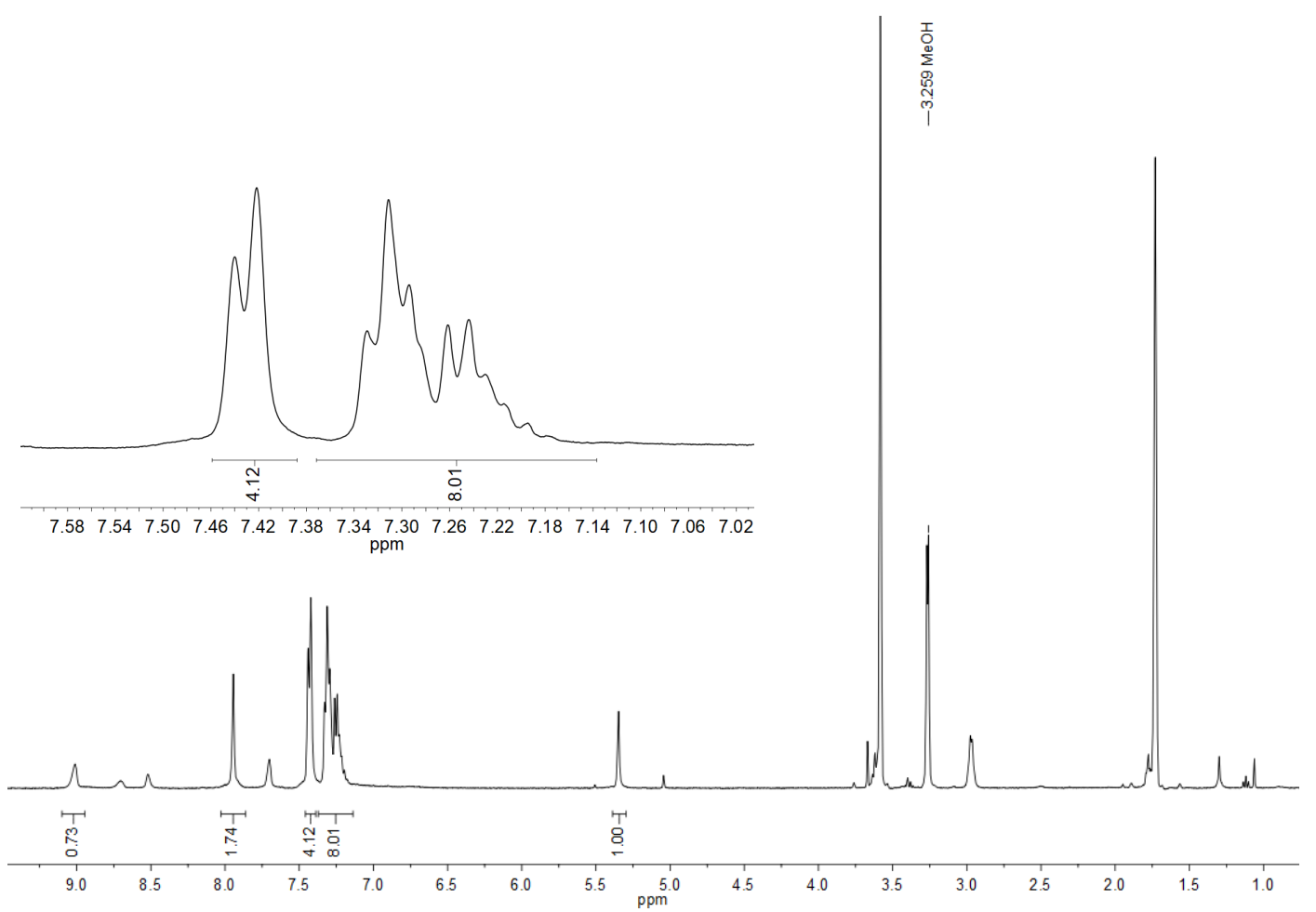

Figure S15. ${ }^{1} \mathrm{H}-\mathrm{NMR}$ spectrum of $\mathrm{Mo}_{24}\left(5\right.$-diphenylacetyl-O(CO)-bdc) ${ }_{24}$ in THF-d8.

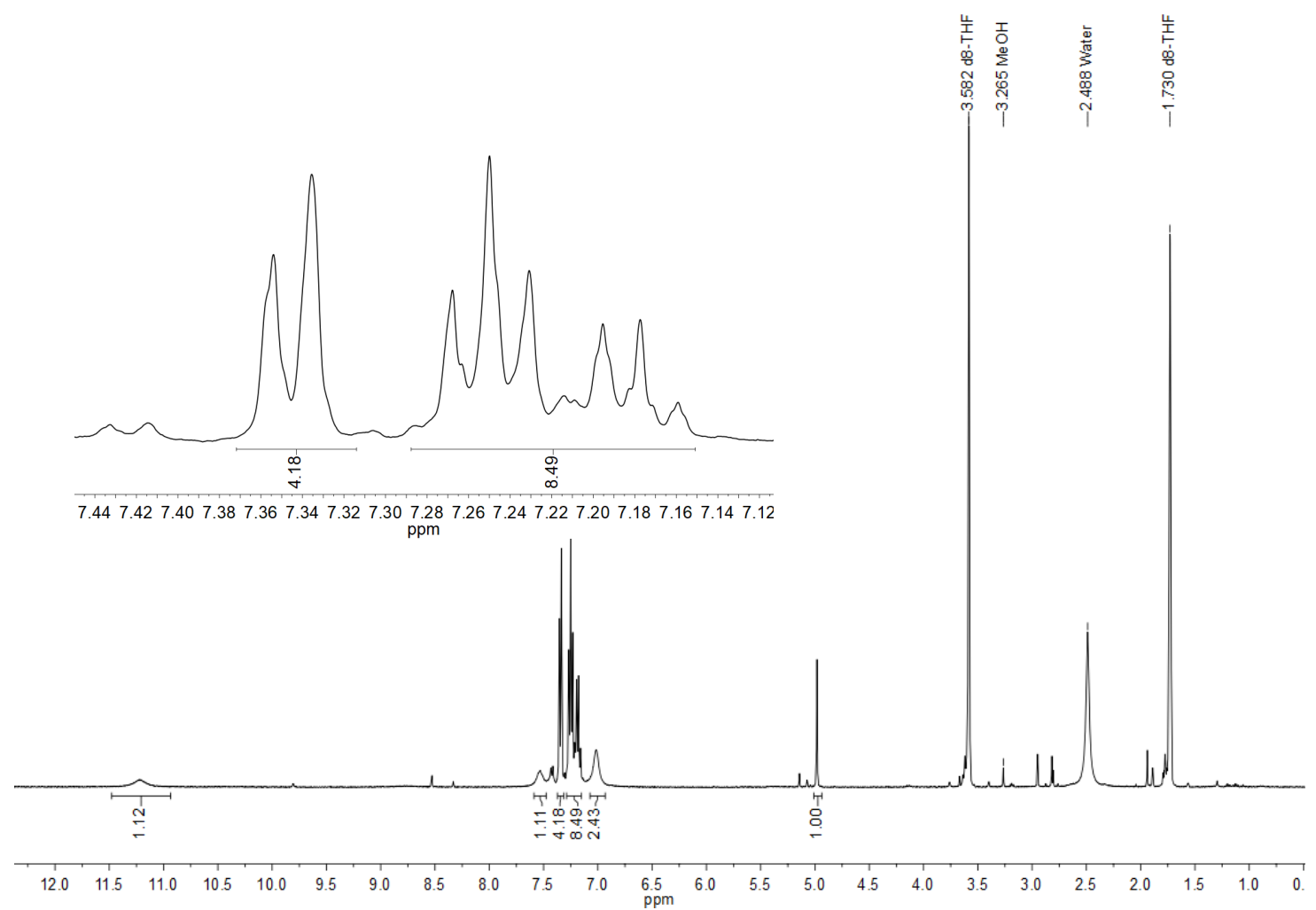

Figure S16. ${ }^{1} \mathrm{H}-\mathrm{NMR}$ spectrum of $\mathrm{Mo}_{24}\left(5\right.$-diphenylacetyl-NH(CO)-bdc) ${ }_{24}$ in THF-d 8 . 


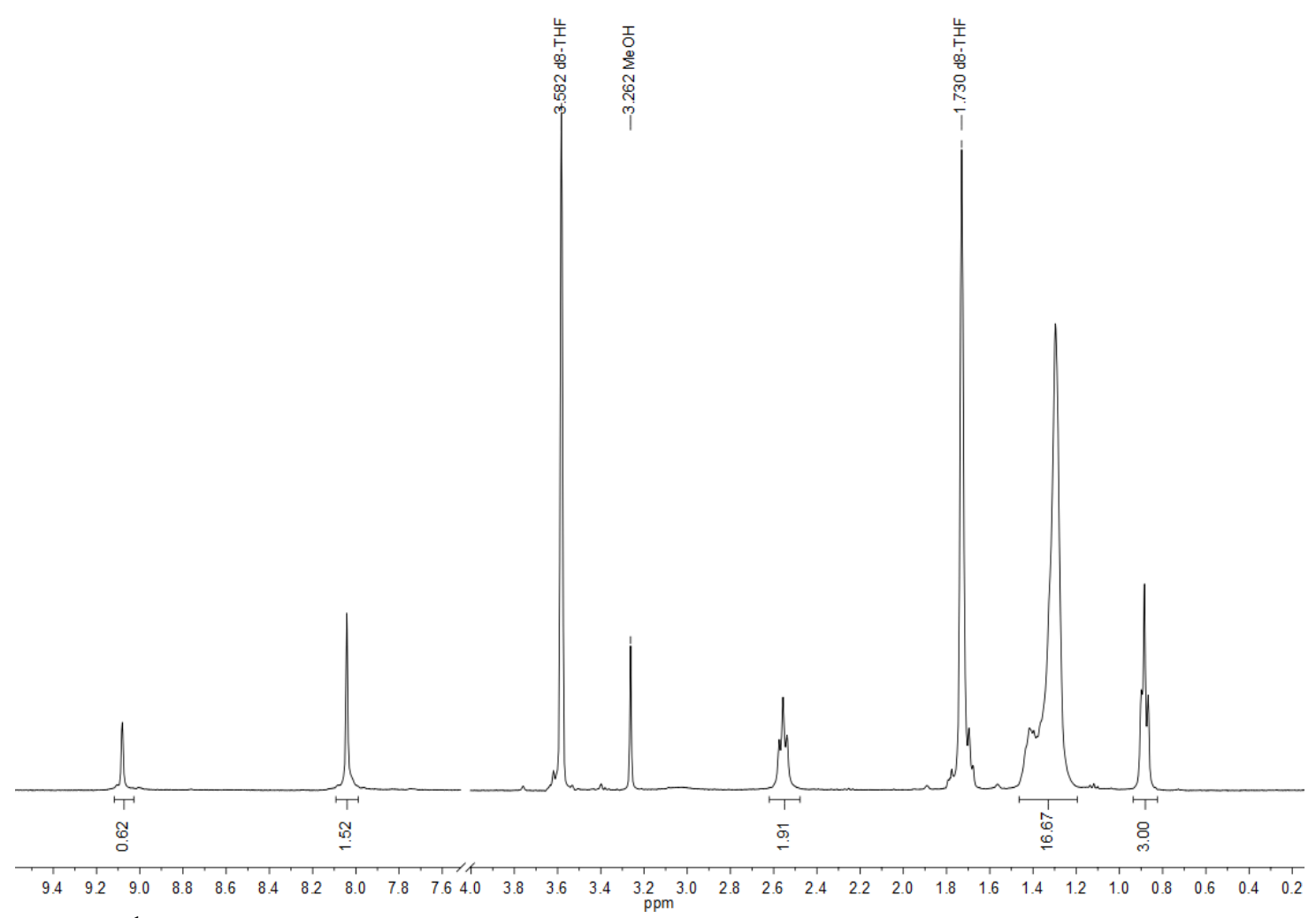

Figure S17. ${ }^{1} \mathrm{H}-\mathrm{NMR}$ spectrum of $\mathrm{Mo}_{24}(5$-lauroyl-O(CO)-bdc) 24 in THF-d 8 .

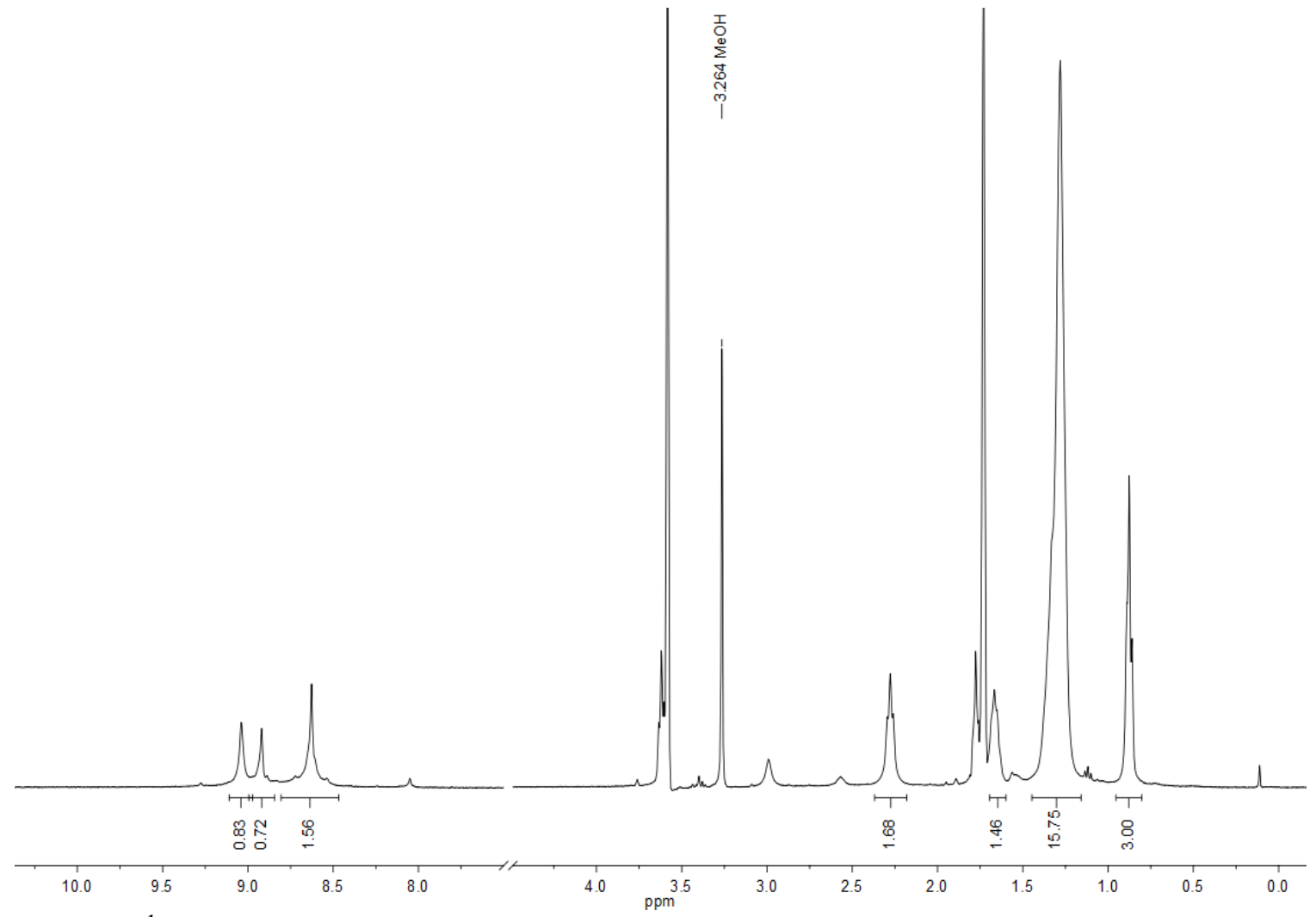

Figure S18. ${ }^{1} \mathrm{H}-\mathrm{NMR}$ spectrum of $\mathrm{Mo}_{24}(5-$ lauroyl-NH(CO)-bdc) 24 in THF-d 8 . 


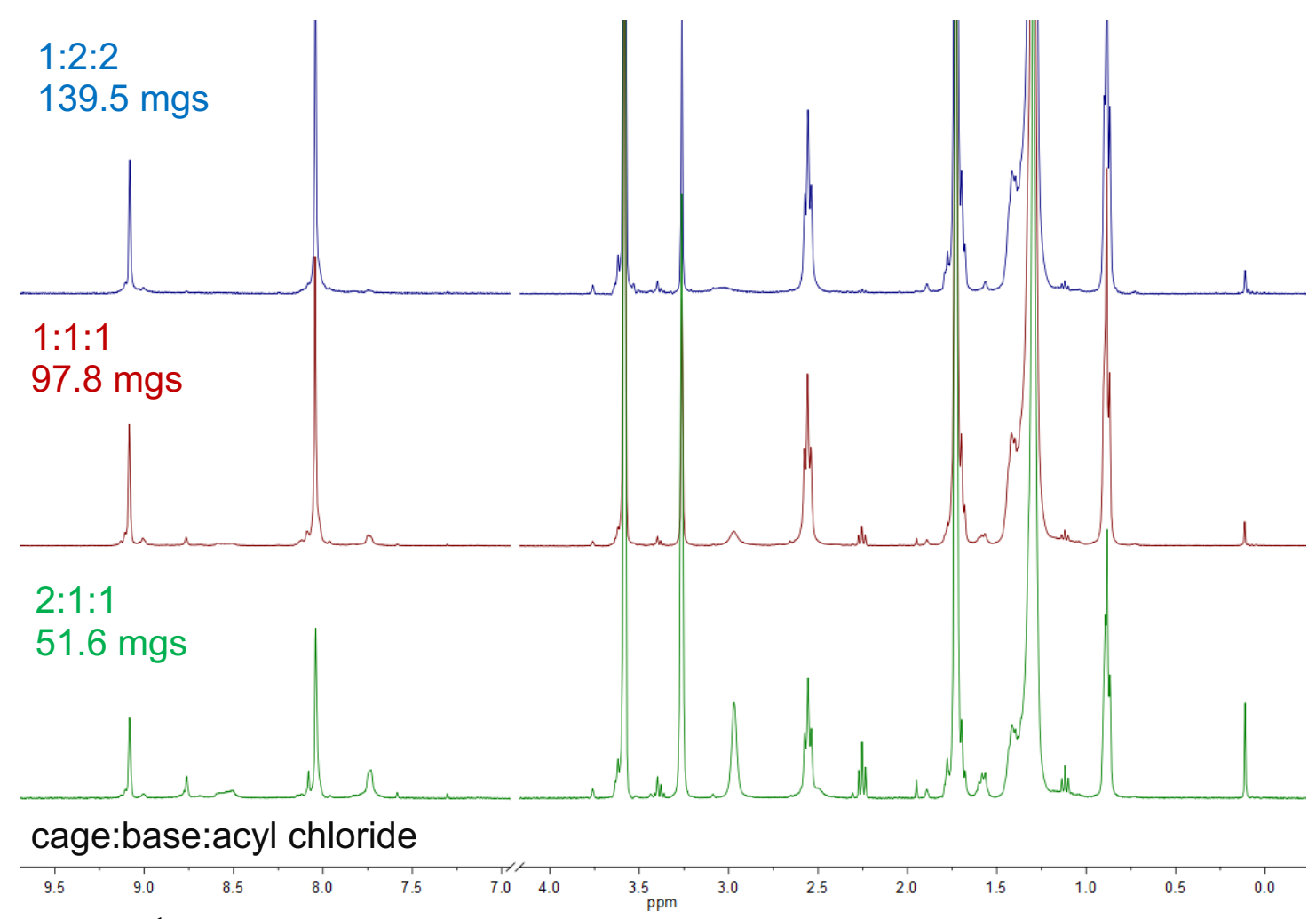

Figure S19. ${ }^{1} \mathrm{H}-\mathrm{NMR}$ spectrum in $\mathrm{THF}-\mathrm{d}_{8}$ of $\mathrm{Mo}_{24}(5-\mathrm{lauroyl}-\mathrm{O}(\mathrm{CO})-\mathrm{bdc})_{24}$ synthesis with different equivalents of cage:base:acyl chloride and resulting yield of post-synthetically modified cage. 

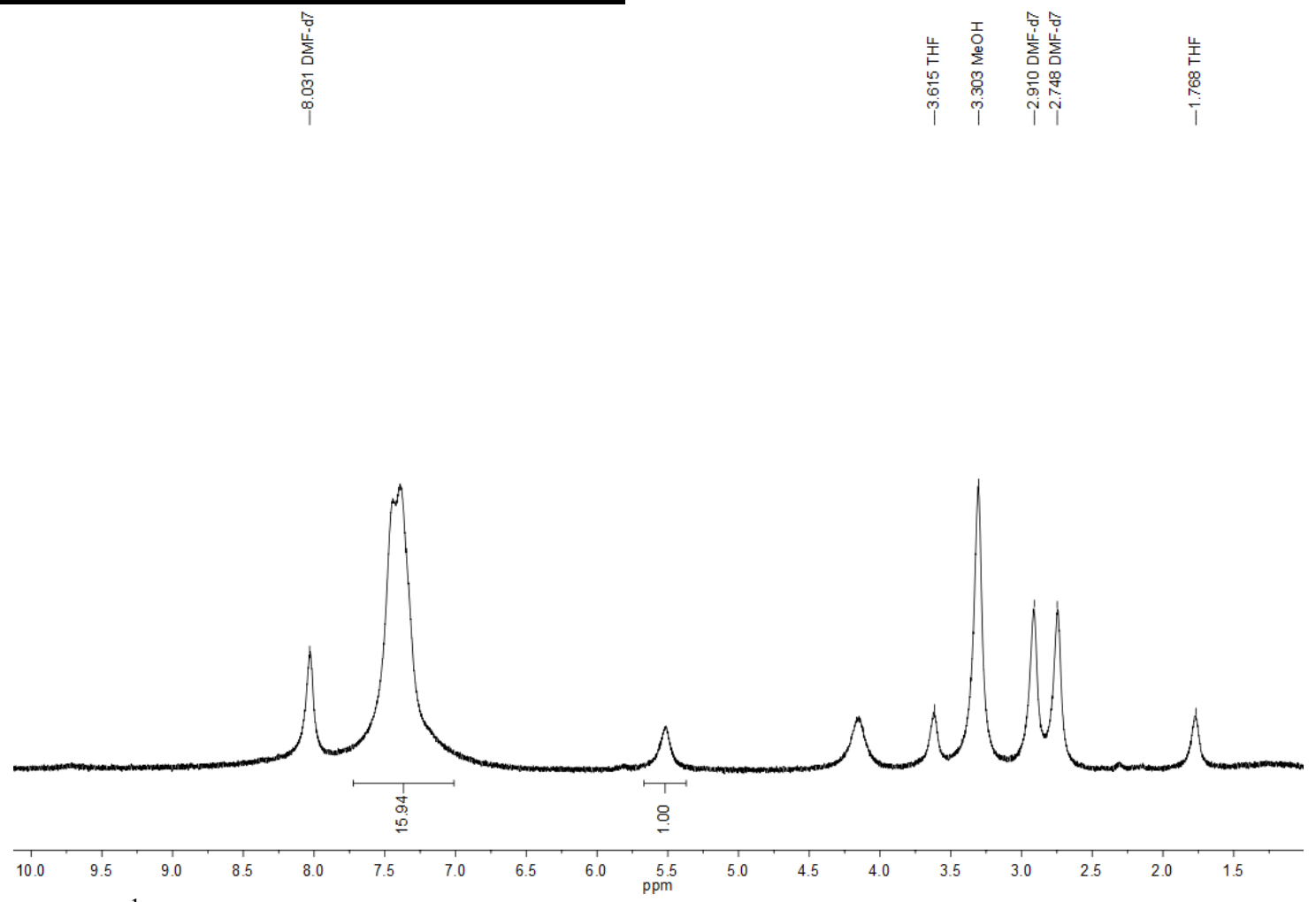

Figure S20. ${ }^{1} \mathrm{H}-\mathrm{NMR}$ spectrum of $\mathrm{Cr}_{24}(5 \text {-diphenylacetyl-O(CO)-bdc })_{24}$ in DMF-d 7 .
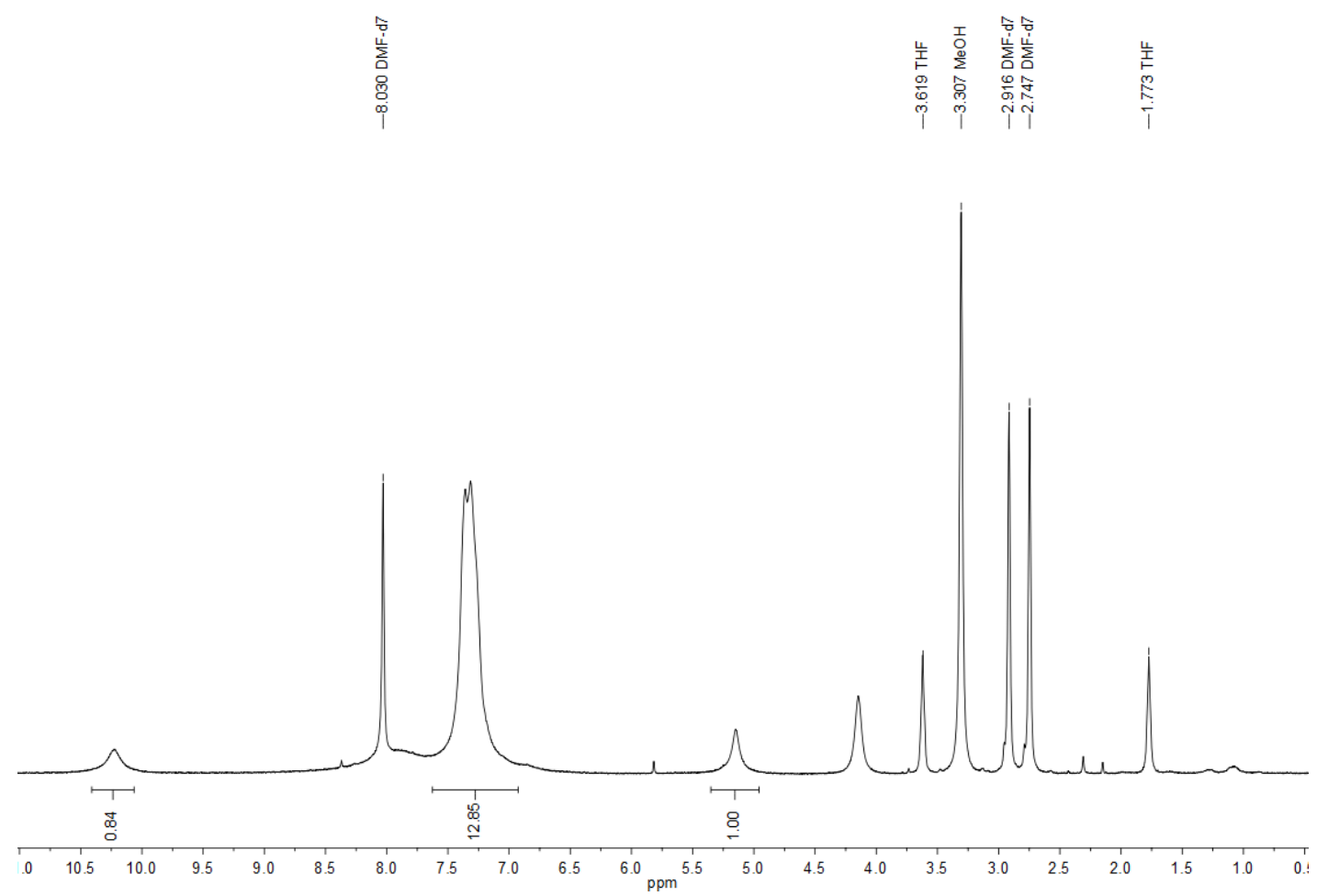

Figure S21. ${ }^{1} \mathrm{H}-\mathrm{NMR}$ spectrum of $\mathrm{Cr}_{24}$ (5-diphenylacetyl-NH(CO)-bdc) ${ }_{24}$ in DMF-d7. 


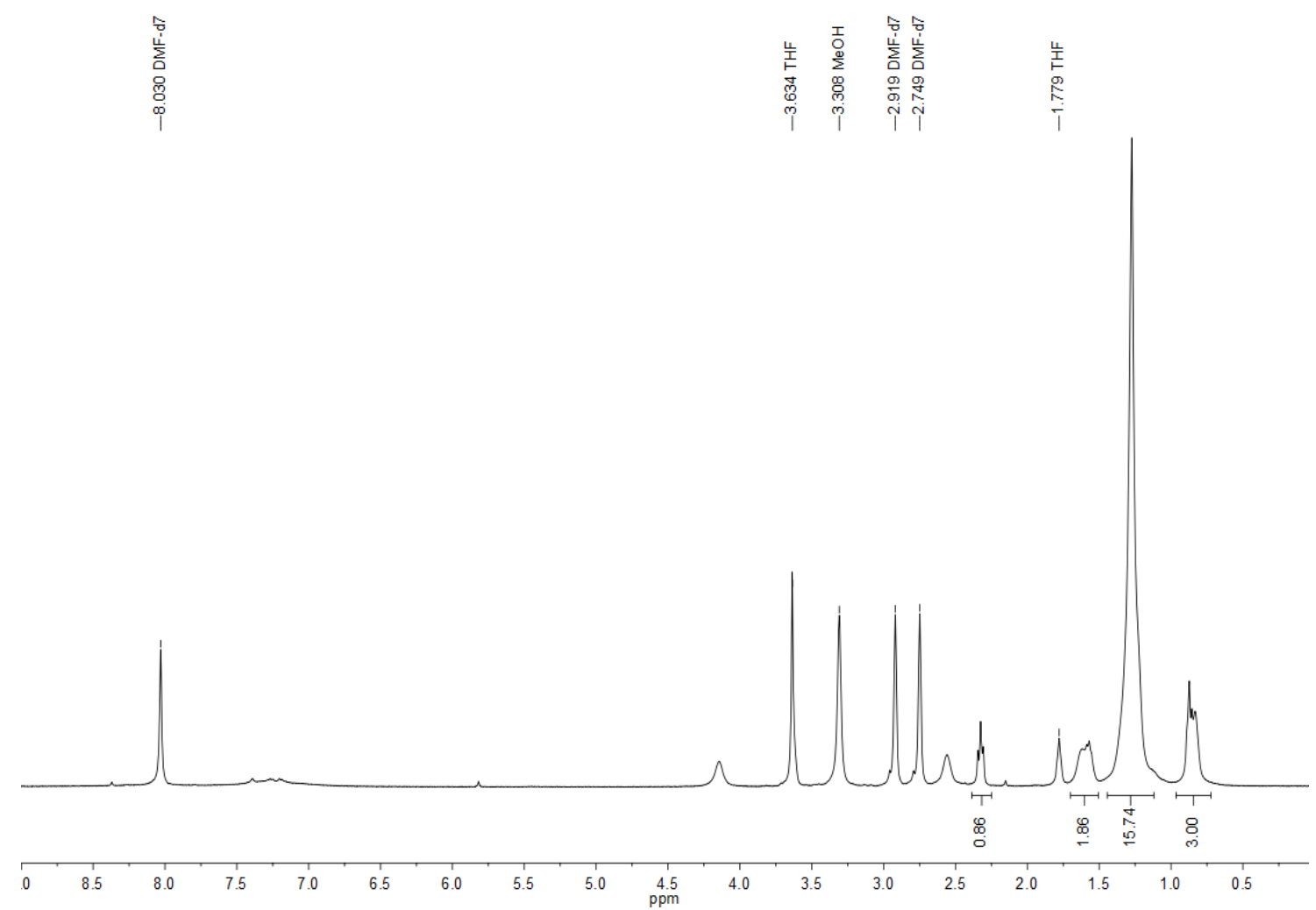

Figure S22. ${ }^{1} \mathrm{H}-\mathrm{NMR}$ spectrum of $\mathrm{Cr}_{24}(5-\text { lauroyl-O(CO)-bdc })_{24}$ in $\mathrm{DMF}-\mathrm{d}_{7}$.

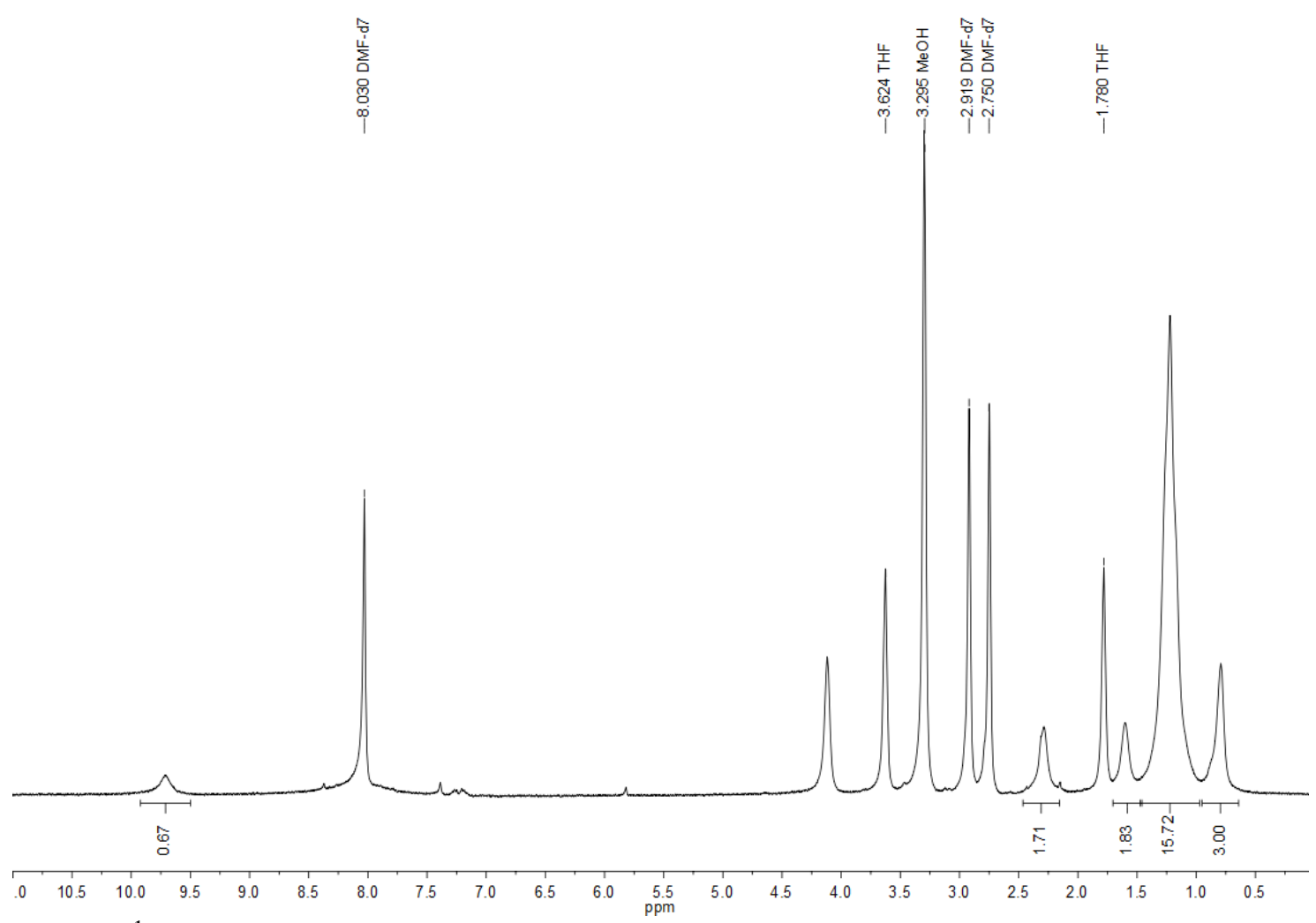

Figure S23. ${ }^{1} \mathrm{H}-\mathrm{NMR}$ spectrum of $\mathrm{Cr}_{24}(5$-lauroyl-NH(CO)-bdc) 24 in DMF-d 7 . 
NMR Spectra of Copper(II) PSM Cages:
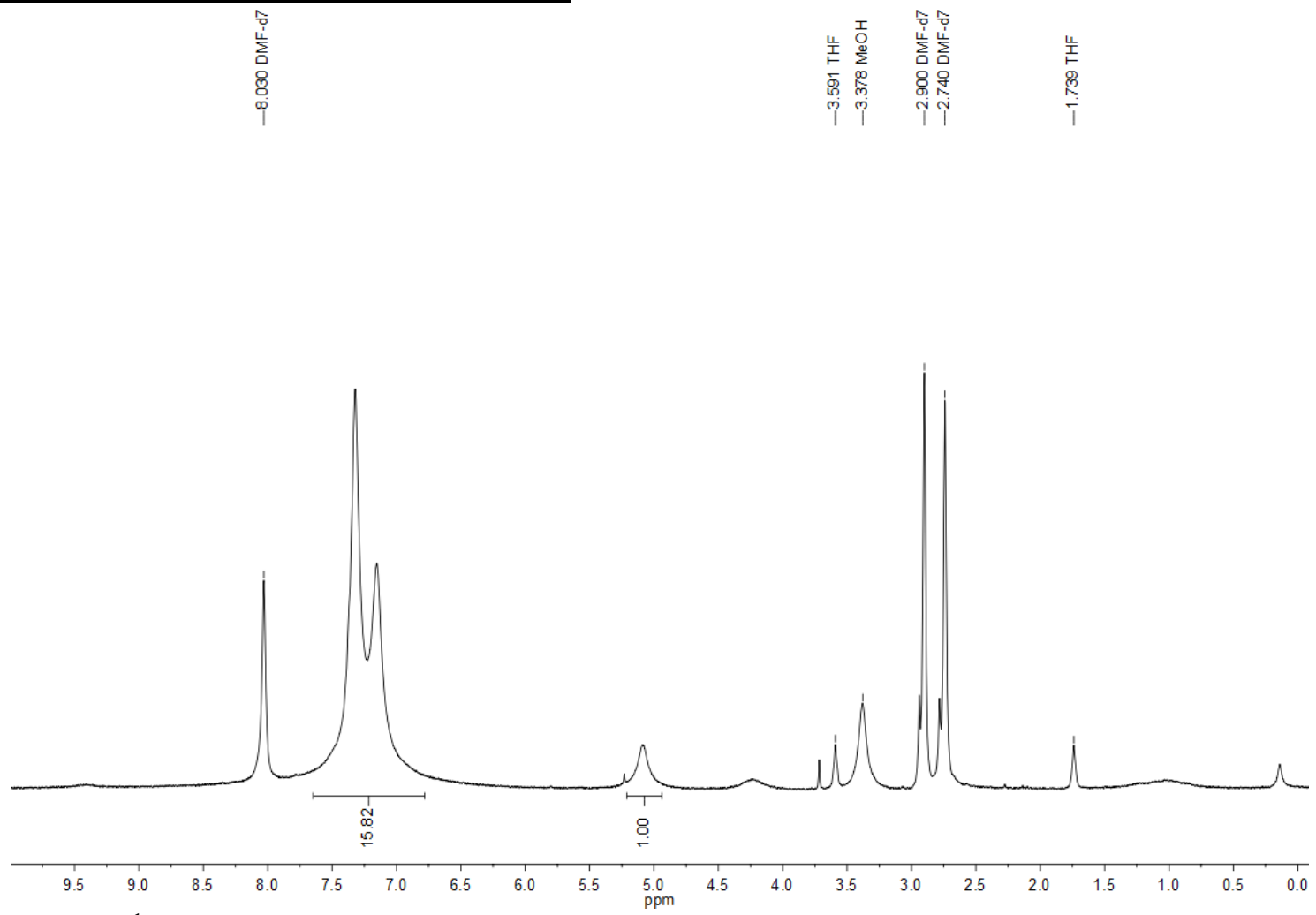

Figure S24. ${ }^{1} \mathrm{H}-\mathrm{NMR}$ spectrum of $\mathrm{Cu}_{24}(5 \text {-diphenylacetyl-O(CO)-bde })_{24}$ in DMF-d .

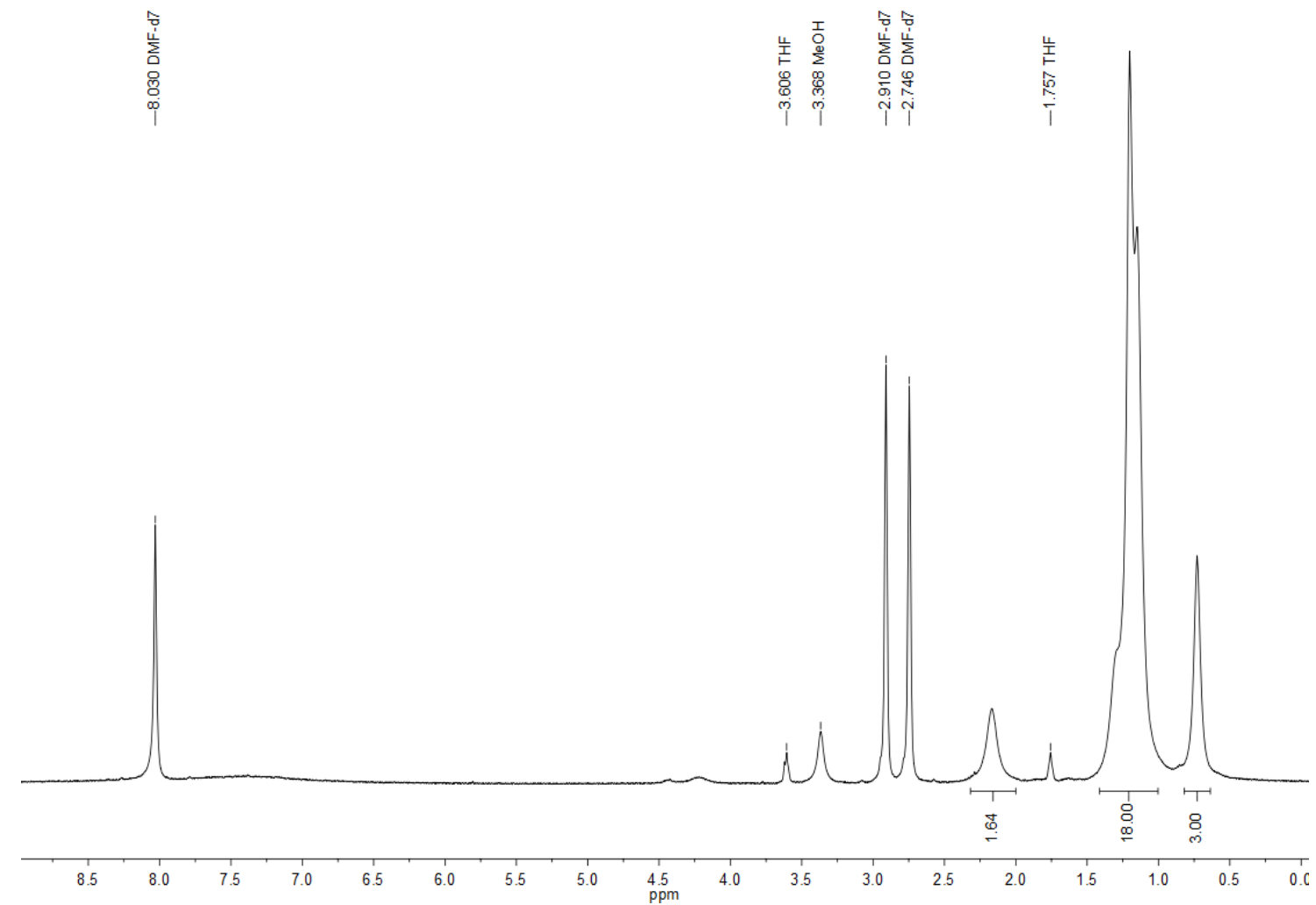

Figure S25. ${ }^{1} \mathrm{H}-\mathrm{NMR}$ spectrum of $\mathrm{Cu}_{24}\left(5\right.$-lauroyl-O(CO)-bdc) ${ }_{24}$ in $\mathrm{DMF}-\mathrm{d}_{7}$. 


\section{X-ray Crystallography:}

X-ray structural analysis for $\mathrm{Cu}_{24}(5 \text {-phenylacetyl- } \mathrm{NH}(\mathrm{CO})-\mathrm{bdc})_{24}, \mathrm{Cu}_{24}$ (5-lauroyl-NH(CO)bdc) $24, \quad \mathrm{Cu}_{24}$ (5-(4-methoxybenzoyl)-NH(CO)-bdc) $24, \quad \mathrm{Cu}_{24}$ (5-diphenylacetyl-NH(CO)-bdc) 24 , $\mathrm{Cu}_{24}$ (5-(3,5,5-trimethylhexanoyl)-NH(CO)-bdc $)_{24}, \quad \mathrm{Cu}_{24}$ (5-benzoyl-NH(CO)-bdc $)_{24}, \quad \mathrm{Cr}_{24}(5-$ benzoyl-NH(CO)-bdc) 24 , and $\mathrm{Mo}_{24}(5$-diphenylacetyl-NH(CO)-bdc) 24 . Crystals were mounted using viscous oil onto a plastic mesh and cooled to the data collection temperature. Data were collected on a Bruker-AXS APEX II DUO CCD diffractometer with $\mathrm{Cu}-\mathrm{K} \alpha$ radiation $(\lambda=1.54178$ $\AA$ ) focused with Goebel mirrors. Unit cell parameters were obtained from 36 data frames, $0.5^{\circ} \mathrm{\omega}$, from three different sections of the Ewald sphere. The systematic absences in the diffraction data are uniquely consistent with $P 2_{1} / n$ for $\mathrm{Cu}_{24}$ (5-(4-methoxybenzoyl)-NH(CO)-bdc) $)_{24}$. The systematic absences, equivalent reflections and unit cell parameters are consistent for $C 2 / c$ and $C c$ for $\mathrm{Cu}_{24}$ (5-phenylacetyl-NH(CO)-bdc) $)_{24} ; R 3$ and $R$-3 for $\mathrm{Cu}_{24}$ (5-lauroyl-NH(CO)-bdc) $)_{24}, \mathrm{Cu}_{24}(5$ (3,5,5-trimethylhexanoyl)-NH(CO)-bdc) ${ }_{24}$, and $\mathrm{Mo}_{24}$ (5-diphenylacetyl-NH(CO)-bdc) 24 ; P4/mnc; and $P 4 n c$ for $\mathrm{Cr}_{24}$ (5-benzoyl-NH(CO)-bdc) 24 , and $\mathrm{Cu}_{24}(5$-benzoyl-NH(CO)-bdc) 24 . No symmetry higher than triclinic was observed for $\mathrm{Cu}_{24}$ (5-diphenylacetyl-NH(CO)-bdc) 24 . Refinement in the centrosymmetric space group options yielded chemically reasonable and computationally stable results of refinement. The data were treated with multi-scan absorption corrections. ${ }^{5}$ Structures were solved using intrinsic phasing methods ${ }^{6}$ and refined with full-matrix, least-squares procedures on $F^{2}{ }^{7}$ The compound molecules are located at special positions: for $\mathrm{Cr}_{24}$ (5-benzoylbdc) 24 , and $\mathrm{Cu}_{24}$ (5-benzoyl-NH(CO)-bdc) ${ }_{24}$, a four-fold axis and mirror; for $\mathrm{Cu}_{24}$ (5-phenylacetyl$\mathrm{NH}(\mathrm{CO})-\mathrm{bdc})_{24}, \quad \mathrm{Cu}_{24}$ (5-(4-methoxybenzoyl)-NH(CO)-bdc) 24 and $\mathrm{Cu}_{24}$ (5-diphenylacetyl$\mathrm{NH}(\mathrm{CO})-\mathrm{bdc})_{24}$, an inversion center; and for $\mathrm{Cu}_{24}(5-\mathrm{lauroyl}-\mathrm{NH}(\mathrm{CO})-\mathrm{bdc})_{24}, \mathrm{Cu}_{24}(5-(3,5,5-$ trimethylhexanoyl)- $\mathrm{NH}(\mathrm{CO})$-bdc $)_{24}$, and $\mathrm{Mo}_{24}(5 \text {-diphenylacetyl- } \mathrm{NH}(\mathrm{CO})-\mathrm{bdc})_{24}$, a three-fold rotoinversion axis. Both $\mathrm{Cu}_{24}$ (5-lauroyl- $\mathrm{NH}(\mathrm{CO})$-bdc) $)_{24}$ and $\mathrm{Cu}_{24}(5-(3,5,5$-trimethylhexanoyl)$\mathrm{NH}(\mathrm{CO})$-bdc) 24 were refined as two-component twinned data.

The disordered contents of highly porous metal-organic framework (MOF) and metal-organic polyhedra (MOP) complexes result in diffraction data that are limited in coverage and resolution. As a result, it is common to have multiple restraints and constraints, incompletely identified moieties, and high residuals in the structural model. ${ }^{8}$

The formulas reported herein reflect only the atoms that were discretely modeled. Presumably disordered solvent molecules were treated, together with electron density which could not be modeled, as diffused contributions. ${ }^{9}$ Non-hydrogen atoms were refined with anisotropic displacement parameters. Hydrogen atoms were treated as idealized contributions with geometrically calculated positions and with $U_{\text {iso }}$ equal to $1.2 U_{e q}$ (1.5 $U_{e q}$ for methyl) of the attached atom. Atomic scattering factors are contained in the SHELXTL program library. The structures have been deposited at the Cambridge Structural Database under the following CCDC depositary numbers: 1937257-1937262, 2004602 and 2004670. 

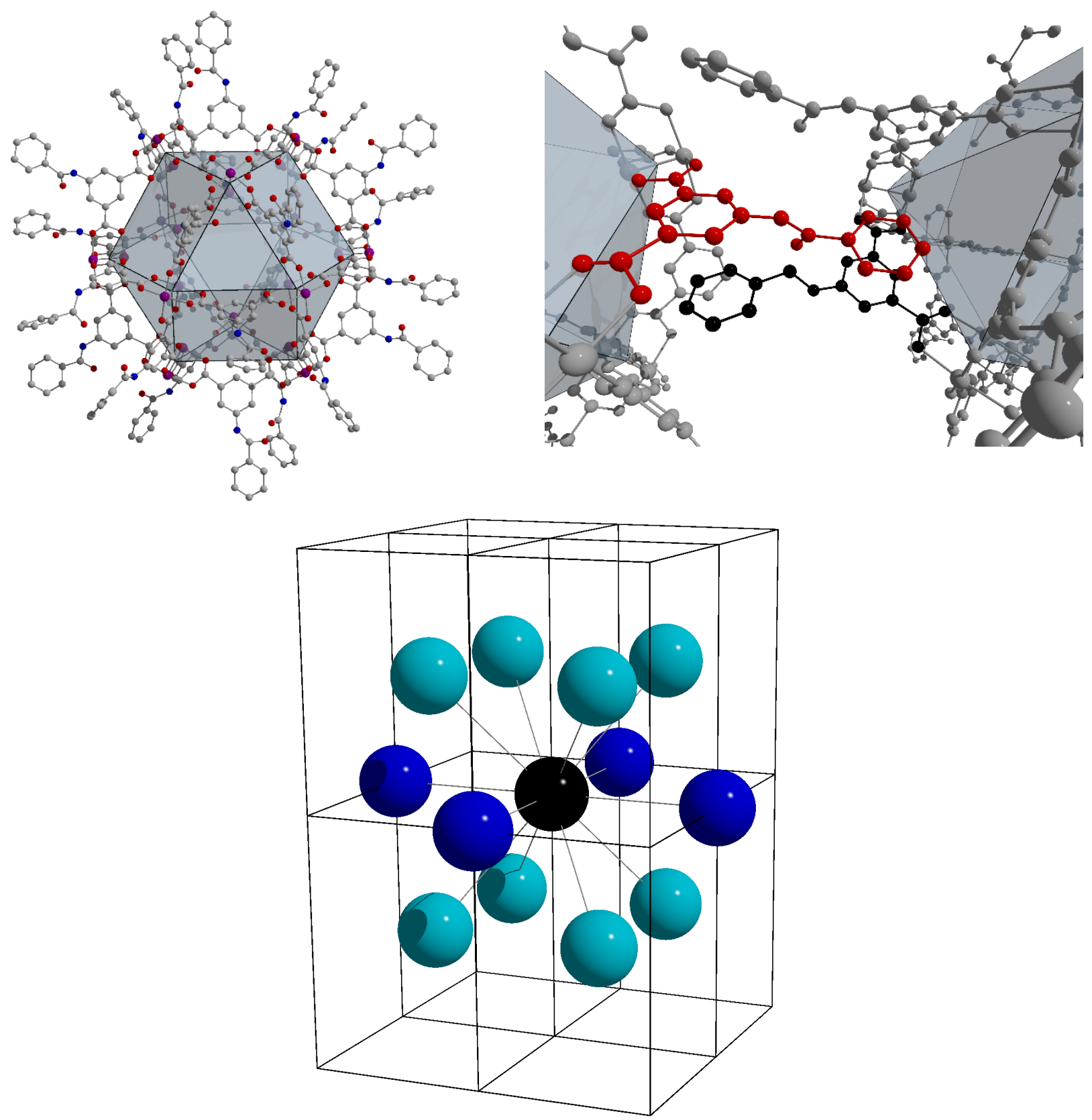

Figure S26. X-ray crystal structure of $\mathrm{Cr}_{24}(5$-benzoyl-NH(CO)-bdc) 24 (Top Left). Due to weak diffraction at wider angles, some of the ligand functional groups could not be fully modeled. Polyhedron corners are centers of the chromium (II) paddlewheels. Interstitial space between two cages in the crystal structure (Top Right). Benzoyl functional groups sit in the triangular windows of adjacent cages and appear to have $\pi-\pi$ interactions with the ring of the isophthalate portion of the ligand. Cage packing in the unit cell represented as spheres to illustrate nearest neighbors of a cage in the $\mathrm{P} 4 / \mathrm{mnc}$ lattice (Bottom). The $\mathrm{Cu}_{24}\left(5\right.$-benzoyl-NH(CO)-bdc) ${ }_{24}$ cage crystallizes in the same space group and has identical $\pi-\pi$ stacking effects. 

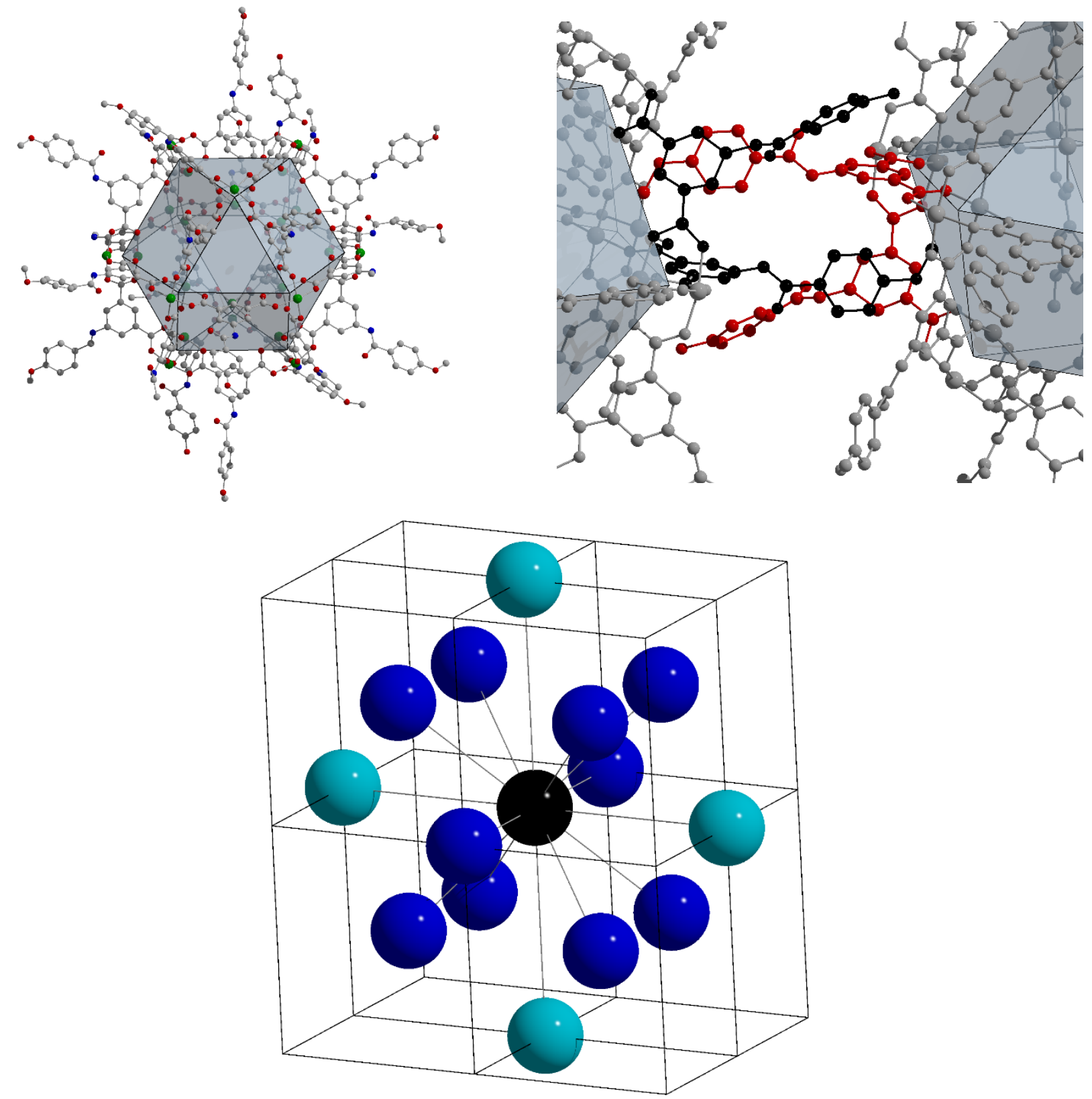

Figure S27. X-ray crystal structure of $\mathrm{Cu}_{24}$ (5-(4-methoxybenzoyl)-NH(CO)-bdc) 24 (Top Left). Due to weak diffraction at wider angles, some of the ligand functional groups could not be fully modeled. Polyhedron corners are centers of the copper (II) paddlewheels. Interstitial space between two cages in the crystal structure (Top Right). Methoxy benzoyl functional groups sit in the triangular windows of adjacent cages and appear to have $\pi-\pi$ interactions with the ring of the isophthalate portion of the ligand. Cage packing in the unit cell represented as spheres to illustrate nearest neighbors of a cage in the P121/n1 lattice (Bottom). 

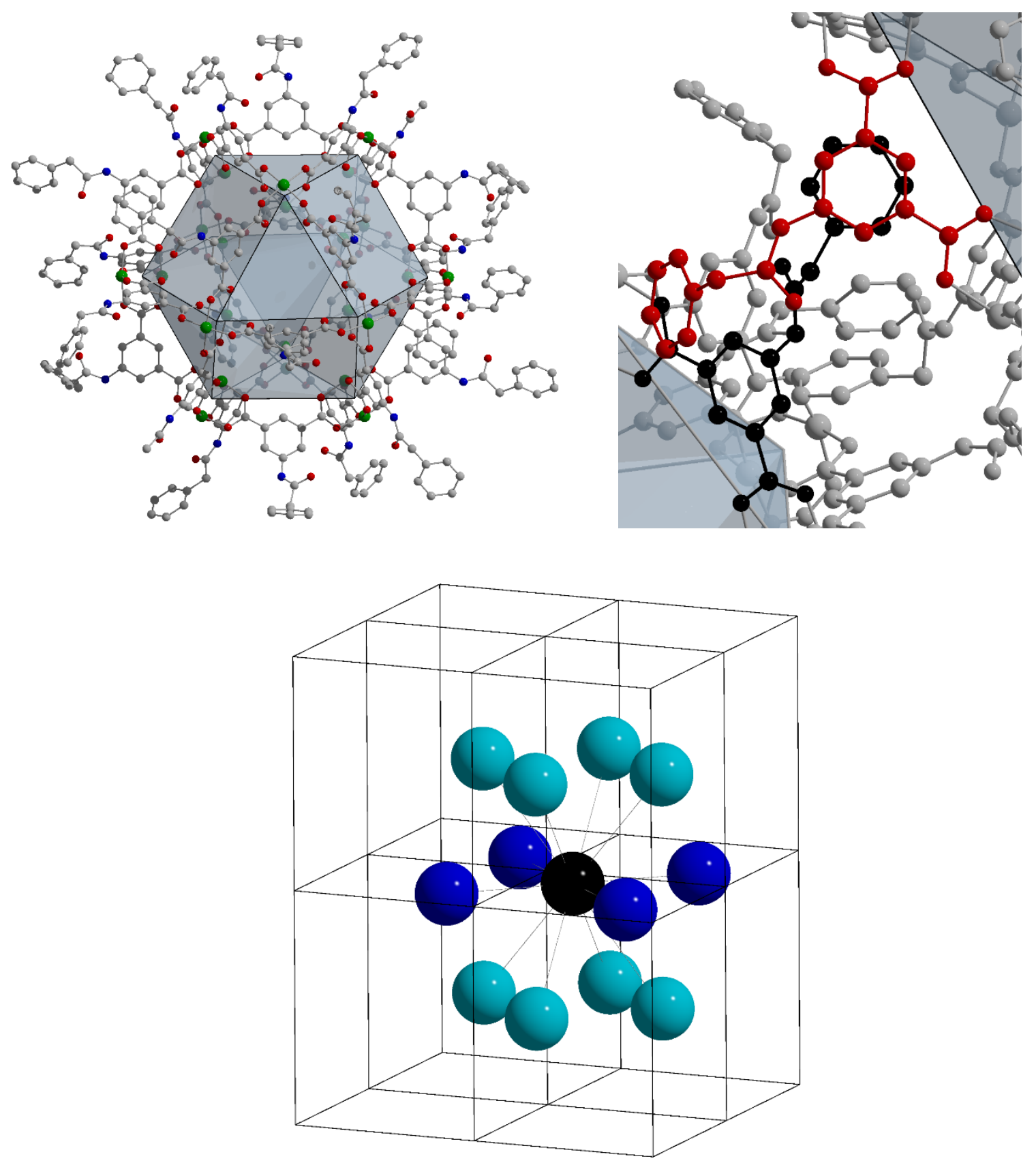

Figure S28. X-ray crystal structure of $\mathrm{Cu}_{24}$ (5-phenylacetyl-NH(CO)-bdc) 24 (Top Left). Due to weak diffraction at wider angles, some of the ligand functional groups could not be fully modeled. Polyhedron corners are centers of the copper (II) paddlewheels. Interstitial space between two cages in the crystal structure (Top Right). Phenyl groups sit in the triangular windows of adjacent cages and appear to have $\pi$ - $\pi$ interactions with the isophthalate portion of the ligand. Cage packing in the unit cell represented as spheres to illustrate nearest neighbors of a cage in the $\mathrm{C} 12 / \mathrm{c}$ lattice (Bottom). 

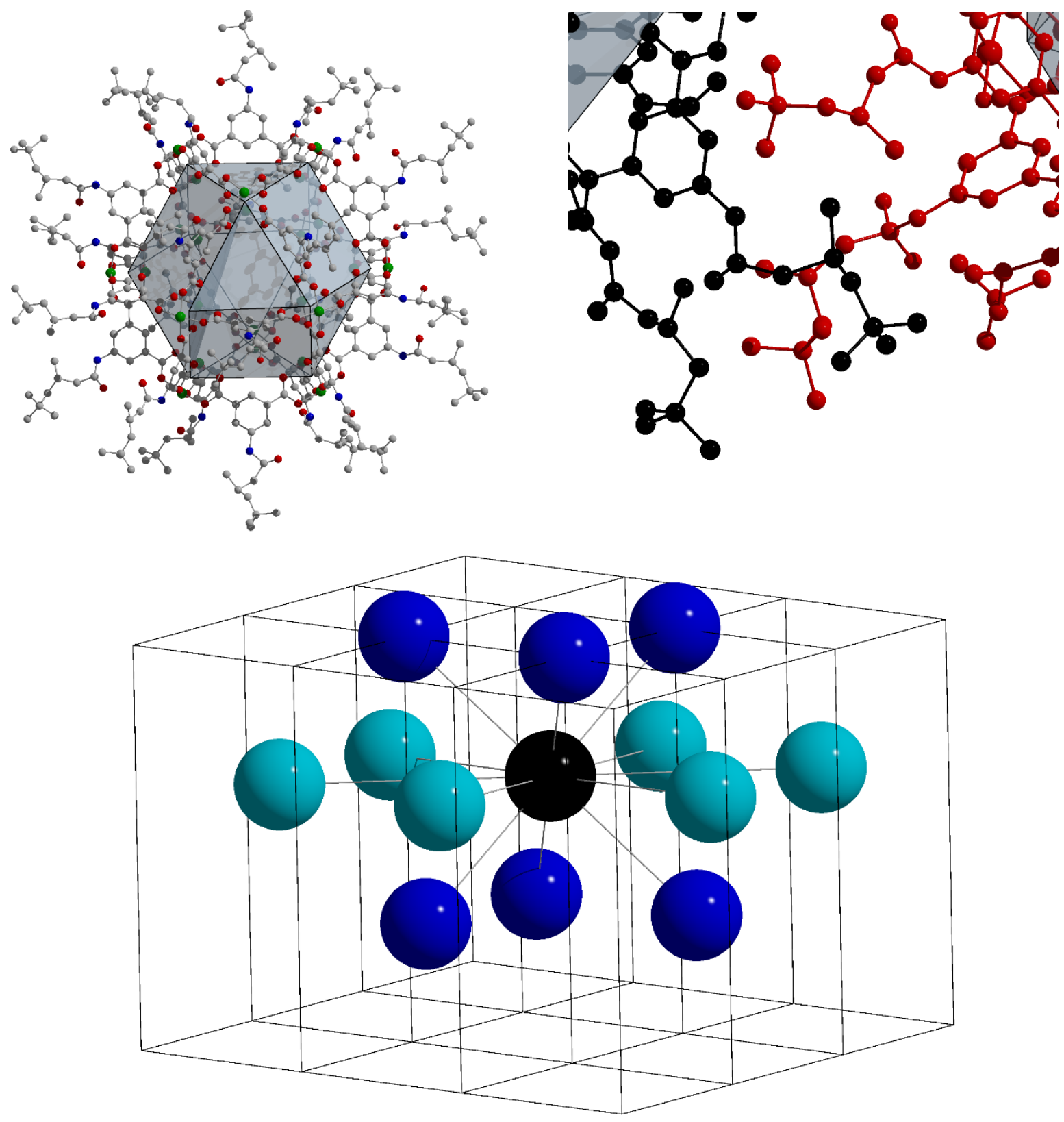

Figure S29. X-ray crystal structure of $\mathrm{Cu}_{24}(5-(3,5,5$-trimethylhexanoyl)-NH(CO)-bdc) 24 (Top Left). Due to weak diffraction at wider angles, some of the ligand functional groups could not be fully modeled. Polyhedron corners are centers of the copper (II) paddlewheels. Interstitial space between two cages in the crystal structure (Top Right). Functional groups do not have clear interactions or ordering in the structure. Cage packing in the unit cell represented as spheres to illustrate nearest neighbors of a cage in the R-3 lattice (Bottom). 

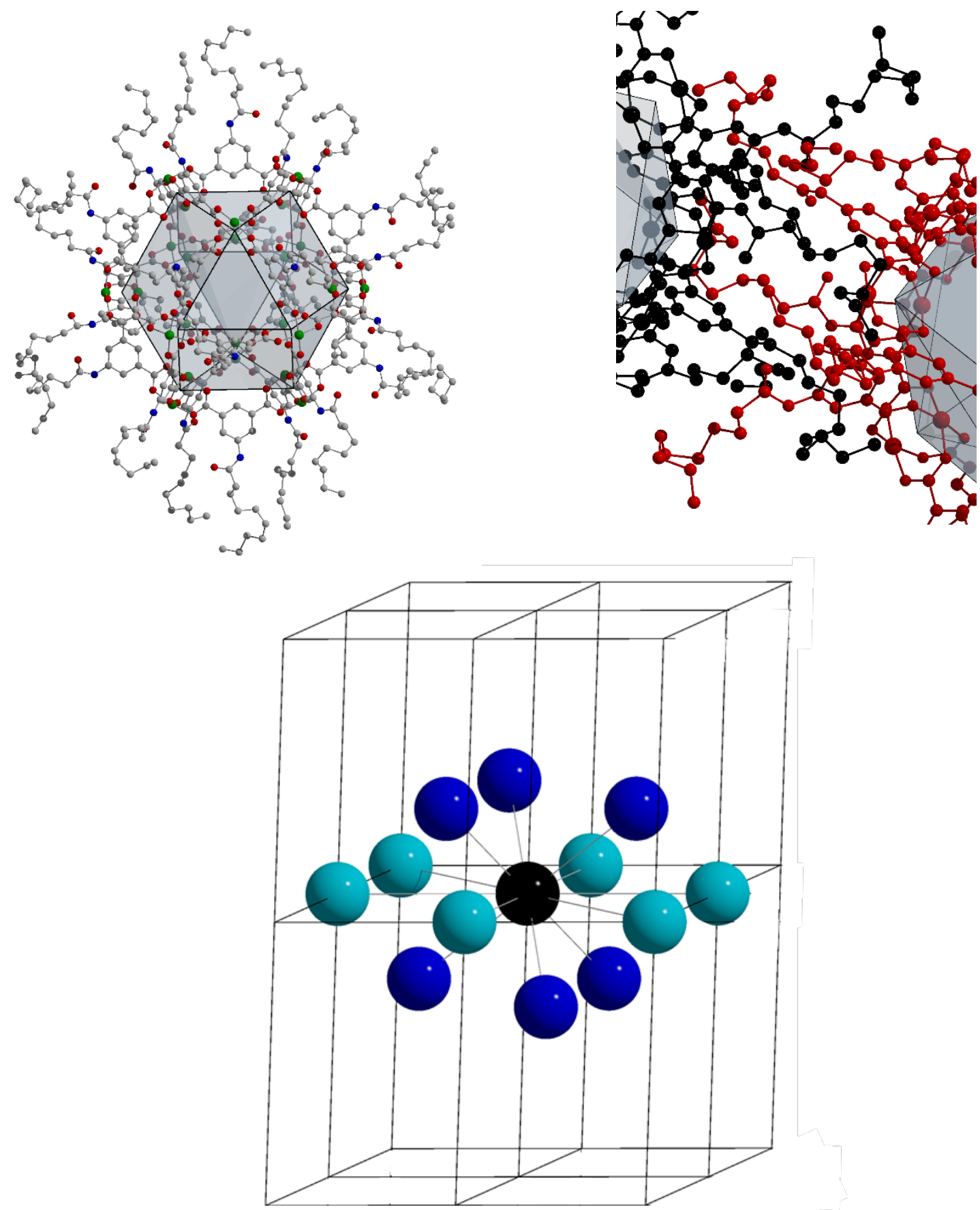

Figure S30. X-ray crystal structure of $\mathrm{Cu}_{24}$ (5-lauroyl-NH(CO)-bdc) ${ }_{24}$ (Top Left). Due to weak diffraction at wider angles and disorder in the structure, some of the ligand functional groups could not be reasonably modeled. Polyhedron corners are centers of the copper (II) paddlewheels. Interstitial space between two cages in the crystal structure (Top Right). Functional groups do not have clear interactions or ordering in the structure. Cage packing in the unit cell represented as spheres to illustrate nearest neighbors of a cage in the R-3 lattice (Bottom). 

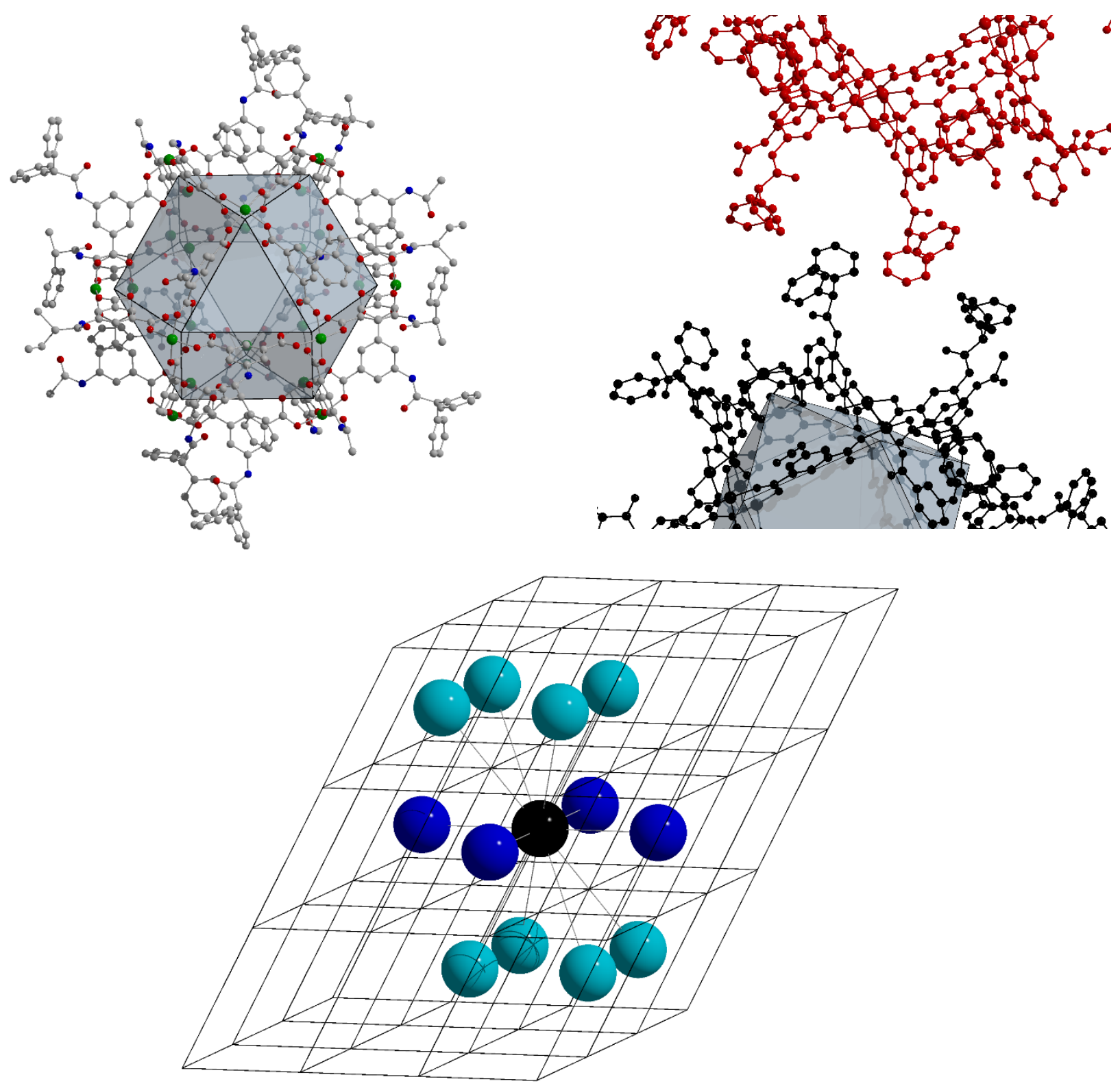

Figure S31. X-ray crystal structure of $\mathrm{Cu}_{24}$ (5-diphenylacetyl-NH(CO)-bdc) 24 (Top Left). Due to weak diffraction at wider angles, some of the ligand functional groups could not be fully modeled. Polyhedron corners are centers of the copper (II) paddlewheels. Interstitial space between two cages in the crystal structure (Top Right). Functional groups are hindered from interactions with adjacent cages due to the steric size and shape of the ligand. Cage packing in the unit cell represented as spheres to illustrate nearest neighbors of a cage in the P-1 lattice (Bottom). 

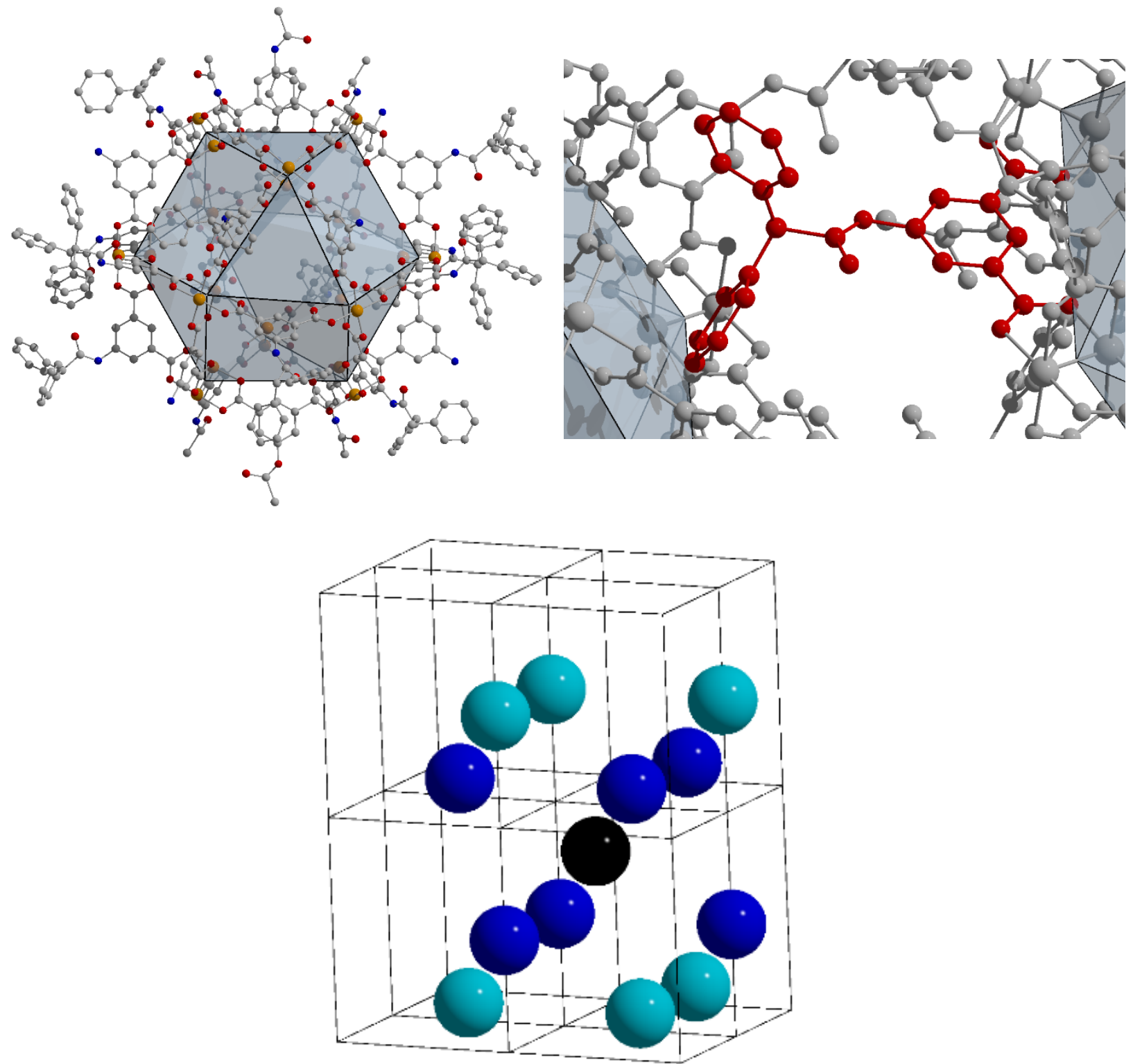

Figure S32. X-ray crystal structure of $\mathrm{Mo}_{24}$ (5-diphenylacetyl-NH(CO)-bdc) ${ }_{24}$ (Top Left). Due to weak diffraction at wider angles, some of the ligand functional groups could not be fully modeled. Polyhedron corners are centers of the copper (II) paddlewheels. Interstitial space between two cages in the crystal structure (Top Right). Functional groups are hindered from interactions with adjacent cages due to the steric size and shape of the ligand. Cage packing in the unit cell represented as spheres to illustrate nearest neighbors of a cage in the R-3 lattice (Bottom). 


\section{Powder X-Ray Diffraction:}
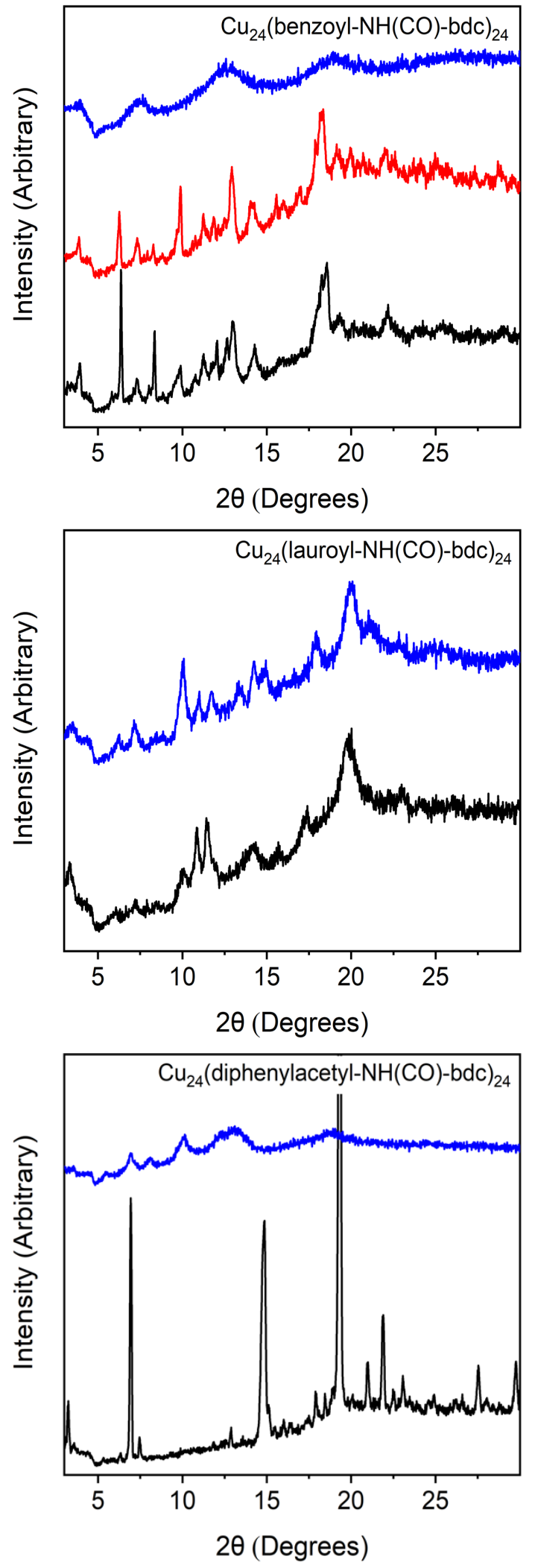
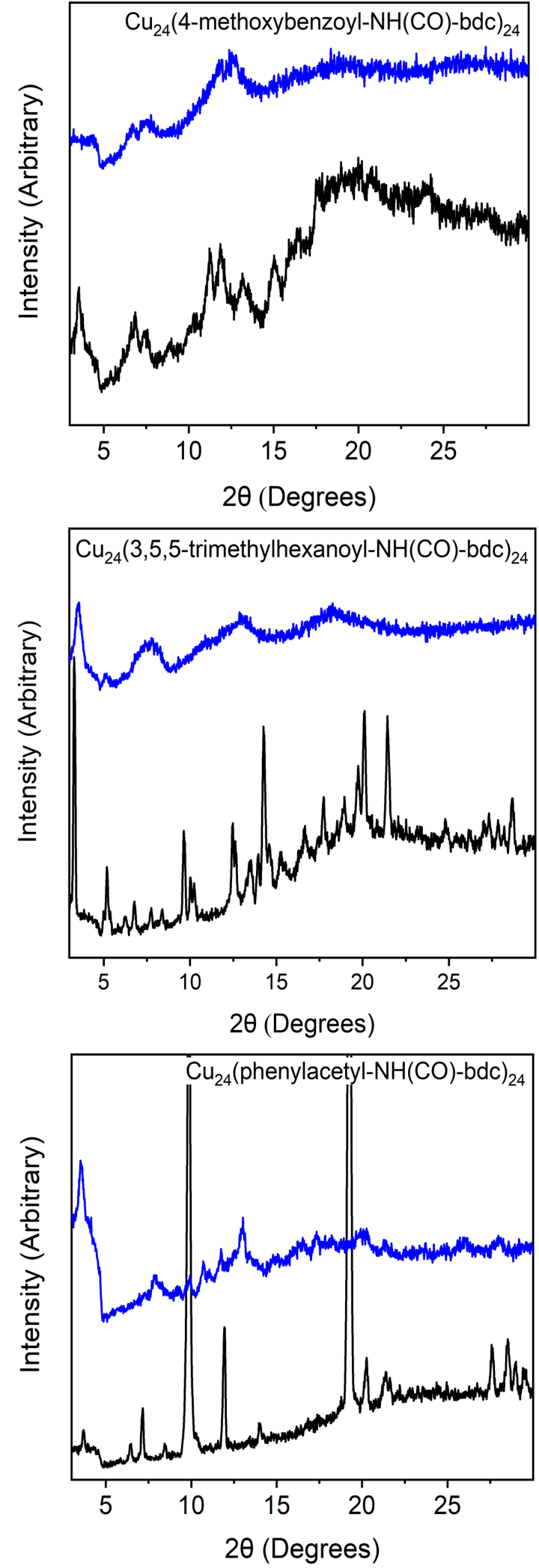


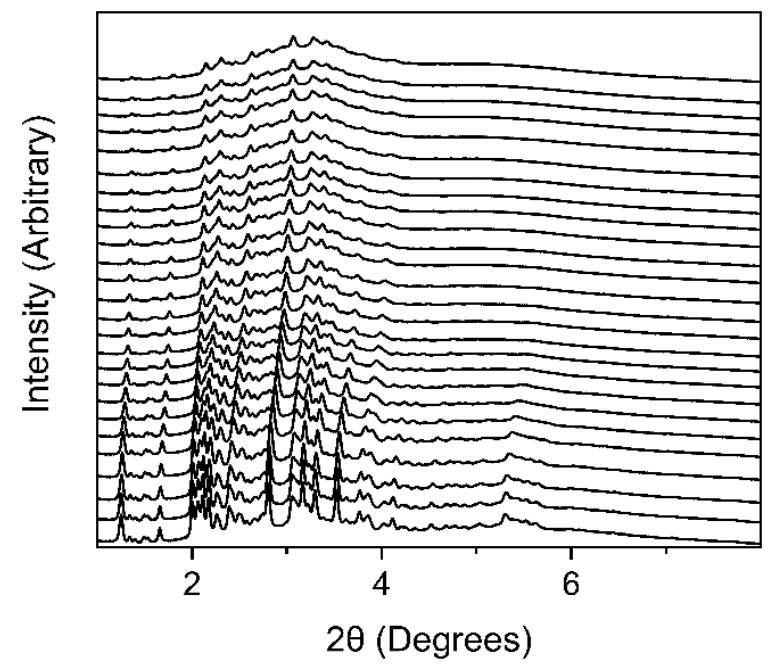

Figure S34. Powder X-Ray Diffraction patterns of $\mathrm{Mo}_{24}(\mathrm{OH}-\mathrm{bdc})_{24}$ ramping by $10^{\circ} \mathrm{C}$ from $25^{\circ} \mathrm{C}$ to $275^{\circ} \mathrm{C}$ using a wavelength of $0.45411 \AA$.

\section{Infrared Spectra:}
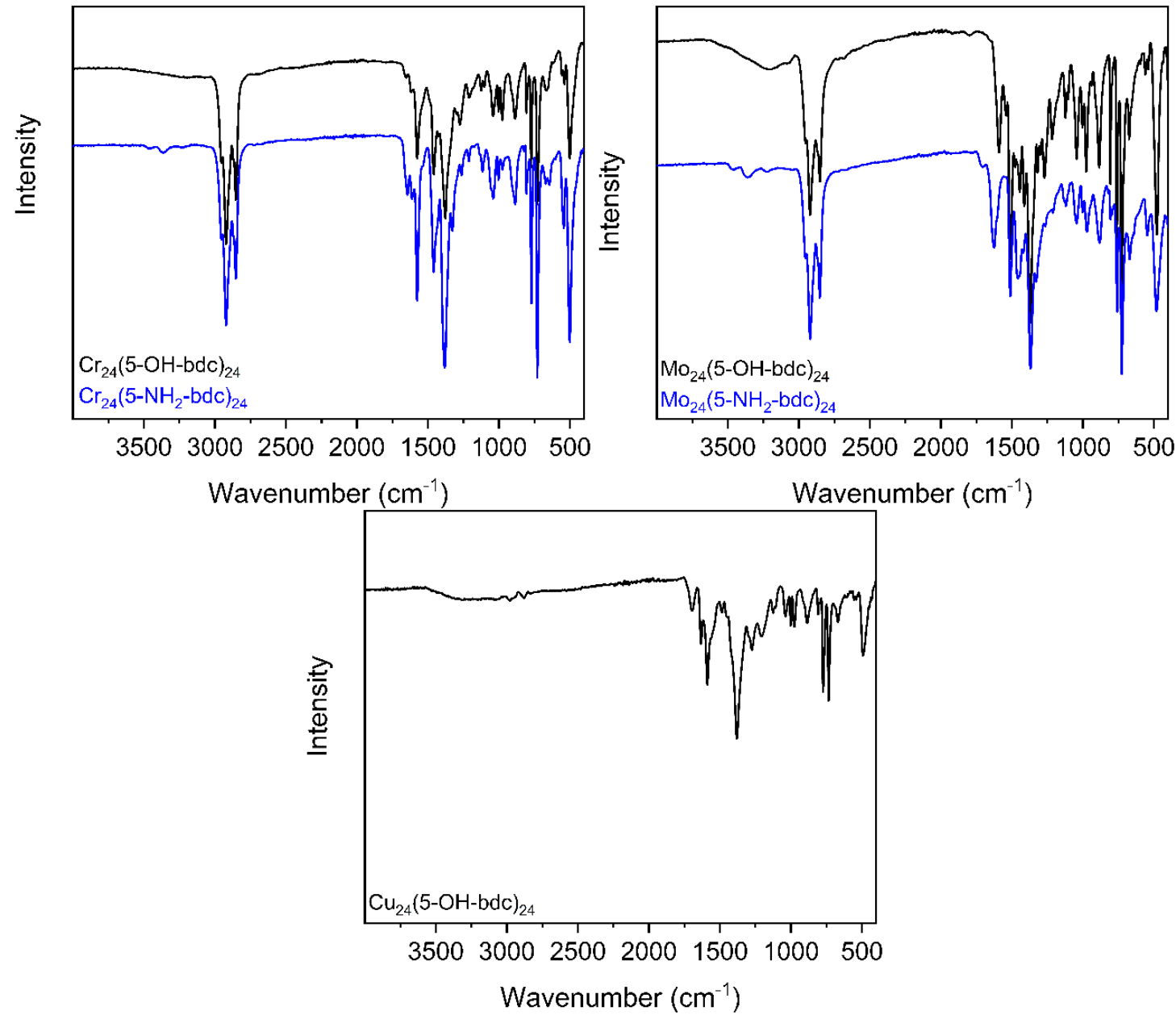

Figure S35. Infrared spectra of solvothermal cages. Peak at $2920 \mathrm{~cm}^{-1}$ is oil. 

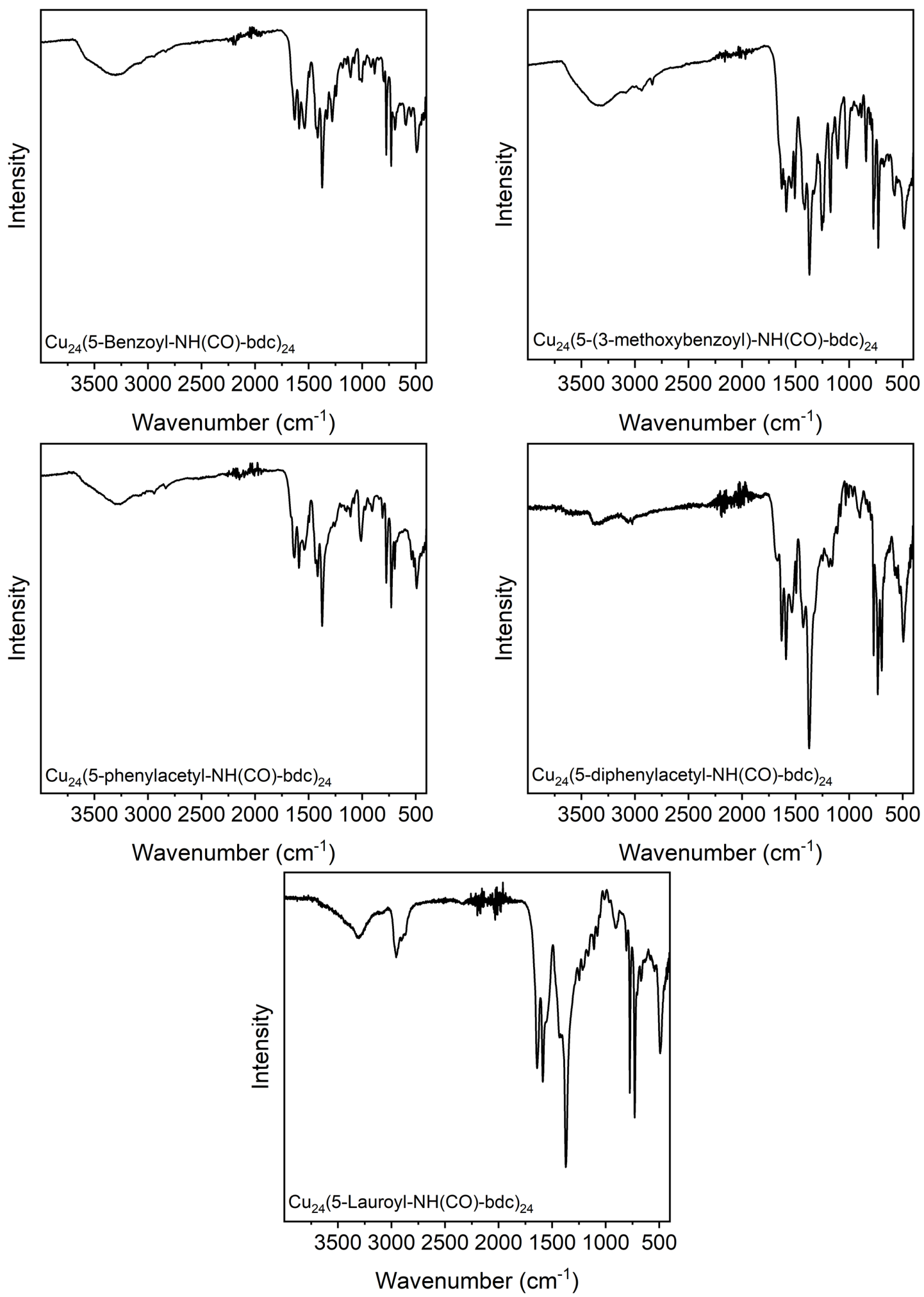

Figure S36. Infrared spectra of activated $\mathrm{Cu}(\mathrm{II})$ Cages. 

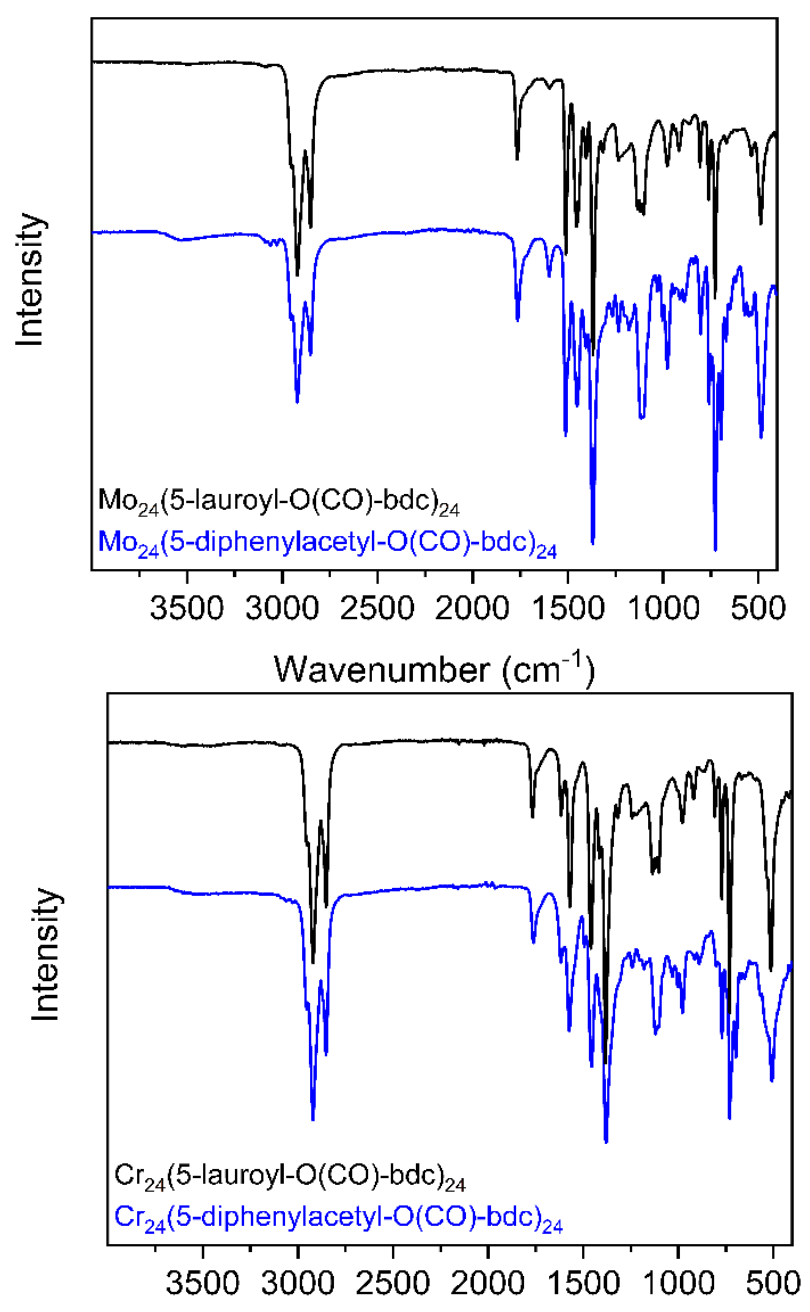
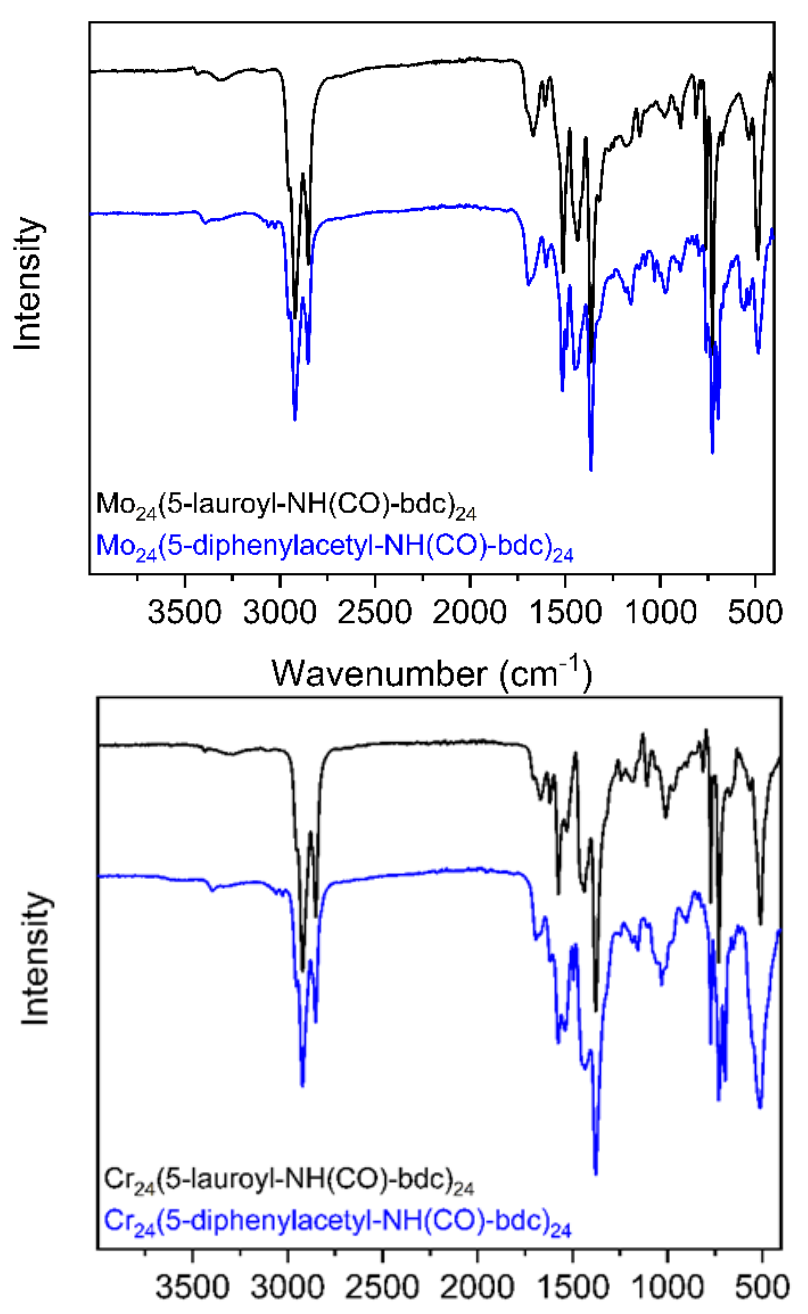
Wavenumber $\left(\mathrm{cm}^{-1}\right)$

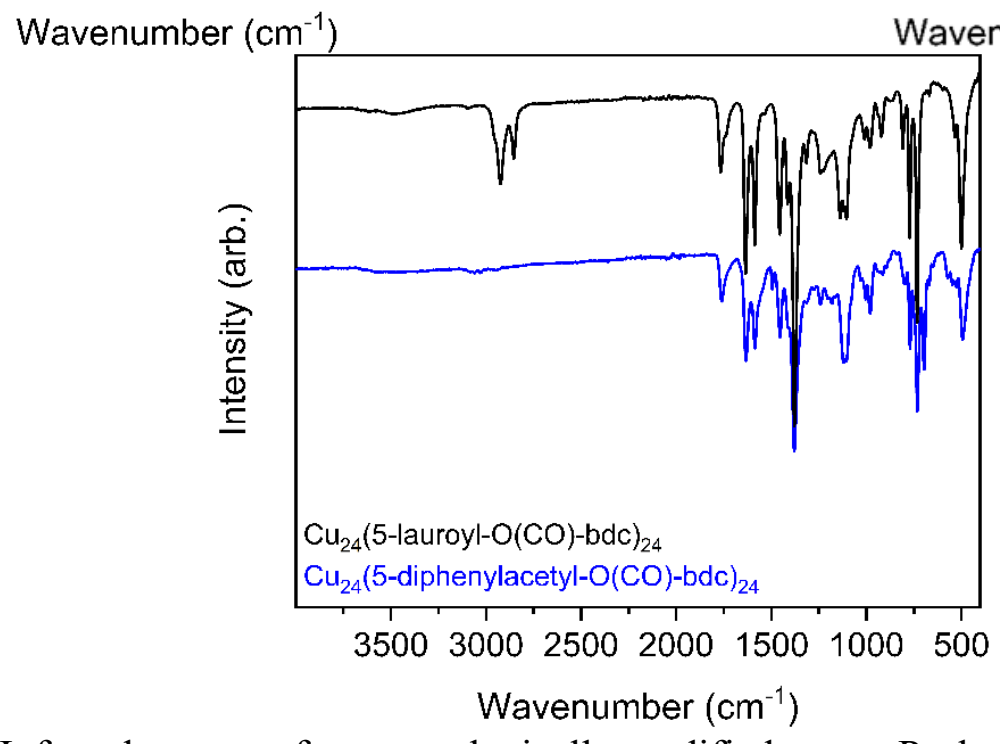

Figure S37. Infrared spectra of post-synthetically modified cages. Peak at $\sim 2920 \mathrm{~cm}^{-1}$ is oil. 


\section{Gas Adsorption Measurements:}

Dinitrogen and Carbon dioxide were used for adsorption measurements. To measure the isotherms, a Micromeritics 3Flex gas adsorption analyzer was used. Samples were loaded into weighed analysis tubes under $\mathrm{N}_{2}$ atmosphere to prevent oxidation or water absorption into samples. The tubes were capped with Transeals and removed from the glovebox. They were activated under vacuum at various temperatures on a Smartvac degas system until the static outgas rate was less than $2 \mu \mathrm{bar} / \mathrm{min}$. After degassing, the tube was removed from the Smartvac under vacuum and weighed to determine the mass of the sample in the tube. For cryogenic $\mathrm{N}_{2}$ measurements, an isothermal jacket was fitted on the tube. Degas surveys using $\mathrm{CO}_{2}$ at $195 \mathrm{~K}$ or $\mathrm{N}_{2}$ at $77 \mathrm{~K}$ were performed on the samples after they were heated in increments of $25^{\circ} \mathrm{C}$ to determine the optimal activation temperature. Langmuir Surface Areas were calculated via the Micromeritics software. BET calculations were calculated via the first and second consistency check. ${ }^{10}$ Both $\mathrm{N}_{2}$ and $\mathrm{CO}_{2}$ sorption measurements were performed on some materials due to the lack of porosity to $\mathrm{N}_{2}$.
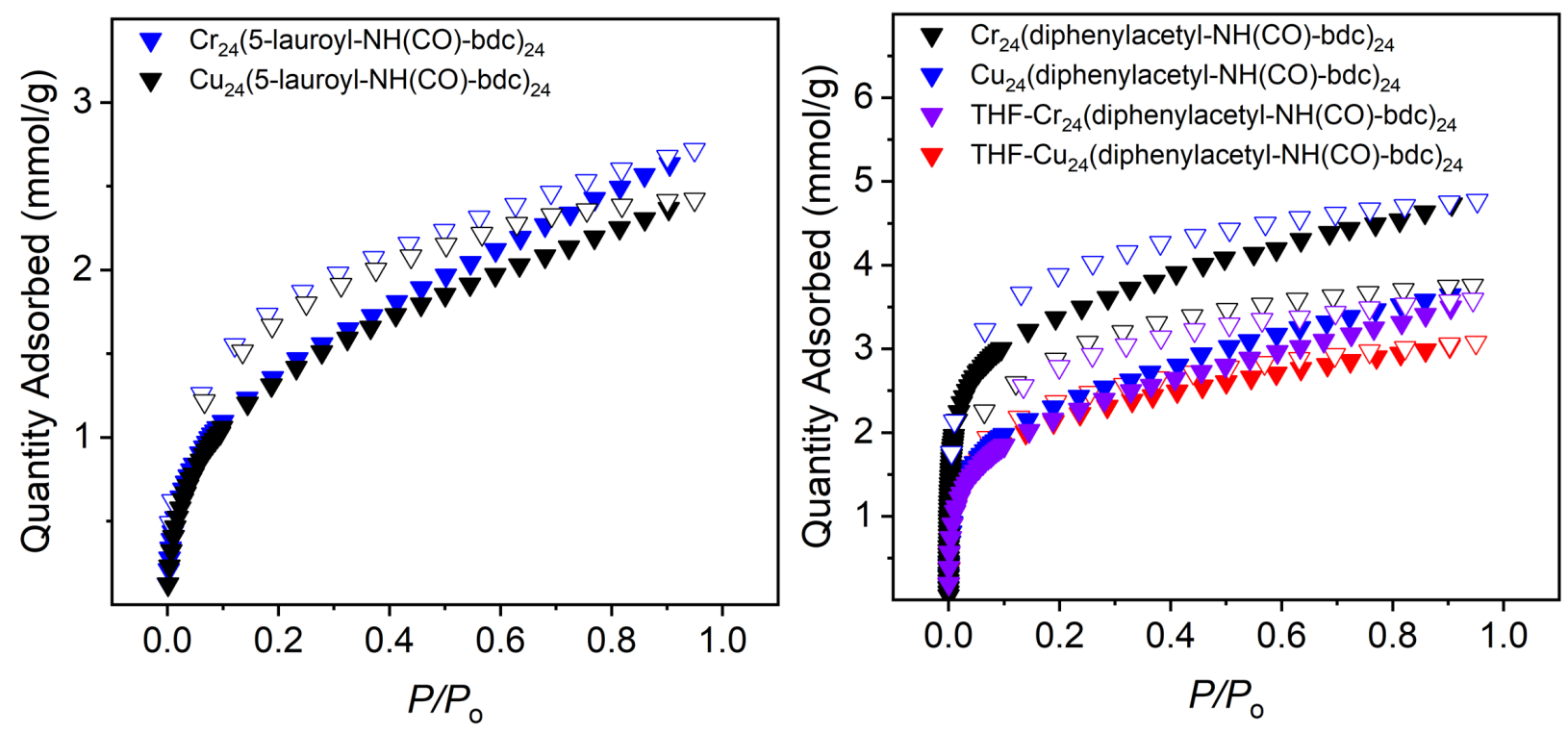

Figure S38. Full $\mathrm{CO}_{2}$ (triangles) isotherms for the $\mathrm{Cu}$ (II) amide cages (Black) and $\mathrm{Cr}$ (II) amide cages (Blue). $\mathrm{CO}_{2}$ isotherms were also performed on the THF-Cu 24 (5-diphenylacetyl-NH(CO)bdc) 24 (Red), and the THF-Cr24(5-diphenylacetyl-NH(CO)-bdc) 24 (Purple). Closed Symbols denote adsorption; open symbols denote desorption. 

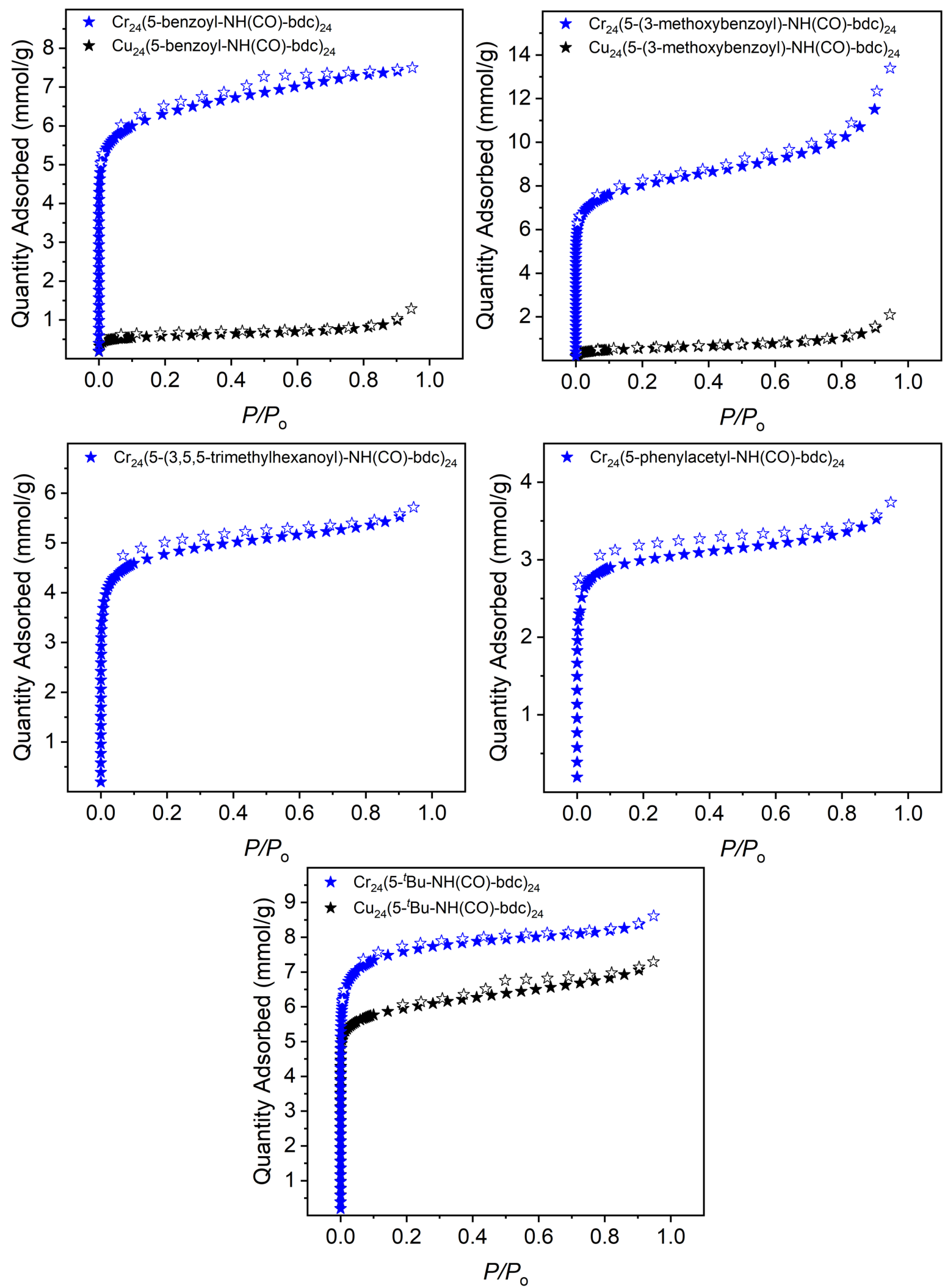

Figure S39. Full $\mathrm{N}_{2}$ BET isotherms for the $\mathrm{Cu}$ (II) amide cages (Black) and $\mathrm{Cr}$ (II) amide cages (Blue). Any isotherm data not shown is due to non-porosity. Closed Symbols denote adsorption; open symbols denote desorption. 


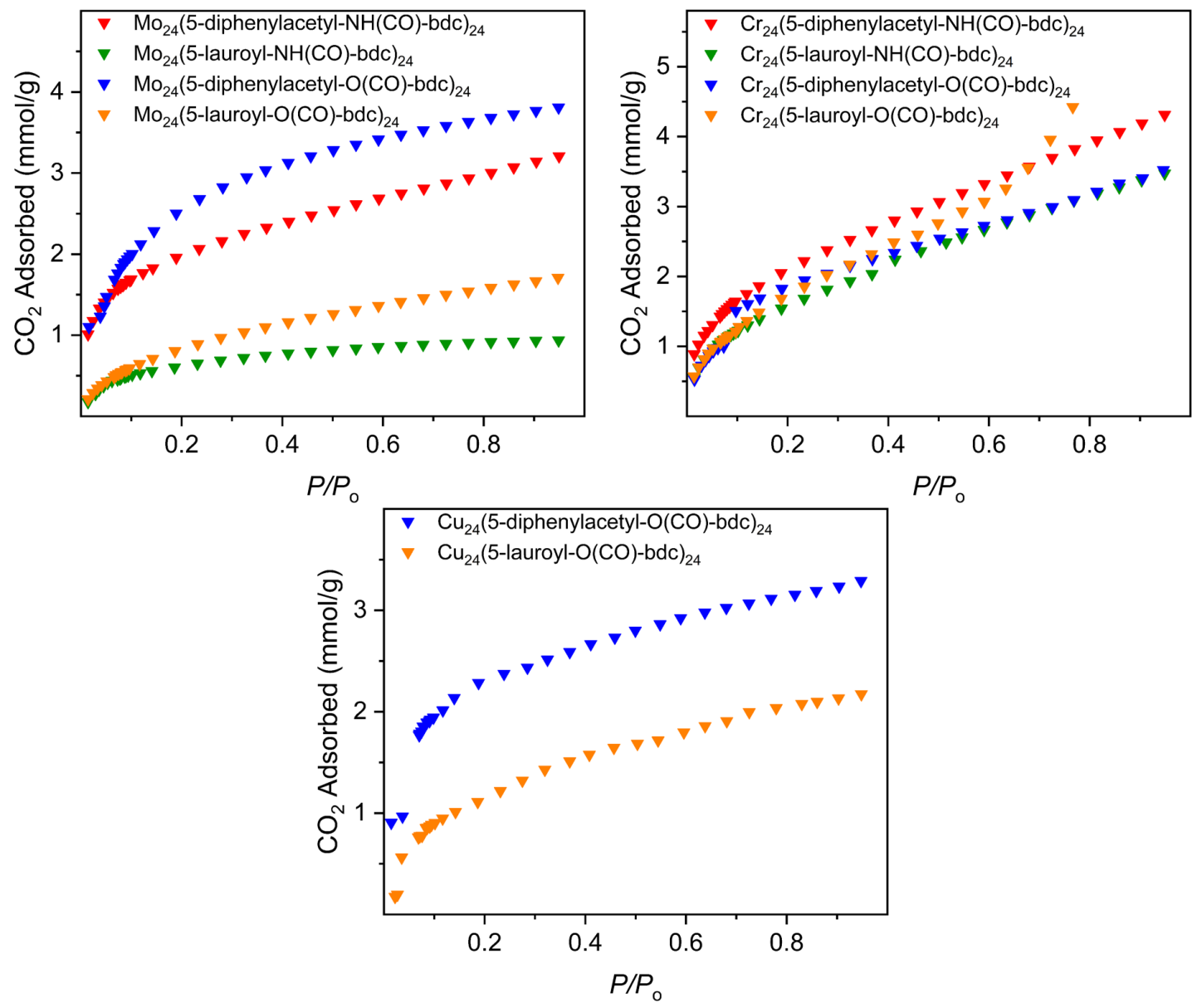

Figure S40. Full $\mathrm{CO}_{2} \mathrm{BET}$ adsorption isotherms of post-synthetically modified cages activated at $25^{\circ} \mathrm{C}$.
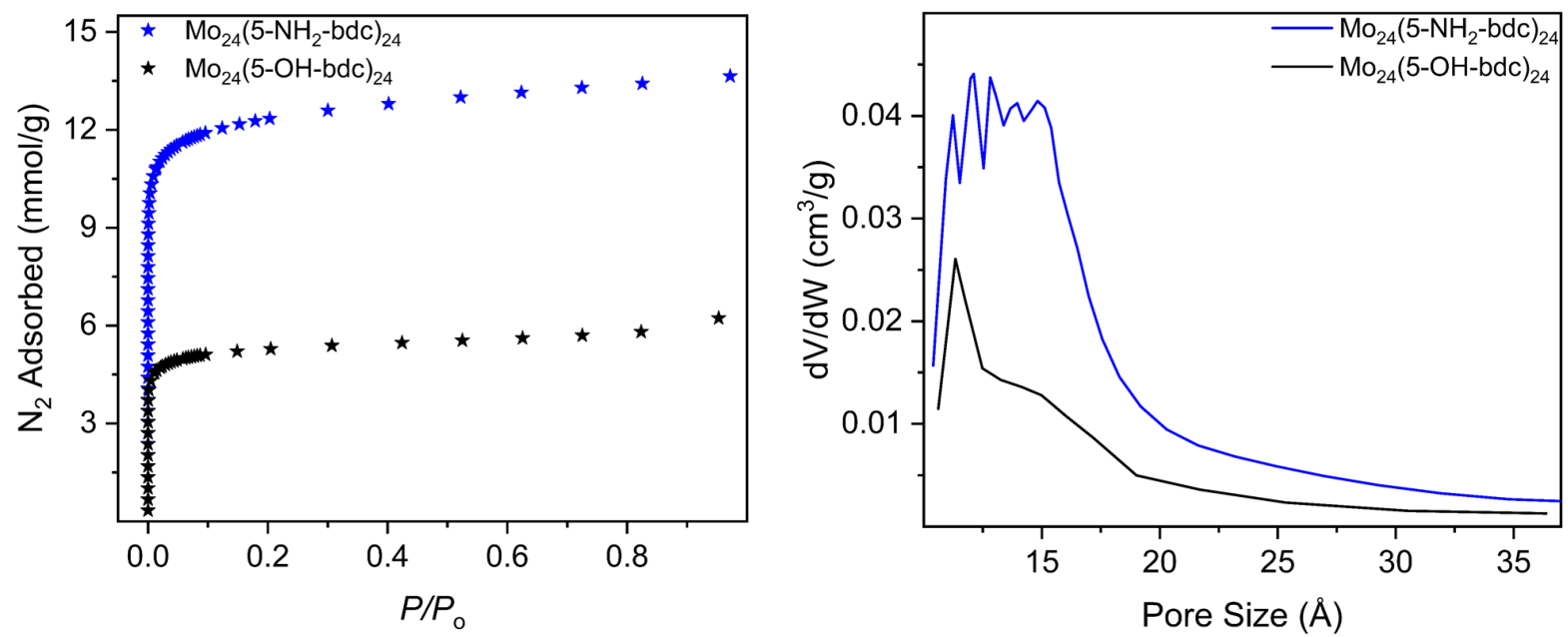

Figure S41. Full $\mathrm{N}_{2} \mathrm{BET}$ isotherms and pore size distribution plots for $\mathrm{Mo}_{24}\left(5-\mathrm{NH}_{2}-\mathrm{bdc}\right)_{24}$ and $\mathrm{Mo}_{24}(5-\mathrm{OH}-\mathrm{bdc})_{24}$ activated at $150^{\circ} \mathrm{C}$. 

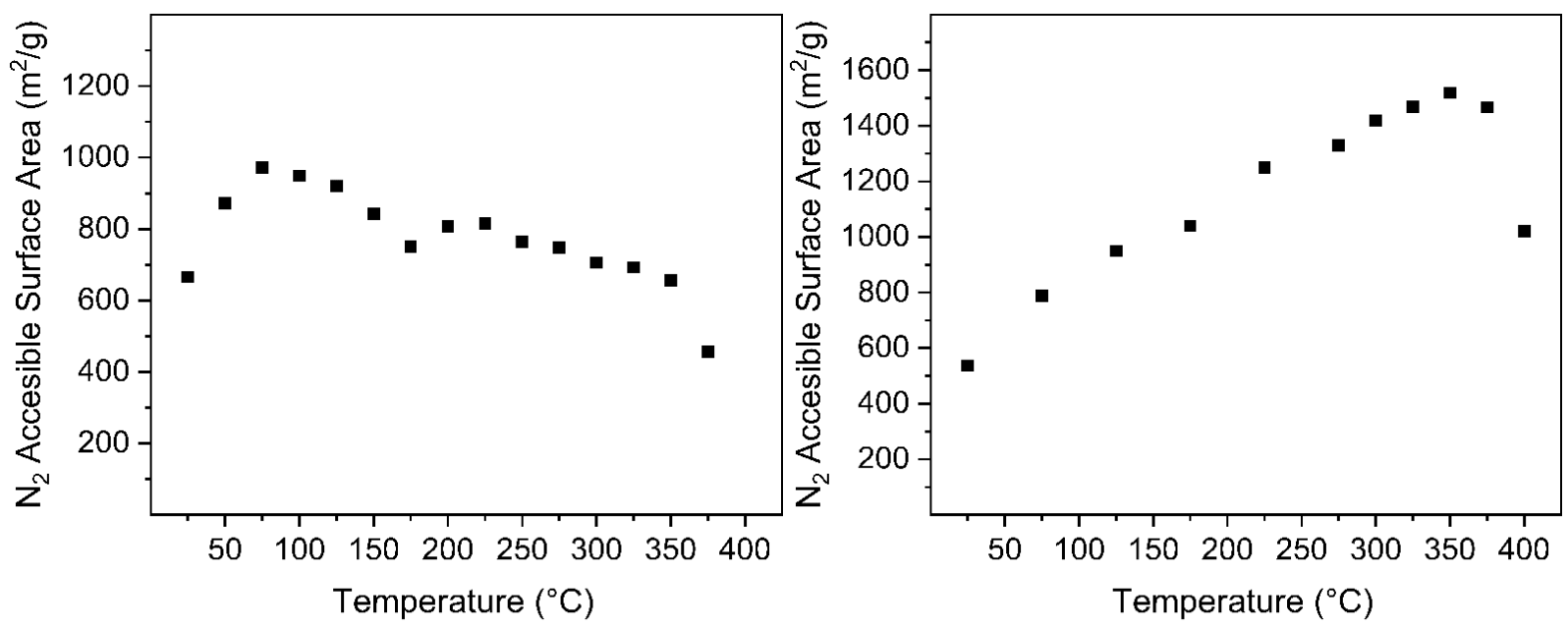

Figure S42. Langmuir $\mathrm{N}_{2}$ Surface Area as a function of activation temperature for $\mathrm{Mo}_{24}(5-$ $\mathrm{NH}_{2}$-bdc $)_{24}$ (left) and $\mathrm{Mo}_{24}(5-\mathrm{OH}-\mathrm{bdc})_{24}$ (right).
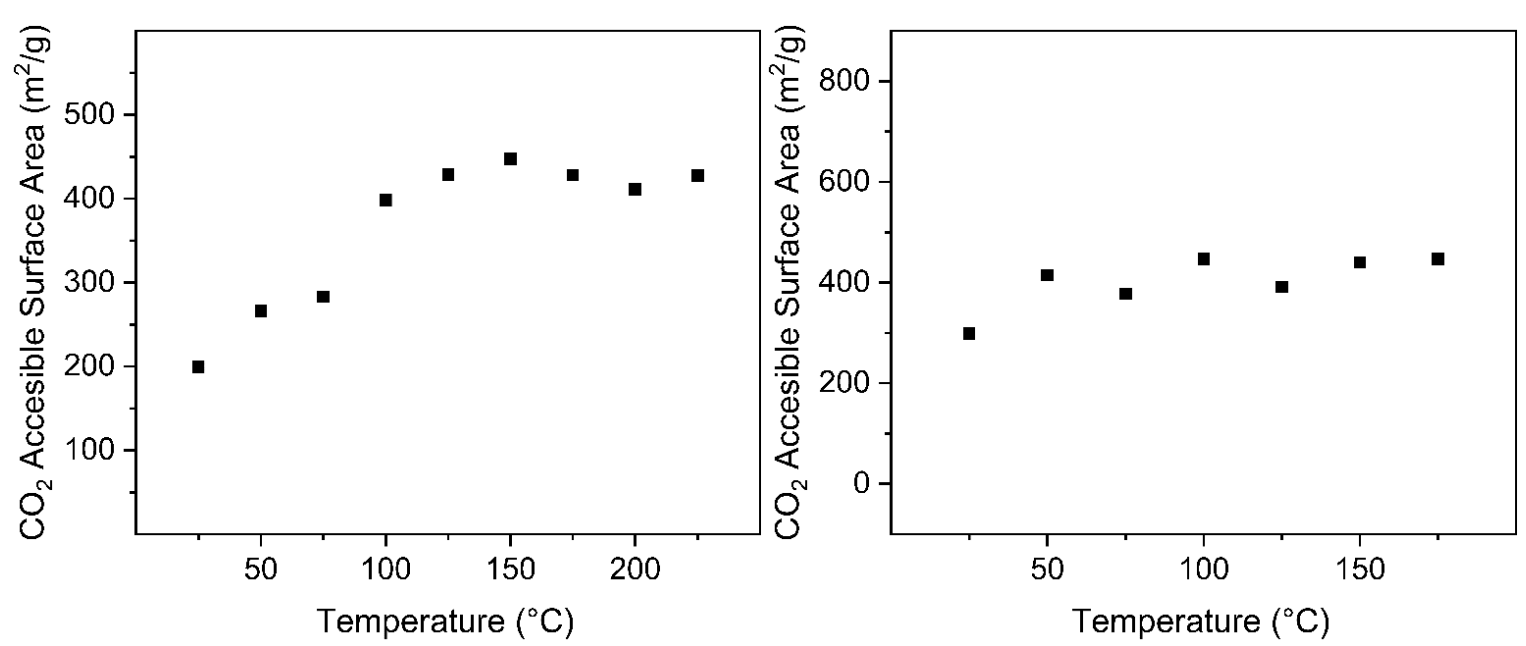

Figure S43. Langmuir $\mathrm{CO}_{2}$ Surface Area as a function of activation temperature for $\mathrm{Cr}_{24}(5-$ $\mathrm{NH}_{2}$-bdc) ${ }_{24}$ (left) and $\mathrm{Cr}_{24}(5-\mathrm{OH}-\text { bdc })_{24}$ (right). 

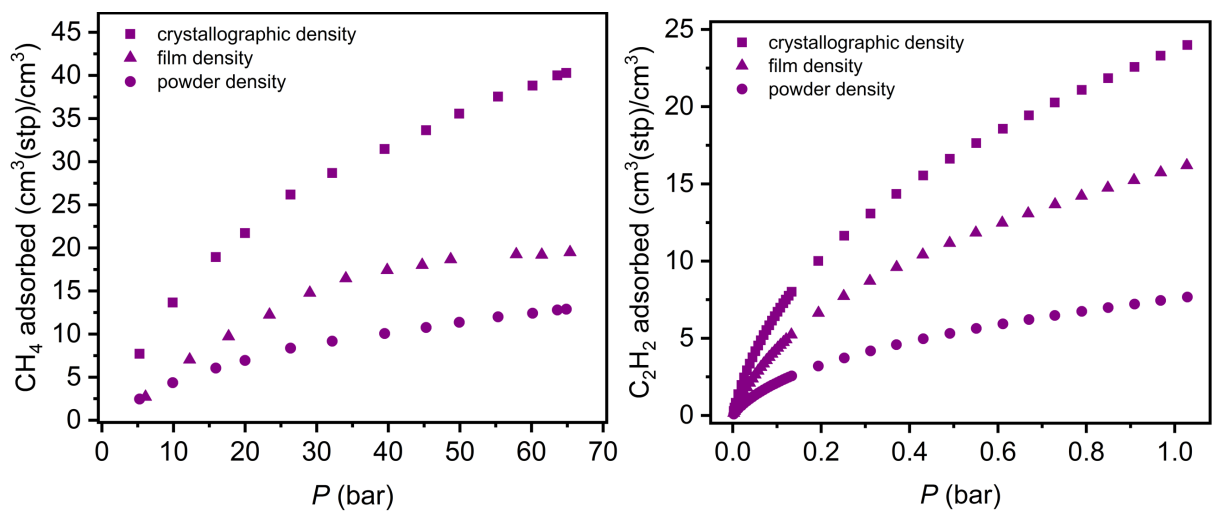

Figure S44. Adsorption of methane (left) and acetylene (right) $\mathrm{Cr}_{24}$ (5-diphenylacetyl-amidobdc) 24 for samples that were obtained via solvothermal syntheses and washed with methanol prior to activation to afford powders (circles) then dissolved in THF and isolated via rapid solvent evaporation to afford dense amorphous films (triangles). These volumetric uptake capacities are plotted versus those based on crystallographic densities (squares).

\section{Surface Areas:}

Table S1. Langmuir and BET Surface Areas of $\mathrm{Cu}(\mathrm{II})$ and $\mathrm{Cr}(\mathrm{II})$ Cages

\begin{tabular}{|l|l|l|l|l|}
\hline \multicolumn{4}{|l|}{ Copper (II) } & \multicolumn{2}{l|}{ Chromium (II) } \\
\hline Ligand & Langmuir $\left(\mathrm{m}^{2} / \mathrm{g}\right)$ & $\mathrm{BET}\left(\mathrm{m}^{2} / \mathrm{g}\right)$ & Langmuir $\left(\mathrm{m}^{2} / \mathrm{g}\right)$ & $\mathrm{BET}\left(\mathrm{m}^{2} / \mathrm{g}\right)$ \\
\hline Benzoyl & $\begin{array}{l}90\left(\mathrm{~N}_{2}\right) \\
326\left(\mathrm{CO}_{2}\right)\end{array}$ & $\begin{array}{l}49\left(\mathrm{~N}_{2}\right) \\
171\left(\mathrm{CO}_{2}\right)\end{array}$ & $752\left(\mathrm{~N}_{2}\right)$ & $540\left(\mathrm{~N}_{2}\right)$ \\
\hline 4-methoxybenzoyl & $\begin{array}{l}146\left(\mathrm{~N}_{2}\right) \\
357\left(\mathrm{CO}_{2}\right)\end{array}$ & $\begin{array}{l}42\left(\mathrm{~N}_{2}\right) \\
159\left(\mathrm{CO}_{2}\right)\end{array}$ & $1090\left(\mathrm{~N}_{2}\right)$ & $684\left(\mathrm{~N}_{2}\right)$ \\
\hline $\begin{array}{l}3,5,5- \\
\text { trimethylhexanoyl }\end{array}$ & $208\left(\mathrm{CO}_{2}\right)$ & $79\left(\mathrm{CO}_{2}\right)$ & $542\left(\mathrm{~N}_{2}\right)$ & $416\left(\mathrm{~N}_{2}\right)$ \\
\hline phenyl acetyl & $351\left(\mathrm{CO}_{2}\right)$ & $209\left(\mathrm{CO}_{2}\right)$ & $340\left(\mathrm{~N}_{2}\right)$ & $265\left(\mathrm{~N}_{2}\right)$ \\
\hline diphenyl acetyl & $281\left(\mathrm{CO}_{2}\right)$ & $163\left(\mathrm{CO}_{2}\right)$ & $432\left(\mathrm{CO}_{2}\right)$ & $236\left(\mathrm{CO}_{2}\right)$ \\
\hline $\begin{array}{l}\text { diphenyl acetyl (THF } \\
\text { evaporated) }\end{array}$ & $356\left(\mathrm{CO}_{2}\right)$ & $153\left(\mathrm{CO}_{2}\right)$ & $333\left(\mathrm{CO}_{2}\right)$ & $143\left(\mathrm{CO}_{2}\right)$ \\
\hline lauroyl & $239\left(\mathrm{CO}_{2}\right)$ & $85\left(\mathrm{CO}_{2}\right)$ & $278\left(\mathrm{CO}_{2}\right)$ & $87\left(\mathrm{CO}_{2}\right)$ \\
\hline
\end{tabular}

Table S2. $\mathrm{CO}_{2}$ Langmuir and BET Surface Areas of Post-Synthetically Modified Cages

\begin{tabular}{|l|l|l|l|l|l|l|}
\hline & \multicolumn{2}{|l|}{ Molybdenum (II) } & \multicolumn{2}{l|}{ Chromium (II) } & \multicolumn{2}{l|}{ Copper (II) } \\
\hline Ligand & $\begin{array}{l}\text { Langmuir } \\
\left(\mathrm{m}^{2} / \mathrm{g}\right)\end{array}$ & $\begin{array}{l}\text { BET } \\
\left(\mathrm{m}^{2} / \mathrm{g}\right)\end{array}$ & $\begin{array}{l}\text { Langmuir } \\
\left(\mathrm{m}^{2} / \mathrm{g}\right)\end{array}$ & $\begin{array}{l}\text { BET } \\
\left(\mathrm{m}^{2} / \mathrm{g}\right)\end{array}$ & $\begin{array}{l}\text { Langmuir } \\
\left(\mathrm{m}^{2} / \mathrm{g}\right)\end{array}$ & $\begin{array}{l}\mathrm{BET} \\
\left(\mathrm{m}^{2} / \mathrm{g}\right)\end{array}$ \\
\hline $\begin{array}{l}\text { diphenyl acetyl } \\
\text { ester }\end{array}$ & 633 & 393 & 428 & 121 & 316 & 205 \\
\hline $\begin{array}{l}\text { Diphenyl } \\
\text { acetyl amide }\end{array}$ & 368 & 169 & 555 & 170 & - & - \\
\hline Lauroyl ester & 227 & 72 & 633 & 131 & 242 & 109 \\
\hline Lauroyl amide & 109 & 64 & 475 & 134 & - & - \\
\hline
\end{tabular}




\section{References}

1 Levy, O.; Bogoslavsky, B.; Bino, A. Anhydrous Chromous Acetate Revisited - A Very Simple Synthetic Route. Inorganica Chimica Acta. 2012, 391, 179-181.

2 Li, J.-R.; Zhou, H.-C. Bridging-Ligand-Substitution Strategy for the Preparation of MetalOrganic Polyhedra. Nat. Chem. 2010, 2, 893- 898.

3. Lorzing, G. R.; Trump, B. A.; Brown, C. M.; Bloch, E. D. Selective Gas Adsorption in Highly Porous Chromium(II)-Based Metal-Organic Polyhedra. Chem. Mater. 2017, 29, 8583-8587.

4. Li, J.-R.; Yakovenko, A. A.; Lu, W.; Timmons, D. J.; Zhuang, W.; Yuan, D.; Zhou, H.-C. LigandBridging-Angle-Driven Assembly of Molecular Architectures Based on Quadruply Bonded Mo-Mo Dimers. J. Am. Chem. Soc. 2010, 132, 17599-17610.

5. Apex3; Bruker AXS Inc.: Madison, WI, 2015.

6. Sheldrick, G. M. SHELXT - Integrated Space-Group and Crystal Structure Determination. Acta. Cryst. 2015, A71, 3-8.

7. Sheldrick, G. M. Crystal Structure Refinement with SHELXL. Acta. Cryst. 2015, C71, 3-8.

8. Park, J.; Perry, Z.; Chen, Y.-P.; Bae, J; Zhou, H.-C. Chromium(II) Metal-Organic Polyhedra as Highly Porous Materials. ACS Appl. Mater. Interfaces 2017, 9, 28064-28068.

9. Spek, A. L. PLATON SQUEEZE: A Tool for the Calculation of the Disordered Solvent Contribution to the Calculated Structure Factors. Acta. Cryst. 2015, C71, 9-18.

10. Walton, K. S.; Snurr, R. Q. "Applicability of the BET Method for Determining Surface Areas of Microporous Metal-Organic Frameworks" J. Am. Chem. Soc. 2007, 129, 8552-8556. 